\title{
U.S. MARKETS DURING WORLD OIL SUPPLY CRISES: \\ AN ANALYSIS OF INDUSTRY, CONSUMER, AND \\ GOVERNMENTAL RESPONSE
}

By

$$
\begin{gathered}
\text { Stephen Erfle } \\
\text { John Pound } \\
\text { and } \\
\text { Joseph Kalt }
\end{gathered}
$$

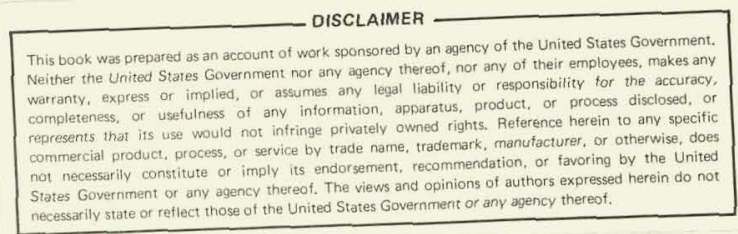

Produced and submitted to the Economic Regulatory Administration, Department of Energy, under DOE contract \#DE-AM01-79PE70106, Task Order $\# 2$.

April 1981

Energy and Environmental Policy Center

John F. Kennedy School of Government

Harvard University

79 Boylston Street

Cambridge, Massachusetts 02138 


\section{DISCLAIMER}

This report was prepared as an account of work sponsored by an agency of the United States Government. Neither the United States Government nor any agency Thereof, nor any of their employees, makes any warranty, express or implied, or assumes any legal liability or responsibility for the accuracy, completeness, or usefulness of any information, apparatus, product, or process disclosed, or represents that its use would not infringe privately owned rights. Reference herein to any specific commercial product, process, or service by trade name, trademark, manufacturer, or otherwise does not necessarily constitute or imply its endorsement, recommendation, or favoring by the United States Government or any agency thereof. The views and opinions of authors expressed herein do not necessarily state or reflect those of the United States Government or any agency thereof. 


\section{DISCLAIMER}

Portions of this document may be illegible in electronic image products. Images are produced from the best available original document. 
ABSTRACT

This paper presents an analysis of the response of American markets to supply crises in world oil markets. It addresses four main issues the efficiency of the operation of American oil markets during oil supply crises; the problems of both economic efficiency and social equity which arise during the American adaptation process; the propriety of the federal government's past policy responses to these problems; and the relationship between perceptions of the problems caused by world oil crises and the real economic natures of these problems.

We find that the crisis-period behavior of the American oil market differs sharply from publlc perception. Oil product prices, both those still under price and allocation controls and those free from formal regulation, appear to be too low in the U.S. throughout crisis periods. Further, major oil companies lag petroleum prices more heavily than do other sectors of the oil industry. These problems of market inefficiency are not caused by inherent deficiencies in the market but rather by explicit and implicit governmental interference with the market process.

The origins of the government-caused pricing constraint may be formal and explicit, as in the case of price and allocation controls. More startlingly, it may also exist in the absence of formal regulation, born of political pressure generated among consumers against higher prices, and catalyzed into a constraint on industry behavior by the actions of regulators, politicians, and the media. When intervention has been formal, markets have sometimes failed to clear, with shortages resulting, such as that which occurred in gasoline during 1979. When the market constraint is purely political, small firms at the fringe of the oil industry behave effictently, charging higher prices; thus, markets clear without shortage problems. We conclude that federal intervention has caused the bulk of the genuine oil market inefficiencies experienced by American consumers since 1973, and has forced major oil companies in particular into price and supply behavior at odds with the interests of the firms themselves and society's interests in maximizing national economic output.

We suggest that the basis for government interference with petroleum markets during periods of world oil crisis has been the confusion by policy-makers of the issues of social equity and economic efficiency. The income problems created for some consumers in society by higher oil prices have been mistakenly perceived as problems with prices themselves, rather than as issues of fairness regarding the sharing across society of the burden of higher world oil prices. Thus, policy-makers have wrongly attempted to alter the way the market functions in order to aid consumers. If the goal of federal policy is to address the distributional issues raised by higher prices, the proper policy response lies in the formulation of income augmenting policies to aid deserving individuals, rather than in interventionist responses which distort the proper workings of the market and create the possibility that all consumers are ultimately made worse off. 
LIST OF FIG̈URES, GRAPHS AND TABLES $\ldots \ldots \ldots \ldots \ldots \ldots \ldots \ldots \ldots \ldots \ldots \ldots \ldots \ldots \ldots$ iv

EXECUTIVE SUMMARY $\ldots \ldots \ldots \ldots \ldots \ldots \ldots \ldots \ldots \ldots \ldots \ldots \ldots \ldots \ldots \ldots \ldots$

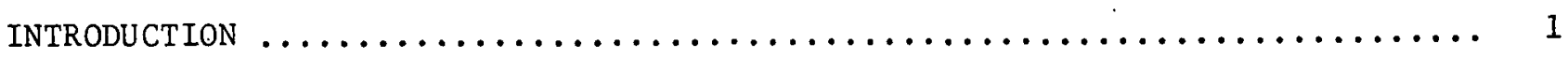

1. DEFINITION OF A WORLD OIL MARKET SHOCK $\ldots \ldots \ldots \ldots \ldots \ldots \ldots \ldots \ldots \ldots \ldots$

1.1 Results of a Supply Interruption $\ldots \ldots \ldots \ldots \ldots \ldots \ldots \ldots \ldots \ldots \ldots$

1.2 The Role of Marginal Prices ....................... 9

1.3 The Role of the Spot Market: A Measure of Marginal Value ....... 11

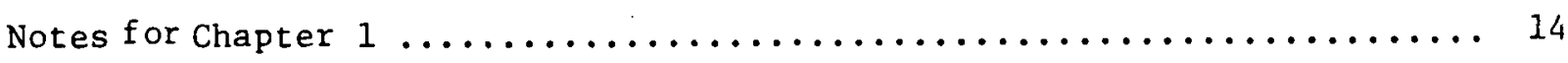

2. EFFICIENT TRANSITION OF THE U.S. OIL MARKET TO HIGHER WORLD OIL PRICES . 15

2.1 An Analytical Framework for Judging Efficiency in Adaptation ..... 15

2.1 .1 A Basic Model of U.S./World Pricing ............... 16

2.1 .2 U.S./World Pricing of Uil Products ................ 19

2.1.2.1 Interaction Costs ....................... 19

2.1.2.2 Regulatory Effects ................... 20

2.1.2.3 Theoretical Conclusions Regarding the U.S./World Pricing Relationship .................... 21

2.2 Empirical Examination of the U.S./World Market Adjustment ...... 22

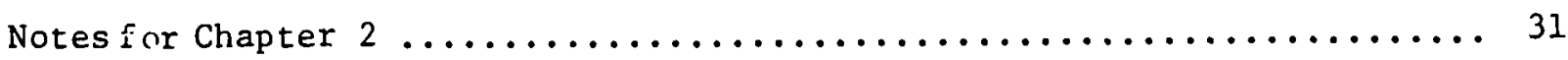

3. ADAPTATION WITHIN THE U.S. MARKET $\ldots \ldots \ldots \ldots \ldots \ldots \ldots \ldots \ldots \ldots \ldots \ldots$

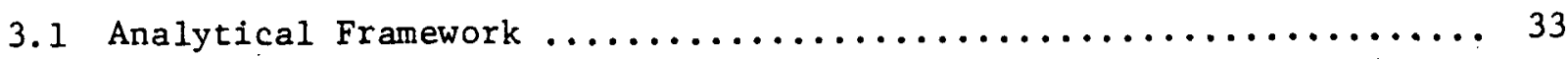

3.1 .1 Effects of Price/Supply Decisions ................ 33

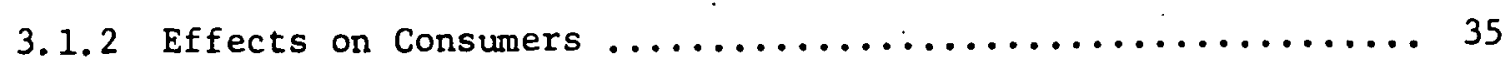

3.1.3 Effects of Market Adaptation on Competition ............ 39

3.1 .4 The Role of Arbitrage $\ldots \ldots \ldots \ldots \ldots \ldots \ldots \ldots \ldots \ldots \ldots \ldots \ldots$ 
3.2 Structural Adaptation: An Analysis of Market Behavior ........ 41

3.3 Price Adaptation: An Analysis of Market Performance .......... 43

3.3.1 Decontrolled Markets ....................... 48

3.3.2 Controlled Product Markets ...................... 59

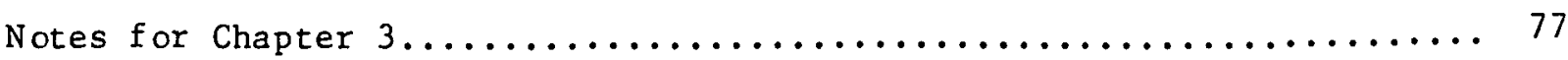

4. POLITICAL PRESSURE ANALYSIS OF INTRA-U.S. PRICING PATTERNS $\ldots \ldots \ldots \ldots$.... 81

4.1 A Model of the Political Pricing Constraint .............. 85

4.2 Description of Pricing Constraint Factors $\ldots \ldots \ldots \ldots \ldots \ldots \ldots \ldots . \ldots 9$

4.2 .1 The Pricing Constraint ........................ 91

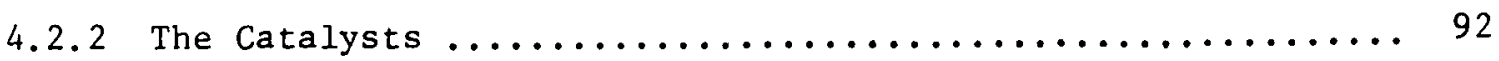

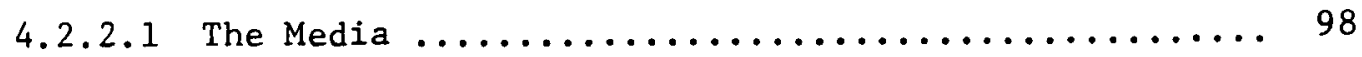

4.2.2.2 The Political Community .................... 99

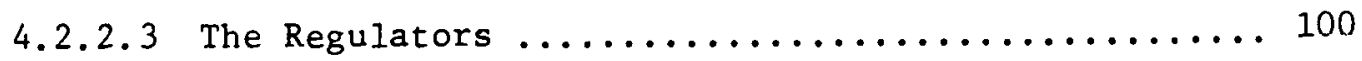

4.2.2.4 Price Guidelines of the President's Council on Wage and Price Stability: A Case Study of the

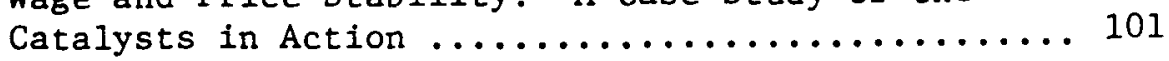

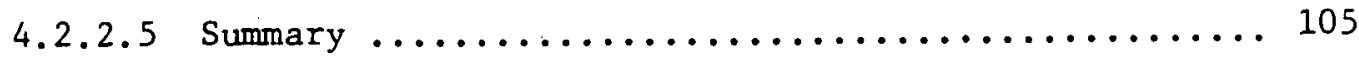

4.2 .3 Determinants of a Firm's Visibility ............... 105

4.2 .3 .1 Firm Size and Scope ......................... 106

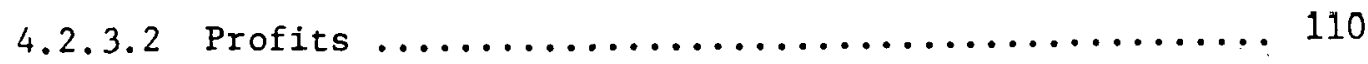

4.2.3.3 Firm Activity in the Political-Regulatory Arena ... 113

4.2.4 Determinants of Effective Consumer Pressure ........... 115

4.2 .4 .1 Price Increases ......................... 116

4.2.4.2 Consumer Expectations ..................... 118

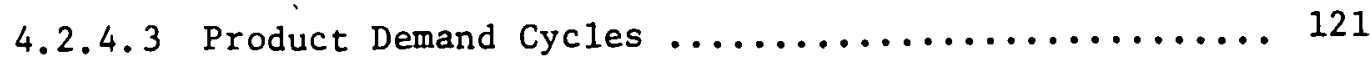

4.2.4.4 Consumer Group Activity in the Policy Process ..... 122

4.2.4.5 Secondary Response to Firm Visibility .......... 123

4.2.5 Pricing Constraint in Controlled Markets ............. 123

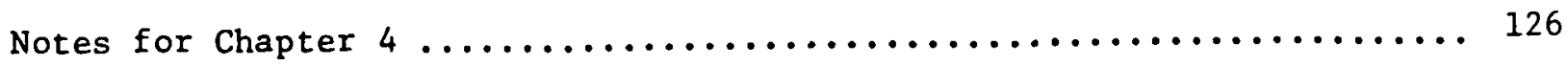


5. ANALYSIS OF 1979 OIL MARKET PROBLEMS AND POLICY RESPONSE $\ldots \ldots \ldots \ldots \ldots$

5.1 Definition of Market Problems $\ldots \ldots \ldots \ldots \ldots \ldots \ldots \ldots \ldots \ldots \ldots \ldots$

5.1 .1 The Problem of Economic Efficiency $\ldots \ldots \ldots \ldots \ldots \ldots \ldots . \ldots \ldots$

5.1 .2 The Problem of Economic Equity $\ldots \ldots \ldots \ldots \ldots \ldots \ldots \ldots \ldots$

5.2 Empirical Examination of Market Problems in $1979 \ldots \ldots \ldots \ldots$

5.2 .1 Controlled Products $\ldots \ldots \ldots \ldots \ldots \ldots \ldots \ldots \ldots \ldots \ldots \ldots \ldots \ldots$

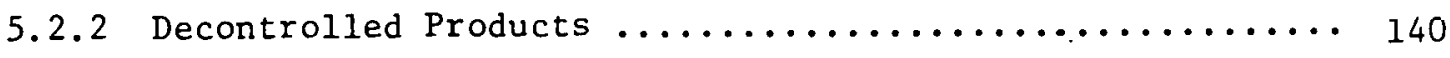

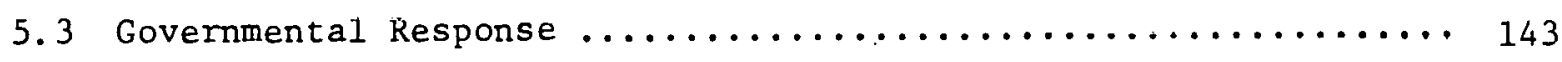

5.3.1 Controlled Products .......................... 143

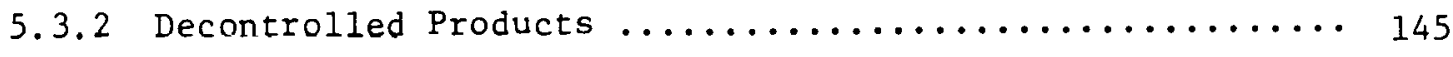

5.3.2.1 Department of Energy Response to the
Agricultural Industry $\ldots \ldots \ldots \ldots \ldots \ldots \ldots \ldots \ldots \ldots \ldots$

5.3.2.2 Trucking Industry Pressure and DOE Response ... 149

5.3.3 Further Prespectives on Governmental Response ........ 150

5.4 Caveats Regarding Consumer, Firm and Governmental Behavior .... 153

5.5 Market Problems and Government Response: Conclusions ....... 157

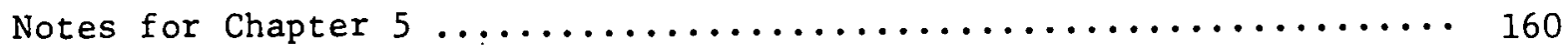

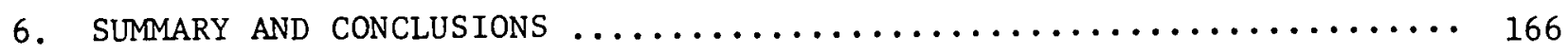

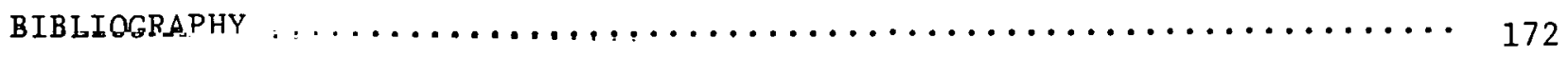


FIGURES, GRAPHS, AND TABLES

\section{FIGURES}

Number

1 Market equilibrium with a subsidy $\ldots \ldots \ldots \ldots \ldots \ldots \ldots$

2 Market equilibrium with a $\operatorname{tax} \ldots \ldots \ldots \ldots \ldots \ldots \ldots \ldots \ldots$

3 U.S. and world supply and demand with the U.S. a net

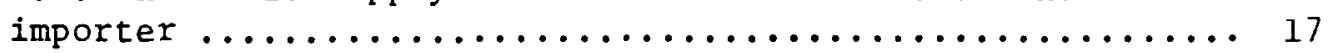

4 U.S. and world supply and demand with the U.S. a net

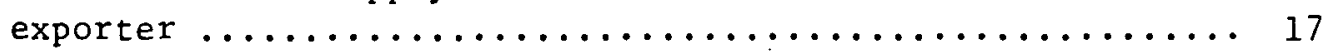

5. Theoretical view of spot-contract price relationship ..... 46

6 Increasing banked cost scenario $\ldots \ldots \ldots \ldots \ldots \ldots \ldots \ldots$

7 Constant and decreasing banked cost scenario ......... 72

$8 \quad$ A pricing constraint model $\ldots \ldots \ldots \ldots \ldots \ldots \ldots \ldots \ldots$

9 Flowchart of pricing constraint mode1 $\ldots \ldots \ldots \ldots \ldots \ldots$

\section{GRAPHS}

1 World and U.S. spot prices, distillate $\ldots \ldots \ldots \ldots \ldots \ldots$

2 World and U.S. spot prices, gasoline .............. 28

3 Spot and contract distillate prices, U.S. ........... 49

$4 a$ Diesel fuel, majors and independents $\ldots \ldots \ldots \ldots \ldots \ldots . \ldots 0$

$4 \mathrm{~b} \quad$ Heating 011 , majors and independents $\ldots \ldots \ldots \ldots \ldots \ldots \ldots$

5 Distillate prices, major refiners $\ldots \ldots \ldots \ldots \ldots \ldots \ldots \ldots$

6 Spot and Exxon contract prices, gasoline ............ 67 


\section{TABLES}

1 World and U.S. spot prices, distillate $\ldots \ldots \ldots \ldots \ldots \ldots \ldots \ldots$

2 Wórld and U.S. spot prices, gasoline ................ 29

3 Spot and contract distillate prices, U.S. ............. 50

4 Distillate allocation fractions, refiners $\ldots \ldots \ldots \ldots \ldots \ldots \ldots$

5 Distillate product prices, majors and independents ....... 62

6 Distillate prices, major refiners $\ldots \ldots \ldots \ldots \ldots \ldots \ldots \ldots \ldots$

7 Wealth transfere from major marketers $\ldots \ldots \ldots \ldots \ldots \ldots \ldots$

8 Spot and contract gasoline prices, U.S. ............. 68

9 Unrecouped costs for refined products $\ldots \ldots \ldots \ldots \ldots \ldots \ldots$

10 Posted wholesale prices, $\$ 2$ oil $\ldots \ldots \ldots \ldots \ldots \ldots \ldots \ldots \ldots \ldots$

11 Firm size and 1979 distillate pricing patterns .......... 97 
EXECUTIVE SUMMARY

This study investigates the behavior of United States oil markets during periods of world oil crisis, using the Iranian disruption of 1979 as the primary basis for analysis. It describes the impact of a world oil market supply disruption on the United States and develops a framework with which to judge whecher the U.S. oil markets function adequately throughout periods of world oil market transition. It analyzes the behavior of U.S. oil consumers, U.S. oil firms, and government regulatory agencies in response to world oil crises. It defines the problems which arise in American oil markets as a consequence of world oil supply disruptions and advances theories to explain both observed market problems and the nature of government policy response.

The study finds that during the supply crisis of 1979:

- both controlled and uncontrolled petroleum products were priced too low in U.S. markets, particularly by major oil companies;

- actual shortages of oil products only occurred in gasoline markets, still under price and allocation controls, while in all products freed from controls, sufficient supplies continued to exist;

- it appears that even in the absence of controls, major U.S. oil companies are forced to underprice during crisis periods, because of the ability of political leaders, regulators, and the media to turn consumers' understandable anger and misperceptions about the adjustment process into political pressure directed against both the industry as a whole and specific firms in particular.

Background

In the wake of the world oil supply crises of 1973-1974 and 1979, American policy-makers and the American public have become increasingly concerned about 
the possibility of future world oil supply disruptions and the U.S. economy's ability to cope with them. Yet, much popular confusion persists regarding the success of American oil markets in adapting to periods of world oil market disruption and realignment, as reasoned public debate on these issues has generally been obscured by political rhetoric. Consumers and policymakers have questioned the ability of firms in the marketplace to price and supply oil products appropriately during these periods of uncertainty, while the oil industry has questioned the government's often contradictory policy responses to the problems which oil crises have created in the II.S. The result has been that the actual effects of world oil market crises on the American economy remain largely undefined.

Given the likelihood of future world oil crises and the need to avoid federal mismanagement of the effects of these crises, it is important to understand the issues surrounding the American oil market's adaptation process. The importance of resolving these issues increases as Octuler 1, 1981 approaches. On that date, the Emergency Petroleum Allocation Act, which is the legislation that grants the Department of Energy the authority to undertake regulatory initiatives to manage American response to oil crises, expires. Thus we believe that the time is right to review the effects of recent world oil supply crises on American oil markets and suggest their implications for future U.S. government policy.

\section{Analytical Framework}

The issues examined in this study are approached from two viewpoints: 1) economic efficiency, and 2) social equity in the sharing of the burdens imposed by oil crises. The workability of U.S. oil markets is judged by whether they appear to be operating efficiently in the economic sense. For the efficiency benchmark to be met, oil products available within the U.S. 
must be priced in a manner that reflects their true cost to society; and they must be allocated to those consumers who value their consumption most highly. If these conditions are met, the damage done by the crises to total American economic wealth, as measured by the impact on the Gross National Product, will be minimized. If these conditions are not met, and oil prices thus do not reflect actual supply and demand conditions in the market, the ability of the economy as a whole to react optimally to constricted world oil supply will be compromised.

The equity issues raised by an economically efficient transition process are examined within a separate and distinct analytical framework. Equity issues will arise during periods of transition even in a market that is functioning perfectly, as higher oil prices lead inexorably to the existence of income problems among members of the oil-consuming public. As a departure point for this analysis, we suggest that the attainment of economic efficiency in the transition process, and the problems of social fairness which arise from the manner in which the burden of higher oil prices is shouldered by various parts of society, constitute separate issues demanding separate redress. We discuss in some detail the different natures of these two types of problems, as well as differences between the appropriate policy approaches to their solutions.

We apply our analysis to the major oil products in the United States -gasoline, heating oil, and diesel fuel. The markets for these products have been the objects of the most public attention and concern during past oil supply crises. A number of prominent studies have examined the dynamic behavior government policy settings of other parts of the U.S. and world oil markets, particularly crude oil markets. Surprisingly little analysis, however, has been applied to the markets for refined oil products. Yet, it is at the refined product level that the public uncertainties and anger born of oil 
crises develop. Regardless of where in the production chain a supply problem occurs, it is in the markets for refined products that its ultimate result affects consumers. It is at this end of the oil market that substantial need exists for analyzing and clarifying the issues.

\section{Study Structure and Primary Conclusions}

This study consists of five chapters. The first two analyze the effects of world oil supply crises on U.S. oil markets. The latter three examine the market and policy adaptation process within the U.S. in response to these supply disruptions.

Chapter 1 presents a theoretical discussion of the effects of a world supply disruption on the price level and supply availability of world market oil to any consuming councry including the United States. A discussion of the importance of world spot markets in the process of country-by-country adaptation to supply disruptions is presented. Prices on spot markets are found to be the best available indicators of efficient world oil prices at any given point during the adaptation process. Chapter 2 provides a theoretical and empirical analysis of the efficiency of the adaptation of U.S. oil product markets to higher world oil prices.

On the basis of the analysis of Chapters 1 and 2:

- We conclude that, in theory, U.S. and world price levels in petroleum products, as measured in spot markets, must be equal for the U.S. economy to function efficiently. This conclusion holds for both periods of stability in oil markets, and periods of world oil supply disruption.

- We find that, empirically, the world market price of oil serves as an upper bound to the price level within the U.S. during both periods of stability and those of disruption.

- We examine price behavior in one period of world oil market stability, 1978, and find that rough priceparity existed in major petroleum products. 
- During the period of world market shock and adjustment in 1979, we find that, contrary to popular perceptions, U.S. oil product prices were significantly and consis.tently lower than world prices.

- The U.S./world price divergence we observe in 1979 represents a market inefficiency, diminishing total U.S. economic welfare. During this period of transition, consumers of oil within the U.S. received incorrect signals regarding the value of the oil they consume.

- We conclude from our examination of the U.S./world price relationship that there exists no basis in fact for the oft-heard charge that U.S. oil prices during crisis periods are, for one reason or another, higher than they should be. Nor does our evidence suggest that U.S. prices have risen faster than conditions in world markets warranted. Rather, the reverse appears to be true: U.S. oil prices were too low and responded too slowly to the reality of higher world prices throughout the 1979 oil crisis.

Chapter 3 examines the responses of various groups of U.S. oil firms to the alterations observed in world markets. Our examination in this chapter focuses on the oil product prices charged within the American market by different groups of sellers. The chapter also assesses the market's overall efficiency in pricing and supplying oil to American consumers. The performance of American oil firms is measured by their pricing decisions, relative to an efficient U.S. pricing norm. We take the U.S. spot price as the criterion for efficient pricing behavior with the U.S. market because the U.S. spot price represents the best available measure of the actual value of oil at the margin to American consumers at any given time.

On the basis of Chapter 3:

- We find that the adaptation process within U.S. markets during 1979 exhibited significant departures from efficient patterns. Throughout the period, prices for major oil products within the U.S. were artificially low. This judgment holds for both those products that were still under price controls during this period and those which were completely free of formal government price regulations. 
- Most groups of sellers of petroleum products lagged prices in 1979, pricing well below the U.S. spot market throughout the year. This trend was slight in the independent wholesaling and small refining sector of the industry. It was of greater significance and conse:quence among major sellers, particularly large refiners.

- In gasoline, the only major product still under price and allocation controls in 1979, major sellers priced significantly below the level that the control framework allowed. Formal price controls did not serve as the binding ceiling on the wholesale market price of this product during 1979.

- In the gasoline market, the inefficiencies created by majors' wholesale-level product underpricing were compounded by the control system's allocation framework and retail-level pricing restrictions. These constraints combined to prevent the market from clearing during several months of 1979 , with the result that genuine product shortages appeared.

- In the heating oil and diesel fuel markets, both free from controls, pricing behavior among major oil companies during 1979 was generally as constrained overall as it was in controlled products. As was the case in gasoline, underpricing of these products engendered a significant increase in consumers' demand. Major companies were forced to nonprice ration available arbitrary allocation rules replaced market forces in the allocation of decontrolled oil products across consumers.

- Spot markets were sufficiently active in decontrolled products during this period that consumer demand that could not be satisfied by major companies was satisfied through spot transactions. Thus, markets in decontrolled products, unlike those in controlled products, evidenced no problems of actual shortage during 1979. In terms of availability, the markets functioned adequately despite the major oil companies' consistent policies of underpricing.

- The oil industry's price-lagging behavior resulted in a large wealth transfer away from oil product producers to oil product consumers during 1979. We estimate that producers of heating oil and diesel fuel in the U.S. lost in the neighborhood of $\$ 8.5$ billion, relative to the potential revenues they would have accrued from efficient transition-period pricing of these two products. Major oil companies alone, whose price-lagging was the most severe, lost approximately $\$ 5$ billion. 
Our conclusions about the U.S. market's operation in times of world oil supply crisis clearly differ radically from many popularly-held views, specifically as regards the behavior of the major oil companies in pricing and supplying oil products.

Chapter 4 presents a theoretical explanation for the price-lagging behavior exhibited by firms in the U.S. oil industry. We suggest that increasing threats of retribution from the political community, caused by consumer anger over price increases, have forced oil companies away from efficient patterns of adaptation during periods of sharply rising world oil prices. Contrary to public perception, consumers of oil hold great indirect power over major companies' actions in the increasingly politicized marketplace. Consumer pressure is focussed into credible political threats by the political community because, in order to sustain their own electoral popularity, political representatives must effectively turn their constituents' frustrations over high oil prices into political action.

Chapter 4 suggests that:

- U.S. oil industry pricing behavior appears to be constrained by political pressure that drives prices away from efficient patterns. Yet, this constraint does not result from any formal regulatory or legal restrictions, but rather from the market's growing politicization. This politicization has resulted from the increasing threat of regulatory intervention in the oil market in response to consumer pressure. The resulting price patterns are not societally optimal and have damaging impacts on the U.S. economy.

- Two factors underlie the nature of the pricing constraint felt in oil markets: 1) consumer anger over price increases; and 2) the high degree of visibility possessed by the major actors in the oil industry. This visibility makes the oil industry firms targets for consumers' anger.

- The cornerstone of our model involves the actions of three groups whom we term the "catalysts." These are: 1) the news media; 2) the regulators; and 3) the political community. These groups catalyze consumer anger 
over higher prices and the high visibility of major oil companies into an effective pricing constraint. The media's treatment of the price increase phenomenon turns generalized public anger into directed consumer pressure. The policy-making community, in response to this pressure, restricts, or at the very least threatens to restrict, various aspects of the oil industry's behavior. Regulators, in turn, have incentives to abet the anti-industry policy process.

- 'Individually, neither firm visibility nor consumer anger over higher prices constitutes a sufficient market condition for the catalysts to generate an effective pricing constraint. Both consumer pressure and high firm visibility must be present for the media, regulators, and political community to function in a manner that inhihits a firm's pricing strategy.

- The pricing constraint described in this model, which emanates from neither market mechanisms nor direct legal pricing restrictions, appears to be endemic to U.S. oil markets, given the size of the firms in the industry and the amount of economic and political discomfort generated by oil price increases. We believe that this constraint will continue to function during future world oil supply shocks, to the detriment of the U.S. adaptation process.

Chapter 5 addresses the nature of both real and imagined oil market problems in the U.S. during periods of world oil market transition. We explore the issue of transitional market efficiency first raised in Chapter 3 in more detail, and document our finding that in decontrolled markets artificially cheap oil products were nonprice rationed by majors, while marginal demand was, or could have been, met through purchases on spot markets. We examine the genuine shortages which appeared in 1979 in gasoline, as a result of the product's remaining under an explicit price and allocation control framework. Finally, we analyze the dual public misperceptions that shortages and price-gouging exist in markets for decontrolled oil products during 1979. 
The analysis of Chapter 5 indicates that:

- All examples of genuine breakdown in American oil product markets appear to stem not from any inherent market deficiencies, but rather from government intervention and threat of intervention.

- The major problem which consumers must face during periods of world oil market disruption is not one relating to market efficiency, but rather that of coping with the sharply higher prices for oil products which stem from world oil supply constrictions. It is the effect of oil price increases on consumers' incomes, rather than any inherent problem in price or supply levels themselves that lies at the core of the public's and policy-makers' concerne during perinds of oil crisis.

- There exist two kinds of income problems among consumers during these periods. All consumers are made worse off by oil price increases; but groups of consumers whose livelihood is tied more directly to oil use than others' are made worse off relative to the rest of society. Predominant among these groups are industries which are oil intensive.

- Much of the motivation behind many policy-makers' arguments for broad-based market interference with prices appears to stem from the effect of higher prices on lowincome members of society. We suggest that the government can address the low-income concern through policies which do not falsely attribute the problem to efficiency in the market's function. Success in this will leave those low-income consumers in question better off, as well as increasing the total well-being of the economy.

- The public perception that shortages of products inherently result from world oil market disruption, with attendant phenomena such as the gasoline lines of 1979, is mistaken and appears to be based upon the problems created by regulatory intervention. Without intervention and the threat of intervention creating artificially low prices in decontrolled markets, the problems most commonly perceived as resulting from world oil market supply disruptions (including product shortages, allocation by fraction, and excess demand for price-lagged product) would not exist.

- In decontrolled products, we find that the perceptions of price-gouging that were prominent in 1979 grew nut of the perception that the actions of the major oil companies constitute a benchmark. for market function. Product prices charged by the majors have been regarded as the only relevant measure of current market prices; 
consequently, higher efficient spot prices were perceived as artificially high. Concomitantly, majors' nonprice allocation by fraction gave rise to the illusion that absolute unavailability of product existed and demand was going unsatisfied, although in actuality, the only demand 'left unsatisfied was that for these firms' artificially cheap product.

Finally in Chapter 5 we examine the critical issue of what the federal government's role should be in the market transition process. We base our conclusions on an analysis of the relevance and propriety of past governmental intervention. This intervention has ranged from the broad-based price and allocation controls of the Emergency Petroleum Allncation Act, as well as narrow or restricted formats such as the governmental responses to the socalled diesel fuel crisis of the summer of 1979 . We present a normative view of the appropriate role for government policy in addressing the different types of social and economic problems that stem from oil market crises, and suggest policies that are appropriate for addressing those policy goals which appear to lie behind most federal o11 market pulicy.

Our major conclusions are that:

- Federal regulation has been designed in response to the equity issues that arise from oil price increases. Regulation has attempted to address the way in which the burden of higher oil prices is shared across society. However, rather than approaching this concern directly through income transfer policies, the government has attempted remedies through market intervention -- through policies which affect oil price and supply. Policy-makers have perceived an inherent problem in U.S. oil prices and have sought to alter these prices. They have failed to recognize that the difficulties of consumer adaptation do not relate to the efficiency of price levels, but rather to the reduced levels of real consumer income that higher prices cause. The cases of consumer hardship caused by oil price increases in decontrolled markets and brought to the DOE in this period were interpreted as evidence of market breakdown. Accordingly, they were remedied with market-distorting intervention, despite the fact that these markets exhibited no evidence of such breakdown. This policy response was the norm even in markets which were officially decontrolled. 
- In addition to the inefficient methods employed by DOE during 1979 for granting distributional relief, there is considerable evidence that the groups that received such aid constituted those with the best political representation in the policy process, rather than those experiencing the severest income problems as a result of product price increases. In diesel fuel, which was decontrolled, both trucking and agricultural interests were granted substantial protection from the reality of higher prices during the summer months. Both groups are well known for the influence of their lobbying efforts on the policy process. Yet, while these groups were successful in securing aid, many other diesel consumers, experiencing similar or more severe problems of rising prices, received no protection.

- Relief was provided to the agricultural and trucking industries by the Economic Regulatory Administration by granting these consumers legally guaranteed rights to additional supplies of artificially cheap diesel fuel from major oil companies. This represented an inappropriate method of addressing the distributional problems experienced by these consuming groups, distorting their adaptation to the reality of higher oil prices and interfering with the efficient operation of the U.S. economy.

- It is highly probable that many groups appealing to DOE for relief during periods of oil market disturbances do so not out of genuine hardship. Rather interest groups are cognizant of the potential windfall gains that they may obtain through beneficial regulatory intervention. These benefits are termed infra-marginal rents. They accrue due to the unevenness of the price adjustment process across firms in the U.S. oil industry, and specifically from the price-lagging behavior of major oil companies. In recent years, many of the appeals brought before DOE have been based upon this price-adjustment unevenness and, thus, constitute competition for the rights to these rents through the policy process.

- It must be concluded from our analysis that the U.S. cannot adapt properly to future crises in world oil markets is government actions mask the truth about price and supply conditions in these markets. Rather, the American economy must be allowed to adapt efficiently to the increases in world oil prices which arise from world oil supply disruptions. If remedial action is to be undertaken by the government in response to distributional concerns, such action should be designed to directly augment consumers' incomes 
and thus provide aid in coping with higher prices. Policy-makers should not repeat recent mistakes by attempting to redress problems of low income by altering the prices consumers face for oil. Adaptation to the reality of higher prices during periods of world oil supply disruption is a necessity. 


\section{INTRODUCTION}

There have been two major oil crises in world and domestic markets during the.past decade. The first occurred in 1973 due to the Arab oil embargo; the second was spurred by the Iranian shutdown beginning December 1978. Both of these crises have stemmed from a sharp reduction in the total amount of oil produced and available on world markets. These supply reductions caused sharp price increases, which in turn had damaging effects upon the domestic economies of major oil consuming nations.

In both periods, the American oil market's reflection of the international realignment has engendered a crisis atmosphere in the United States, with sharp consumer anger arising in response to the changes occurring in the oil. market and resulting political and regulatory response from governmental institutions. During both 1973-1974 and 1979, there were many charges made by those at virtually every level of policy making that actors in U.S. oil markets (and major U.S. oil companies in particular) were functioning in a manner completely at odds with the needs of the American economy. There have been numerous complaints that the prices charged for oil products, particularly by the major oil companies, were either too high or climbing too fast. There has been a common perception that the U.S. oil companies created actual shortages of various oil products -- that is, that consumers could not purchase products at any price, and certainly not at one reasonably close to what consumers considered to represent a fair and efficient price for the commodity. Consumer anger over these perceived problems created a great deal of adverse political fallout for the U.S. oil industry, which 
in turn resulted in various regulatory restrictions on oil industry behavior during these periods.

In the wake of events, it has become the general expectation among U.S. policy-makers that world power balances and uncertainty within the Middle East are such that we must assume that events of a similar nature are likely to occur again in the near future. Thus, a major topic of debate centers on how governmental institutions should plan for and react to world oil crises in the future.

In order to plan policy for future oil supply emergencies, policy-makers, academicians, and planners must have a clear understanding of the nature of the problems that developed in American oil product markets during past periods of disruption.

Yet, despite the volatility of the issues that surround periods of oil market disruption and change, and their significance for policy-makers, few attempts have been made since 1973 to study this market pheonmenon in depth and to make empirically supported conclusions regarding the existence and nature of the market problems that have been widely perceived by the public. It is therefore important to the functioning of our economy for us to understand more fully the nature of the process by which the U.S. oil market transitions reflect new conditions of supply and price in world oil markets and the role that the U.S. oil industry plays and should play in that transition.

This study presents such an analysis of the process by which U.S. markets adapt to major changes in the price and supply levels of oil in the world market. We have chosen the most recent period of turbulence, 1979, for our examination. Unlike 1973, this period allows us to study the American adaptation process both in petroleum products still under governmental price and allocation regulation, and in those that are ostensibly free from such 
restrictions and are priced and traded in an unfettered market.

We approach our analysis of the issues surrounding the effects of oil crises upon United States markets in what we believe constitutes a different manner than that contained in most existing studies that address the market's transition-period state. Most studies that have addressed the issues relating to these periods -- of which the most prominent have been those of Kalt (1981), MacAvoy (1977), Harvey and Roush (1980), and Verleger (1979) -- have focussed upon the effects of specific regulations on the market's ability to operate, waking assumptions abnit the performance of the market devoid of such regulation. We, however, take a different approach. It is our goal in this study to analyze the actual patterns of adaptation that we see in these markets, both those devoid of governmental interference and those still under the control framework of EPAA. Having established the workings of this market as our base -- rather than using certain regulatory initiatives as our starting point - - we attempt to draw cnnclusions about the nature of the influence of political institutions on these markets.

We approach our examination of the nature of crisis in American oil markets in several stages. We begin our study by defining the nature and effects of a world oil market disruption: why these disruptions have occurred, what they have meant for United States oil consumers, and what measure we believe should be used to gauge the seriousness of any world oil market crisis. In Chapter II we proceed to define the economic position of the United States relative to world markets in oil products. We demonstrate the economic implications that stem from various methods of U.S. adaptation to world supply shocks, and then, from empirical examination, judge what we believe to be the pattern of the United States market's adaptation to world market changes. In the third chapter, we offer an examination of those issues that have 
been of most direct concern to U.S. policy-makers and the public: those that surround the process of adaptation and change within American markets and that relate to the conduct and performance of different sectors of the American oil industry. Here, we arrive at our primary conclusions about the price levels that Americans see in the market during times of disruptions and the market's efficiency in allocating available oil products across consumers. We also draw conclusions about whether American oil markets, if left unfettered, adequately function to meet the economy's oil demands in times of change, or whether there are serious problems inherent in the working nature of these markets.

In the fourth chapter of the study, we propose a theory to explain the pricing patterns that are observed to occur in the market during periods of disruption and change. The theory attempts to draw together the types of pressures that interfere with market function over the short-term, and thus describe the constraints that American oil companies face when making price and supply decisions during these periods. Finally, in our fifth chapter, we tackle the task of defining the problems that we believe exist in these markets. We approach this from three perspectives. First, we define, in categorical terms, the real nature of the problems that we believe arise in the U.S. in times of oil crisis. Second, we relate the reality of these problems to the many misperceptions regarding their nature, effects, and cure which we beleive have existed to a striking degree among the public and policymakers since 1973. Here, we present evidence, in the form of case studies on the $1979^{\prime}$ market problems, of the divergence between the realities of these problems and the illusions that cloud perceptions of policy-makers and thus adversely affect regulatony response. Finally, we make observations regarding the appropriateness of government regulatory response to these market problems 
and render conclusions on the nature of government response in relation to the reality and illusions we have described in this market. We close with some final:recommendations on the appropriate forms of government planning for and response to future world oil market crises. 
Chapter I

DEFINITION OF A WORLD OIL MARKET SHOCK

We begin our study by examining several aspects of the nature of a world oil crisis, such as those experienced in 1973-1974 and 1979. We will examine what these crises are, what their results are in world oil markets, and what aspects of the market we should look to in order to gauge the seriousness of any such crisis.

To begin this examination, we note the framework within which the analysis is performed as regards the competitive characteristics of the U.S. oil industry. Many examinations have been made of the competitive viability of the American and international petroleum markets in periods of equilibrium; that is, in times when world market forces in oil are fairly stable (for example, the years 1975-1978). These examinations virtually unanimously conclude that the U.S. oil market is workably competitive at every level as judged by traditional economic standards, and that, in the absence of regulatory disturbances, oil products are efficiently priced in the long run on a parity with world markets. 1

While out study of the dynamics of the adjustment process thus assumes long run competitive behavior, we clearly do not enter this study assuming that U.S. oil prices will be at efficient levels during periods of transition in the absence of regulatory interference. Rather, our task is to determine this. Examinations of the market's equilibrium competitive behavior are not necessarily reliable predfctors of the U.S market's dynamic efficiency in adapting to periods of change. In times such as 1973 and 1979, abrupt changes In world oil markets caused disruptions in the domestic markets for oil products; 
and many problems, including absolute price levels, rates of price increase, and lack of product availability were perceived by policy-makers and the public alike. Thus, in this study we attempt to describe the dynamic adjustment processes in U.S. markets during periods of world oil market turmoil such as 1979 .

\subsection{Results of a Supply Interruption}

Periods of intense disruption and readjustment in U.S. oil markets are caused by events that disrupt the traditional equilibrium of the world oil market. In 1957, the Suez Crisis caused a cutoff of Persian Gulf oil to much of the world, with a resulting increase in oil prices. In 1973, the Arab embargo caused major permanent changes in traditional oil production and distribution patterns, again resulting in major oil price increases. The most recent major disruption occurred in 1979 , beginning with the Iranian oil field shutdown in December 1978 and stretching into the late fall of 1979. We must be clear at the outset regarding the nature of these supply disruptions: what their consequences are in world markets and what effect they have upon the United State's access to imported oil.

The basis of each of the major periods of emergency and disruption in United States oil product markets over the period since 1973 has been a sharp supply constriction in world markets for crude oil and oil products. In 1973, the OPEC production cartel exerted its ability to raise price for the first time by cutting back the production of crude. In 1979, the Iranian revolution took five million barrels per day of production of $f$ world markets. ${ }^{2}$ While neighboring producing states stepped up their output somewhat, the result was to reduce total world production below what it otherwise would have been. In both of these periods, serious public misperceptions arose regarding the effects of the cutbacks. Many percelved that the world was 
simply "short" the number of barrels of supply that had been lost -- that the world had a "shortage" of a certain amount of oil. relative to its consuming needs.

This common misperception arises out of a misunderstanding of the workings of a supply-demand economy such as that which world oil markets represent. When total world production diminishes, no individual consumer in these markets -- not even one as large as the U.S. -- experiences a supply gap. Rather, with world oil more scarce, each individual consuming firm, state, or individual must bid in world markets for a scarcer supply. Supply becomes more expensive; consuming nations reduce consumption in response lo higher prices. Thus, the world market re-equilibrates: price increases until consumption drops to the level of remaining supplies. So long as prices are allowed to adjust, supply cutoffs do not result in an absolute unavailability of oil in world markets, as the popular talk of world oil "shortages" often suggests. Rather, they result in higher prices and lower overall world consumption.

Likewise, it must be clear that embargoes against specific countries cannot be enforced in a market of the size, extent, and complexity of the world oil market. The fact that OPEC producers, for instance, refuse to sell to U.S. firms does not leave the U.S. out of world markets, as nothing prevents intermediaries throughout the market -- a neutral country or private firm -from reselling product to the U.S. Nor can producing countries "turn off" the U.S.'s consumption needs in world markets by reducing production by the amount the U.S. consumes. This would serve to make oil far more expensive, but not to alter the competitive dynamic between the huge number of national and corporate actors in the market.

In each of the above cases, it must be noted that there do exist additional costs for certain countries caught in particular situations as consumers in 
in these markets. In the case of an embargo, or that of a country which held a large number of supply contracts with a producer that has ceased to. produce, there exist definite transaction costs, over and above the prevailing market price, in searching out and securing supply from new sources. These are, however, direct monetary costs; they do not, make oil "less available" to the country, only more expensive.

Thus, we conclude that the most direct effect of a reduction in oil supply on world markets (i.e., a supply shock) is an increase in the world price of oil products. A cutoff of production or shipping of oil from any producer or producers will serve to make oil more scarce, and, therefore, more valuable. The price of all petroleum products will rise to reflect that new scarcity. In this situation, any individual consumer in world markets -- the United States, for example -- will have to pay more to secure the same amount of oil as was obtained before the market tightened.

\subsection{The Role of Marginal Prices}

In a period of rapidly increasing world oil prices, what price should we look to as a measure of what consumers should be paying for oil? It is important to distinguish between the price paid at the margin for oil (i.e., the price paid for the most expensive barrels bought) and the average price paid across all barrels. In periods of oil market stability, the cost of the average barrel and the marginal barrel approach rough parity. However, in periods such as 1979 , the marginal price of crude becomes sharply divergent from the average price. In 1979, for instance, the difference in price between the average and the marginal barrel of crude rose as high as $\$ 22$ per barre1. 3

This divergence arises because the process of raising prices to higher levels is uneven across sellers. But it is the marginal price which 
measures the relevant cost of oil to the U.S. -- not the average cost. If firms or consumers must replace the average gallon of oil they use by purchasing from marginal sources, the average cost of the barrel they consume is virtually meaningless. Likewise, if oil is priced below its marginal cost to society, it will be over-demanded among consumers; many will choose to consume who would abstain if confronted with actual marginal prices. In Figure 1, the D curve is meant to represent the value placed on incremental units of oil by consumers; and the $S$ curve represents the cost to the country of procuring incremental units of oil. If a price p less than $p *$ (the country's marginal cost) is chosen due to intervention in the market -- in this case a subsidy of s per unit -- consumers will demand more than is socially optimal $\left(D_{p}>D_{p^{*}}\right)$. Too much is consumed in the sense that consumers receive oil worth only $p$ to them at the margin, but the provision of this benefit to consumers costs the country $\hat{p}$. Conversely, by the same reasoning, consumption is less than is socially optimal if the product is taxed $T$ per unit as Figure 2 attests.

Figure 1

Price

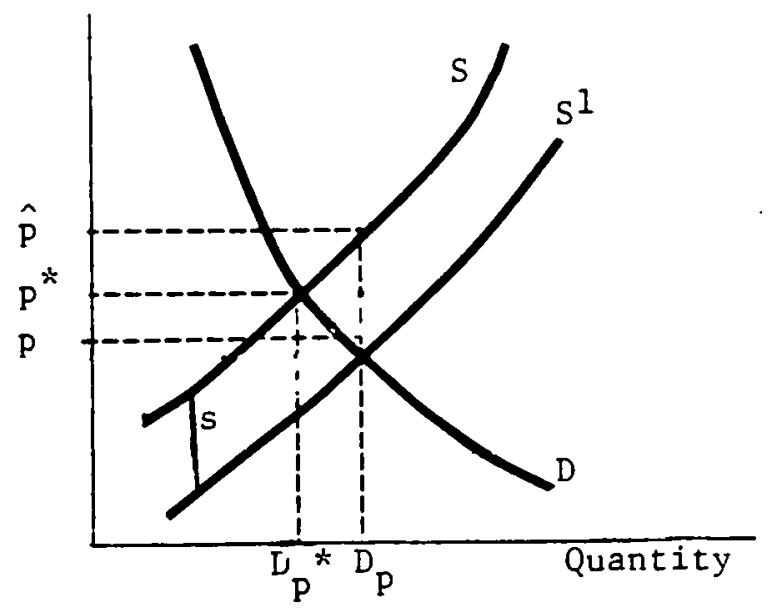

Figure 2

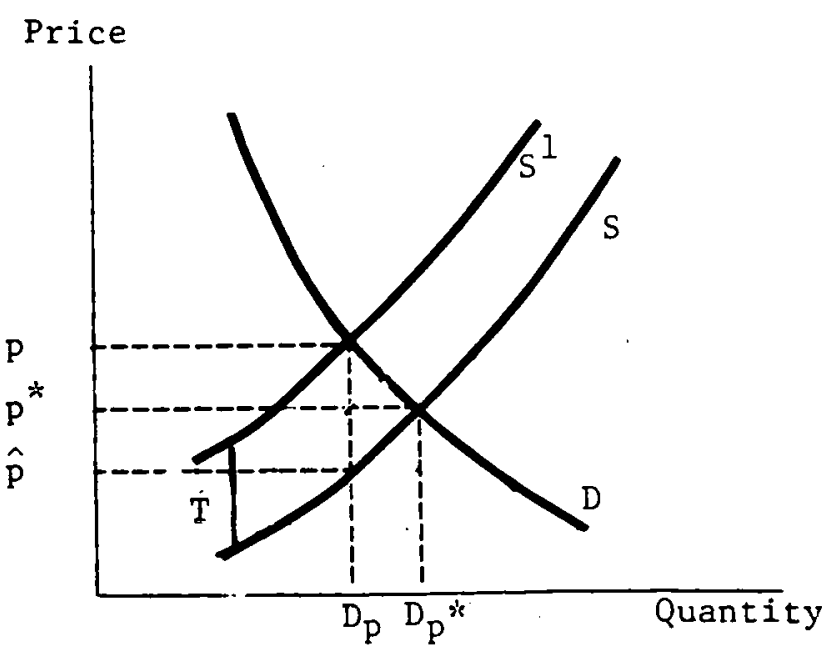


Thus, when we examine the behavior of oil prices in world and U.S. markets, we must look to the value of the marginal barrels as the determinant of what the price for oil in the economy should be if we are to avoid the waste of national resources. Any other price does not represent the cost to society of using a barrel of oil. Average costs, which are commonly misinterpreted as having some significance in oil pricing, are not relevant as indices of the resource costs to the economy of oil products. (The distributional issues raised by the marginal vs. average price comparison we makc here are discussed in Chapter 5.)

\subsection{The Role of the Spot Market: A Measure of Marginal Value}

We have now established that we would desire the equation of oil prices to the marginal cost for oil if the market price is to be efficient. During periods of world oil supply disruption the cost. of acquiring marginal units increases. World oil prices rise concomitantly with the increase of marginal costs in these markets. In order to begin to judge the efficiency of the adaptation process, we must find a measure of price which accurately reflects marginal costs through these periods of great uncertainty and change.

Throughout world and U.S. markets for crude oil and oil products, there exist several market mechanisms through which producers exchange their commodities with consumers. The two most prominent of these, which account for almost all oil sold, are contract transactions and spot transactions. Contract transactions, the features of which we will discuss at length in Section 3.3, represent the vehicle whereby approximately 90 percent of the world's oil passes from producers to consumers. However, because of the many accoutrements of the contracting relationship including long term commitments, producer-consumer good will, and limited ability of both sides to bargain in pricing decisions, these prices are not likely to represent accurate 
indicators of the immediate marginal value of oil at any given moment in time. Pather, we believe that this function falls to those markets which have historically served as the most flexible link in the oil production and distribution chain, responding to the immediate changes occurring in the needs of both consumers and producers. These are oil spot markets. An institutional examination of this market shows that the spot market is indeed the source of marginal supplies of oil. When a purchaser in the market for oil or oil products has an unanticipated immediate need for additional supplies, the unly source where he has an ensured ability to obtain such aupplies is the spot market. This is the function of a marginal market. Thus, the characteristics of spot markets ensure that they are relatively accurate reflections of the incremental value of the various products to consumers at any given point in time. Due to these factors, spot markets are the most readily available standard utilized to measure the marginal price -- the real resource value -- of oil.

Spot markets are in some sense speculative. In a market in which price changes of varying magnitude are taking place at an unpredictable rate, prices in the spot market for immediately available oil products reflect both buyers' immediate demand for oil, and their expectations regarding future oil availability and price levels. Speculation in this sense is not a negative force. Rather, it allows those participating in the market to adapt to intertemporal changes in value of oil or its products in an efficient manner. Expectations of imminent price increases will drive spot prices up as consumers purchase currently available oil, which is assumed to be cheaper than future oil, as a hedge. Conversely, when oil prices are expected to decline in real terms, the spot market becomes a discount market, reflecting buyers' perceptions that future oil deliveries will actually cost them less. 'Due to the uncertainties described above, we may expect to see sharper gyrations in spot market 
prices than in other prices in any given period. This is in no way ineficient, but is simply a consequence of an uncertain market environment.

In an unregulated world market, then, we may look to spot prices to determine the nature of the changes taking place in the market. Given the structure of that market (delivered) world spot prices for oil are a fairly reliable measure of what we would expect to see charged for spot ail products in any country at any given time -- if spot oil prices within that country are unregulated and if no arbitrary barriers such as tariffs or quotas have been erected which inculate that market (see Chapter 2). 
NOTES FOR CHAPTER 1

1. See, for example, Duchesneau (1975), Eppen (1975), Erickson (1977), Erickson and Spann (1974), Johnson, Messick, Victor, and Wyant (1976), Teece (1976), and U.S. Treasury Department (1973). For dissenting views see, for example, U.S. Federal Trade Commission (1973), and Sampson (1975)

2. See DOE, EIA, Monthly Energy Review for country-specific world crude oil production data.

3. See Petroleum Intelligence Weekly for prices of world-market crude oil. At times in early 1979, world spot was $\$ 40 /$ bbl while Saudi contract was $\$] 8 / \mathrm{bbl}$. 
Chapter 2

EFFICIENT TRANSITION OF U.S. OIL MARKETS

TO HIGHER WORLD OIL PRICES

This chapter examines the relationship between American and world oil markets during periods of world market disruption. The chapter proceeds in two sections: the first is theoretical, the second empirical. In the former, we provide a framework in which to analyze how the U.S. adapts to world markets during periods of world oil market transition. We demonstrate what the relationship between U.S. and world prices must be for an efficient transition to take place, and define the inefficiencies which will result if that efficient outcome is not met. In the latter portion of the chapter, we examine available evidence of the U.S./world transition pricing relationship and draw conclusions regarding the implications of the relationship for U.S. and world oil consumers.

\subsection{An Analytical Framework for Judging Efficiency in Adaptation}

In order to determine the efficient dynamic response of U.S. oil markets to changes in world oil markets, we must pose two questions. First, in periods of stability or disruption, what should be the relationship between domestic prices and world prices for an efficient market outcome to occur? Second, what inefficiencies result in U.S. and world markets if this is not the case? These questions are ones of dymanic transition; that is, they relate to the movement of world and U.S. markets from the old equilibriuri to the new. As the direct examination of market dynamics is extremely inexact in nature, we take as a basis for examining these dynamic issues an analysis of their static counterparts. These may be summarized as follows: at any given 
point in time what does an efficient U.S./world pricing relationship look like, and what inefficiencies exist if. this does not occur?

\subsubsection{A Basic Model of U.S./World Pricing}

Initially, let us examine the U.S./world price relationship that would be expected in an idealized world market. Specifically, our idealized world market faces no transportation costs, transaction costs, or time lags in the delivery of the product, Further, no import, or export restrictions between the U.S. and the rest of the world (ROW) exist. In this idealized market situation, global welfare is maximized if U.S.prices ( $P_{u s}$ ) are equal to rest-of-world prices ( $\left.P_{\text {row }}\right)$. This efficient outcome will be obtained by our idealized market and is depicted in Figures 3 and 4 . These figures show the efficient solution of U.S. and world markets, given the possible outcomes of the U.S. /world supply-demand interaction. Figure 3 depicts the cffictent result ohtained if, on balance, the U.S. is a net importer of product. Figure 4 demonstrates the equilibrium obtained if the U.S. is a net exporter of product.

Figures $3 a$ and $4 a$ show supply and demand within the U.S. I.f the U.S. did not trade in the world market and were thus only affected by U.S. supply $\left(S_{u S}\right)$ and U.S. demand $\left(D_{u s}\right)$, the U.S. outcome would be a price of $P_{u s}$ and consumption at point B. However, since we initially assume no barriers or costs to world trade, U.S. consumer-plus-producer welfare is increased by allowing trade with the rest of the world. This may be seen if we aggregate U.S. supply and demand with the ROW supply and demand. $S_{W-u s}$ and $D_{w-u s}$ in Figures $3 b$ and $4 b$ are the ROW supply and demand curves and are found by subtracting the U.S. supply and demand from total world supply and demand $\left(S_{w}\right.$ and $\left.D_{w}\right)$. This results in a world equilibrium price of $P_{0}$, since $S_{w}=D_{w}$ 
U.S. and world supply and demand with the U.S. a net importer

Figure $3 a$

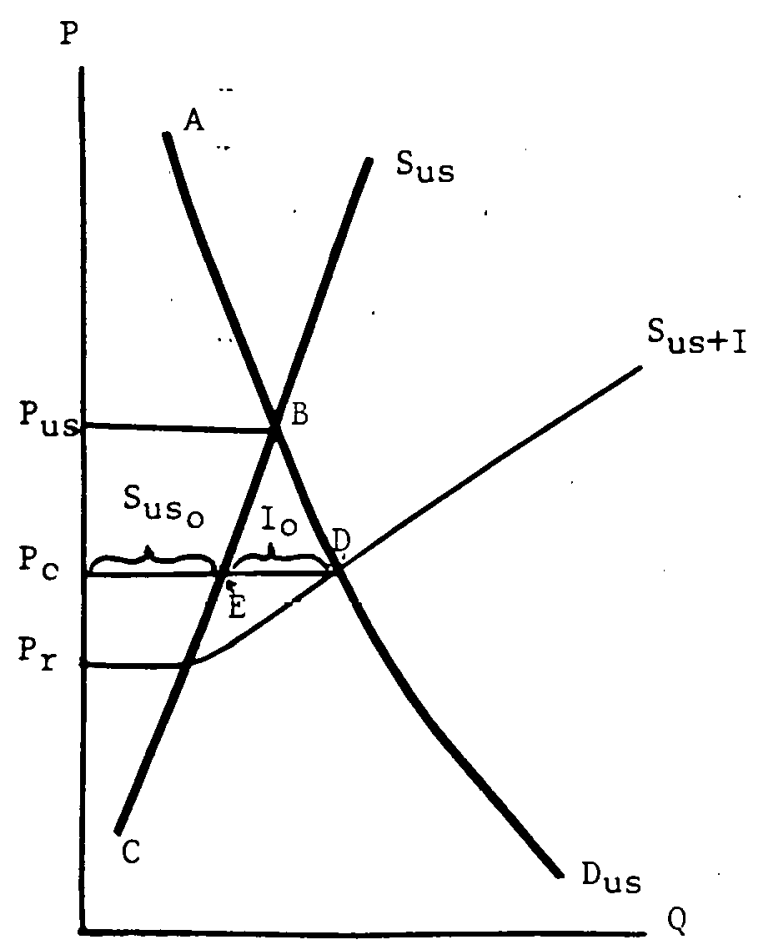

Figure 3b

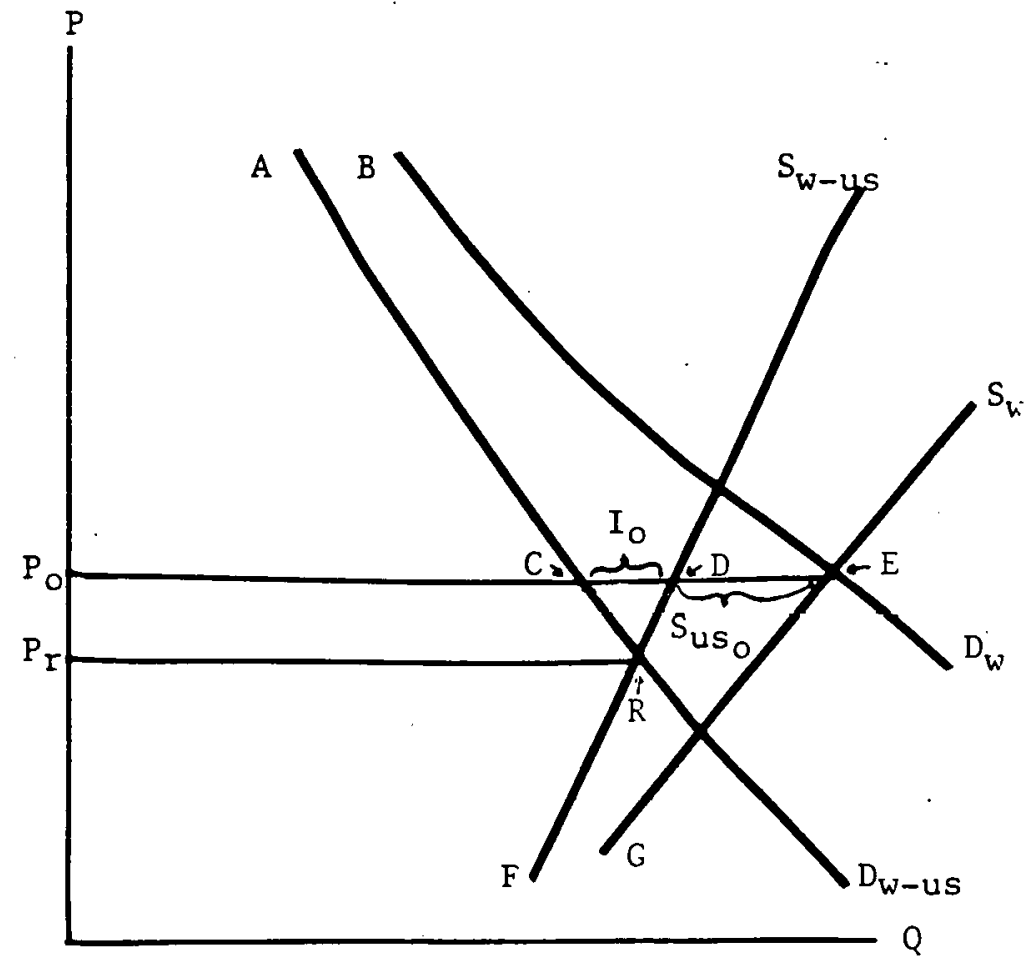

U.S. and world supply and demand with the U.S. a net exporter

Figure $4 a$

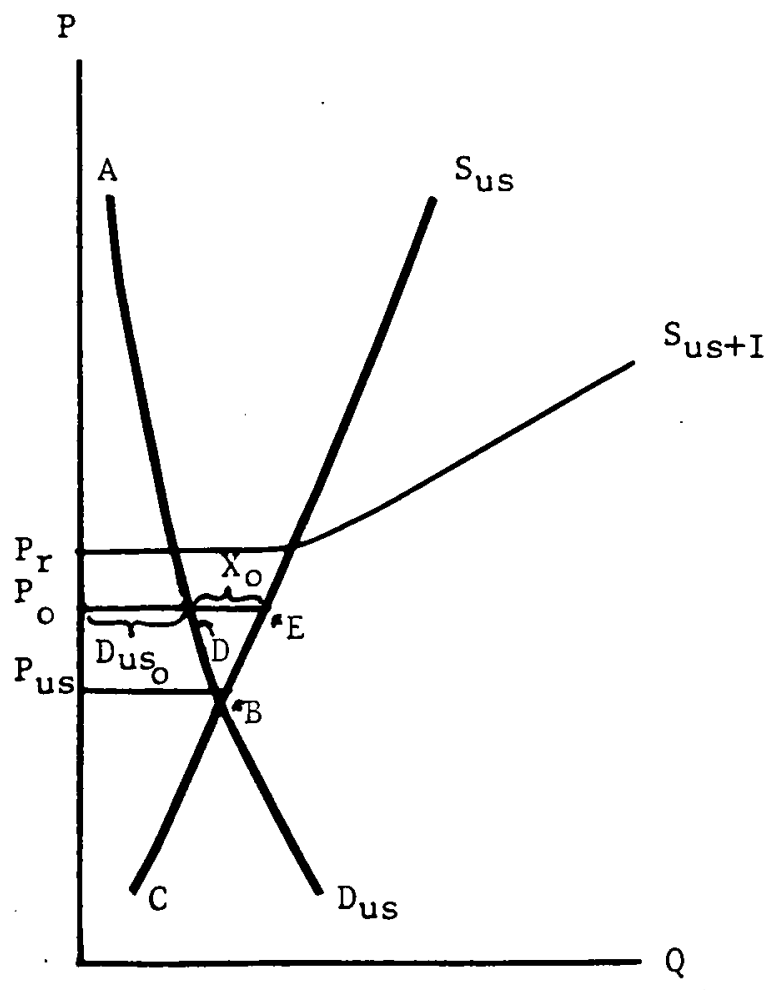

Figure 4b

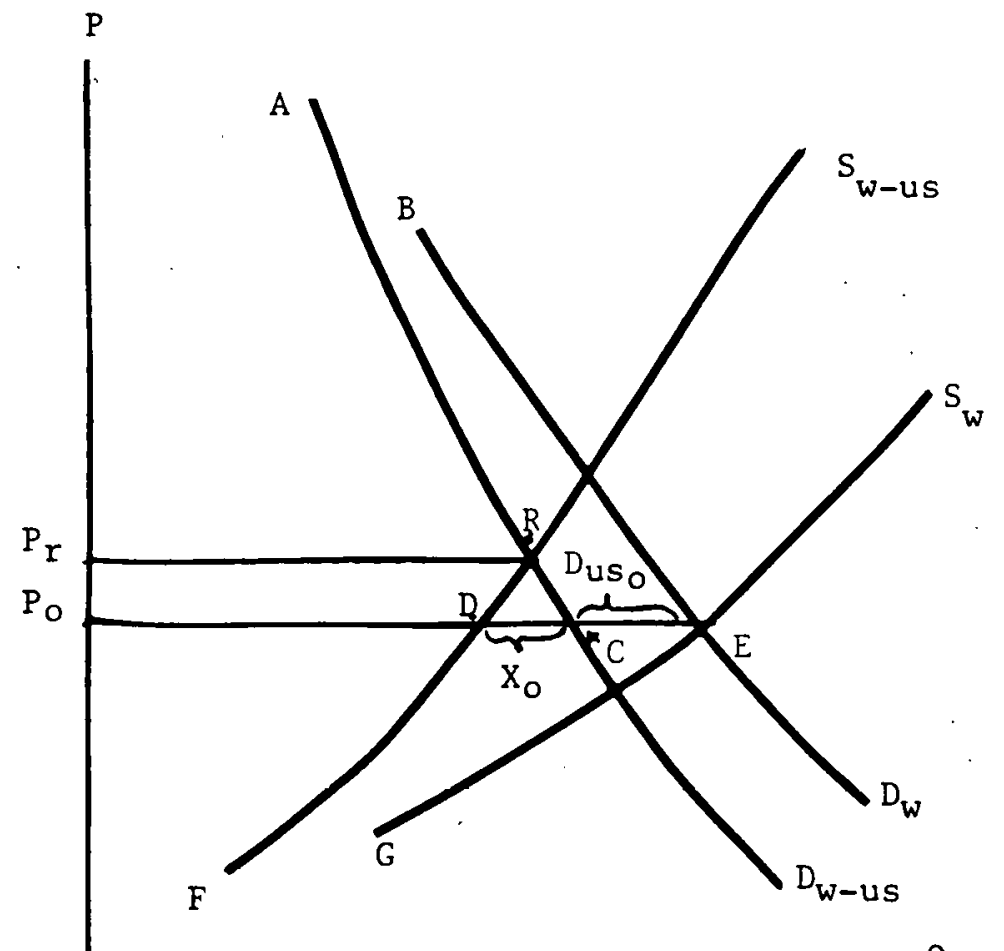


at $E$ in Figures $3 b$ and $4 b$. In Figure 3, at Price $P_{O}$, the $U . S$. is a net importer of oil products. The supply of imports to the U.S. is represented by the horizontal distance between $S_{w-u s}$ and $D_{w-u s}$ (i.e., ROW supply less ROW demand) for prices greater than $\mathrm{P}_{r}\left(\mathrm{P}_{\mathrm{r}}\right.$ is the ROW equilibrium price). Conversely, the ROW demand for exports is given by the horizontal distance between $D_{w-u s}$ and $S_{W-u s}$ for prices less than $P_{r}$. Thus, in Figure $4 b, x_{0}$ is exported from the U.S. to the ROW at price $P_{O}$ (where demand for exports, represented by the line segment DC in Figure 4b equals supply of exports DE in Figure 4a).

In the absence of trade between the U.S. and the rest of the world, U.S. consumer surplus plus producer surplus is given by $A B P_{u s}+P_{u s} B C$ in Figures $3 a$ and $4 a .^{1}$ ROW consumer surplus plus producer surplus with no trade involving the U.S. is given by $A_{R P}+P_{r} R F$ in Figures $3 b$ and $4 b$. With trade, however, domestic consumer surplus plus producer surplus is given by $A D P_{0}+P_{O} E C$ in Figures $3 a$ and $4 a$ (which is equal to BECA + FDEG in Figures $3 b$ and $4 b$ ). Thus, domestic total surplus has increased by $\mathrm{DEB}$ in Figures $3 \mathrm{a}$ and $4 \mathrm{a}$ as a result of trade between the U.S. and the rest of the world. Similarly, ROW total surplus is increased by area $C D R$ in Figures $3 \mathrm{~b}$ and $4 \mathrm{~b}$ as a result of trade (as consumer surplus plus producer surplus is given by $\left.\mathrm{ACP}_{O}+\mathrm{P}_{\mathrm{O}} \mathrm{DF}\right)$. Trade results in gains to both the U.S. and the rest of the world, regardless of whether the U.S. is a net exporter or importer of the product.

It is evident, thus, that the efficient outcome of the interaction between U.S. and world markets is equality between the U.S. and the world price of the product. This result holds at any point in time in this idealized world. of course, the markets for oil products do not conform to the stringent requirements of this idealized base case. We now turn to a discussion of the pricing that economic theory suggests will occur when faced with the realities of the U.S. and world oil markets. 


\subsubsection{U.S./World Pricing of Oil Products}

The model of U.S. /world pricing described above must be extended in two directions to describe more realistically the interaction between the U.S. and world oil product markets. First, we must account for the tangible costs which are associated with U.S./world market interactions. Second, the existing regulatory environment facing the U.S. oil market must be taken into account. We discuss these considerations in turn, and then conclude by advancing our overall theoretical view of dynamic pricing behavior between U.S. and world oil markets.

\subsubsection{Interaction Costs}

There are various costs associated with the purchase and sale of oil products by U.S. consumers and producers in world markets. There must be accounted for in determining the pricing linkages between the two markets. Some of these affect both the static and dynamic price telations betwcen the twn markets, while others exclusively affect dynamic pricing behavior. Examples of the former include transportation costs and transaction costs while the latter is exemplified by time lags in the transportation process.

The static costs associated with U.S. actors entering the world market are basically of two types: transactions costs and transportation costs. Examples of transactions costs associated with operation in world product markets include foreign purchasing agent fees, costs of information, costs of comunication, and possible monetary exchange costs. Transportation costs are simply the costs associated with waterborne transport to the U.S. market. These static costs must be added to the price paid at the point of purchase to determine the effective delivered price paid by U.S. consumers for imported product. Thus the world price of products will diverge from the U.S. price of products by the amount of these static costs (the U.S. price will, of course, be higher). 
The time lag of transport of world market product to U.S. markets provides further slack in the relationship between U.S. and world prices, and represents a primary example of a cost which affects dynamic pricing. The delivery lag for product bought on the world market is greater than that bought on the domestic market; thus, product bought on foreign markets is less attractive in meeting immediate needs than product obtained domestically. There is thus a cost involved in this delayed delivery. Significantly, the transportation lags imply that periods of U.S./world price inequality can persist over the short-run when uncrpected changes in domestic and/or world markets occur.

\subsubsection{Regulatory Effects}

Domestic policies toward oil product markets also have major effects on the relation between U.S. and world prices for those products. To demonstrate the importance of incorporating exloling regulatory structure in our analysis, we will here examine the effects of two of the most important government constraints that have existed in product markets during recent periods. The most important of these regulations is the effective ban on exports of U.S. oil products which has existed since December $1973 .{ }^{2}$ Also of importance during 1979 was the emergency extension of entitlements benefits for importation of middle distillate. 3

A ban on exportation of oil products such as that currently in effect in the U.S. is not binding as long as the U.S. is an importer of those products. This is the situation depicted in Figure 3. In this case, we see that if trade between the U.S. and the world were not allowed, the U.S. price would be higher than the rest of the world price $\left(P_{u s}>P_{r}\right.$ in Figure 3a). This induces U.S. consumers to import product from the rest of the world. 
In situations like those depicted in Figure 4, however, the efficient U.S. and world outcome requires the U.S. to export product to the rest of the world. If this is not allowed, the U.S. price becomes $P_{u s}$ in Figure $4 a$ and the world price becomes $\mathrm{Pr}_{r}$ in Figure 4b. As discussed above, the welfare losses of this situation are given by area DEB in Figure $4 a$ for the U.S. and area RCD in Figure 4b for the rest of the world. Further, the ROW price is above the U.S. price $\left(P_{Y}>P_{u s}\right)$ in Figure 4. Thus, export controls cause the world price to be an upper bound to the U.S. price. Prices are equal if the U.S. is acting as an importcr of world product.

Emergency entitlements benefits of the type extended to the importation of middle distillate during 1979 also have an effect on the U.S./world price relationship. The entitlement for middle distillate imports in 1979 provided a $\$ 5$ per barrel (12c per gallon) rebate on the importation of the product. Thus, instead of the U.S. importing middle distillate whenever the U.S. price was greater than the rest of the world piice $\left(F_{u s}>F_{r}\right.$ in Figure 3a), the U.S. will import product as long as $\mathrm{P}_{\mathrm{us}}>\mathrm{P}_{\mathrm{r}}+\$ .12$.

\subsubsection{Theoretical Conclusions Regarding the U.S. /World Pricing Relationship}

The result of the above conditions in U.S. oil markets would be to lead us to expect U.S./world product price equality, corrected for the cost differentials between U.S. and world markets created by transportation and transaction costs, U.S. subsidies or tariffs on importation, and the cost of transport lag. ${ }^{5}$ However, the existence of the export ban in U.S. markets leads us to qualify this conclusion of effective U.S./world equality. Due to the restrictive effects of this regulation, we expect the effective price of imports to act as an upper bound to the price of products in the U.S. market. As far as U.S. consumers are concerned, we do not see any factor which 
leads us to conclude that shortages, prices too high in U.S. markets, or other popularly-perceived problems should appear during the market transition. Rather, Américan spot, or marginal, prices, if anything, may remain too low by world standards as changes in world markets may take some time to be translated into changes in delivered prices to the U.S. Moreover, the level of imports into the U.S. may not be zero upon the appearance of a gap between world and U.S. prices, as pure theory devoid of complications would predict. Certainly, in periods where the divergence between the U.S. and world price is large, importation of forelgn piviluct would bc cupected to decrease. Conversely, when the difference is small, more imports are likely to occur. That is, the U.S. price would have to be further above the world price (world price being measured absent transport lag cost) in times when product is needed on an immediate basis than in times of less immediate need if imports are to occur.

We not turn to an examination of empirical data tu judge whether our conclusions hold true generally for various U.S. oil products over the short term. In this section, we will also address briefly the relationship of our conclusions to that of others who have recently studied this issue.

\subsection{Empirical Examination of the U.S. /World Market Adjustment}

Previous studies of U.S./world refined product pricing have reached a number of conclusions regarding the relationship between U.S. and world prices. Phelps and Smith (1977) have suggested that the U.S. is a price taker in world product markets and that, as such, U.S. actions do not affect world product prices. They argue that "U.S. petroleum prices are set, not by the FEA, but by world market conditions, and that one could conceptually show this equality, once proper adjustments had been made for transportation 
costs, tariffs, true exchange rates, and other factors." 6 Their conclusions have had considerable impact upon the policy process, as proponents of oil decontrol cited the authors as evidence that U.S. prices will not rise as a result of decontrol. Kalt (1981) has argued that their analysis is flawed and is based on a misreading of the empirical evidence. Kalt finds that in the majority of product markets, and especially in gasoline and distillate, the U.S. is not an importer to a sufficient extent that the U.S. price is determined by the world price. Rather, the world price offers an upper bound to the U.S. price. As discussed above, the upper bound nature of world prices is due to the ban on exports of product from the U.S. 7

An examination of data from 1978 and 1979 supports this hypothesis regarding and U.S./world price relationship. This may be seen in Graphs 1 and 2, and Tables 1 and 2 which present the U.S. and world (i.e., Caribbean) spot prices for distillate during 1978 and 1979. Our data from 1979 show that during lie most rccont period of major adjustments in world and U.S. markets, the U.S. price lagged substantially behind world prices. This result is consistent with our expectations regarding the upper bound nature of the world market's effect on U.S. prices. During the period of relative equilibrium in 1978, the price of distillate on world markets maintained an approximately constant and relatively minor positive differential with the U.S. spot price. Were the U.S, an active importer, a negative differential would have been expected. Beginning with January 1979, we see sharp increases in the price differential between U.S. and world spot markets, at times reaching over $20 c$ per gallon. (We note that from June through October, an entitlement was in place which subsidized U.S. producers to import world-market distillate; this subsidy amounted to $12 \&$ per gallon. However, except in early June, this entitlement did not result in the U.S. entering world distillate spot markets to any significant degree, as, with this exception, the U.S./world 
price differential exceeded the amount of the subsidy during the entitlement period.) Data confirm that in March 1980, fourteen months after the original world market disruption, a substantial differential remained between U.S. and world spot market distillate prices. 8 The same price lagging tendency may be observed in gasoline and is depicted in Graph 2.

Thus, we see that U.S. spot prices exhibited pronounced price lagging relative to world market prices during 1979. It is evident that in no event has the market adjustment process in the U.S. led to U.S. prices for petroleum products during the transition that are too high, as some have charged. 9

Problems of absolute supply level, as much as sharply higher prices, were perceived by the public as rampant throughout 1979. A thorough examination' of the process of transition in the U.S. market will yield not only a verdict regarding the efficiency or inefficiency of U.S. prices relative to world levels, but will allow us to determine the source of the perceived problems of shortage, or supply unavailability, in U.S. markets in 1979. 
GRAPH 1

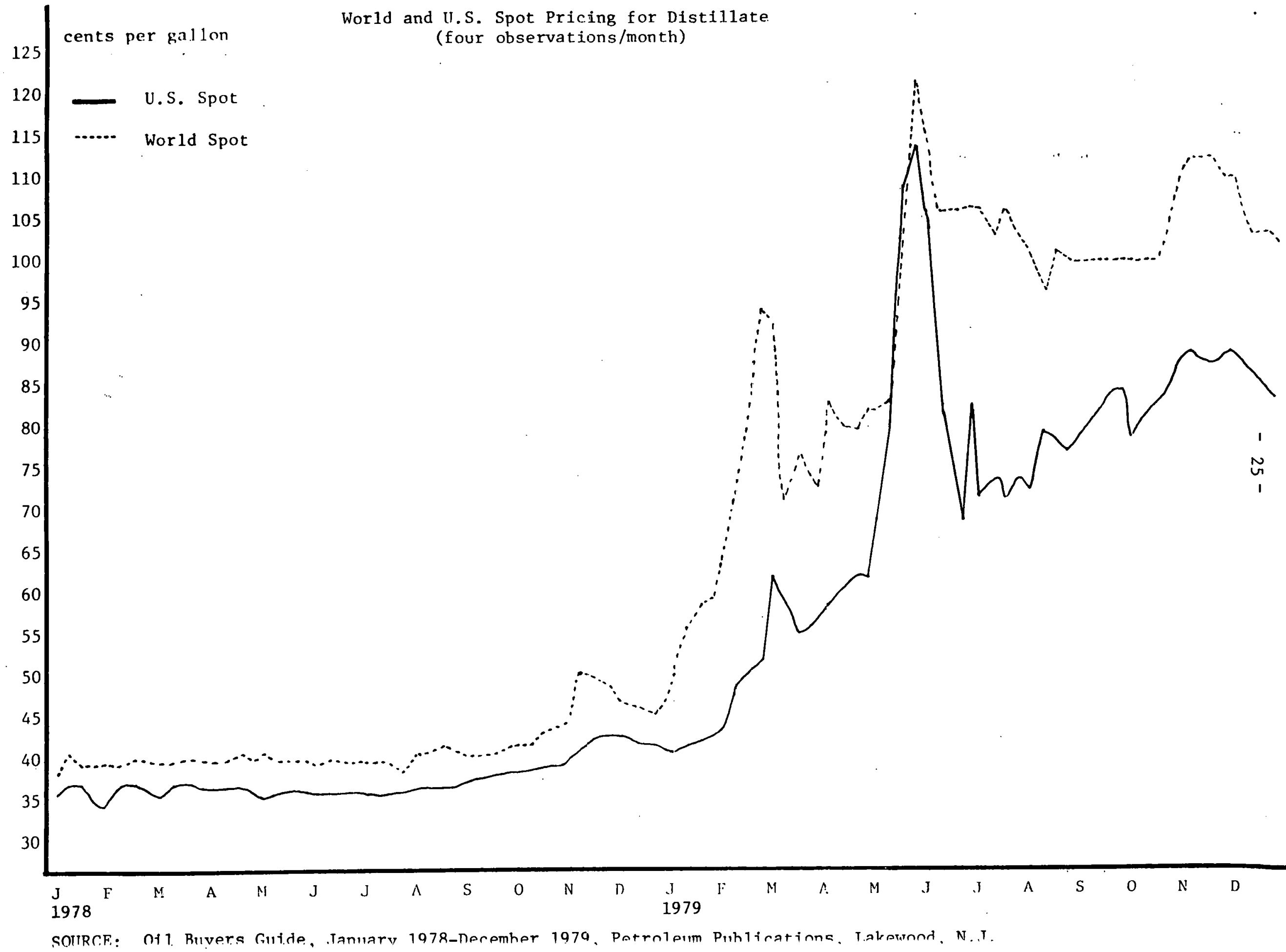


TABLE 1

World and U.S. Spot Prices for Distillate 1978 and 1979

( 4 observations per month)

1978

1978

Month

New York Caribbean

Month

New York

Caribibean

January

35.900

37.500

July

35.150

39.050

36.200

40.275

35.300

39.750

36.200

38.750

35.300

37.750

34.900

38.350

35.800

40.050

February

34.800

38.450

August

38.450

39.550

39.300

36.500
36.000

35.500

March

35.400

39.000

39.500

September

37.250

37.700

38.000

36.000

40.350

36.000

39.725

38.200

40.400

36.550

41.140

36.000

39.775

36.600

40.350

35.650

April

$\begin{array}{ll}35.550 & 39.900 \\ 35.500 & 39.800 \\ 35.500 & 40.050 \\ 35.375 & 39.600\end{array}$

October

38.200

38.850

39.000

39.250

39.625

40.550

40.550

40.800

41.800

May

35.100

35.250

35.375

35.375

40.200

39.100

November

40.200

41.500

42.375

42.375

39.300

38.975

39.100

December

42.375

47. 100

35.250

38.750

41.000

46.600

35.150

39.350

41.200

45.700

35.150

40.750

47.600 
TABLE 1 (continued)

1979 1979

\begin{tabular}{|c|c|c|c|c|c|}
\hline Month & New York & Caribbean & Month & New York & Caribbean \\
\hline \multirow[t]{4}{*}{ January } & $=41.000$ & 50.600 & July & 73.250 & 106.000 \\
\hline & 42.250 & 56.200 & & 75.250 & 104.200 \\
\hline & 42.000 & 59.700 & & 73.000 & 106.000 \\
\hline & .43 .350 & 60.400 & & 75.250 & 104.200 \\
\hline
\end{tabular}

February

44.500

64.700

August

74.500

103.800

49.500

72.700

81.000

98.500

50.750

81,700

79.000

103.500

52.500

95.700

78.000

102.500

March

62.750

94,000

September

80.500

102.300

59.250

72.000

83.500

102.500

56.000

78.000

86.500

102.700

57.250

74.600

86.500

102.700

Apr11

59.000

84.600

Or.tober

80.500

102.400

61.000

81.200

83.500

102.700

62.750

80.700

85.000

102.500

62.500

82.700

88.000

108.200

May

70.000

$82.700 \quad$ November

89.000

113.000

81.000

84.950

90.000

114.700

109.000

110.000

89.000

114.600

114.000

122.700

89.000

112.600

June

106.000
82.000
70.000
87.000

115.800

December

90.500

112.600

87.000

106.300

88.000

105.600

106.500

86.000

105.600

106.500

85.000

104.600

SOURCE: Oil Buyers Guide, January 1978-December 1979. Petroleum Publications, Lakewood, New Jersey. 
GRAPH 2

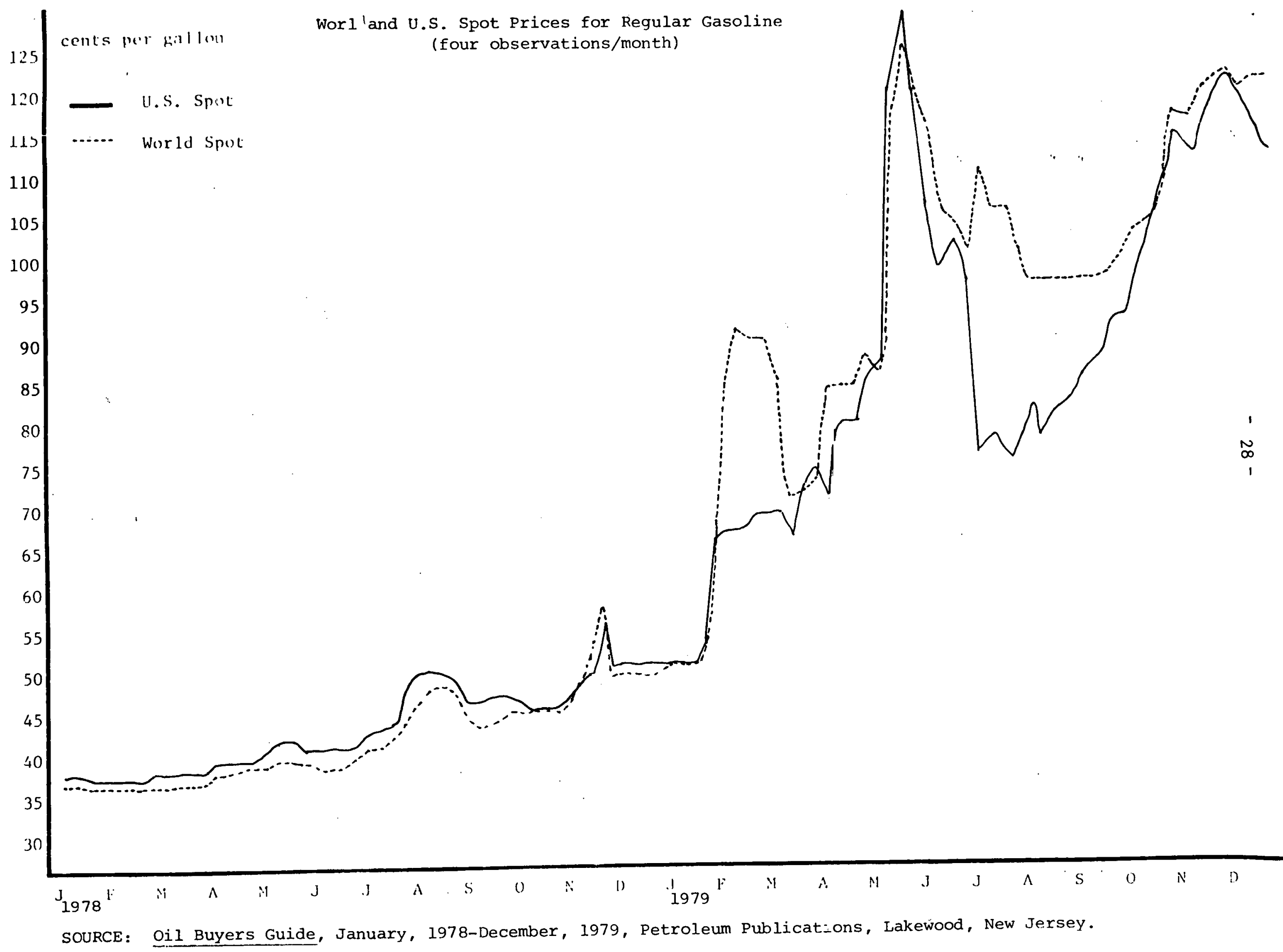


TABLE 2

World and U.S. Spot Prices for Regular Gasoline 1978 and 1979

(4 observations per month)

1978

Month

January

$\frac{\text { East Coast }}{38.500}$

38.300

37.750

37.500

37.500

37.450

37.550

38.000

38.000

38.500

38.500

39.000

39.250

39.250

39.750

April

1978

Month

East Coast

Foreign Spot

$42.750 \quad 41.250$

43.250

41.250

44.500

43.000

47.850

46.500

August

36.000

36.000

36.250

36.250

36.250

36.500

36.500

37.000

37.750

38.250

38.250

38.500

39.000

39.250

38.375

40.900

40.900

38.250

38.500

38.750

39.750

40.900

40.900

41.400
September

46.500

46.250 ,

46.500

46.500

October

46.000

45.800

45.800

46.550

November

48.000

47.500

50.350

56.250

50.000

51.750

50.000
51.500

December

51.000

51.000

51.000
44.500

43.500

44.000

45.000
45.500

45.000

45.000

45.500 58.000

50.000

50.000

51.500
48.250

48.250

47.750

46.000 
1979

\begin{tabular}{|c|c|c|c|c|c|}
\hline Month & East Coast & Foreign Spot & Month & East Coast & Foreign Spot \\
\hline \multirow[t]{4}{*}{ January } & 51.000 & 51.750 & July & 96.000 & 100.000 \\
\hline & 51.250 & 51.750 & & 76.000 & 110.000 \\
\hline & 51.500 & 51.750 & & 78.500 & 105.000 \\
\hline & 54.250 & 55.000 & & 75.500 & 105.000 \\
\hline \multirow[t]{4}{*}{ February } & 65.750 & 67.000 & August & 78.500 & 100.000 \\
\hline & 66.000 & 84.000 & & 82.000 & 96.000 \\
\hline & 66.500 & 91.000 & & 78.750 & 96.000 \\
\hline & 67.350 & 90.000 & & 82.000 & 96.000 \\
\hline \multirow[t]{4}{*}{ March } & 68.300 & 90.000 & September & 83.250 & 96.000 \\
\hline & 68.300 & 85.000 & & 85.500 & 96.000 \\
\hline & 65.500 & 70.000 & & 88.000 & 96.000 \\
\hline & 72.000 & 71.500 & 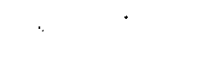 & 93.000 & 96.000 \\
\hline \multirow[t]{4}{*}{ April } & 74.500 & 73.500 & October & 93.000 & 99.000 \\
\hline & 70.000 & 84.000 & & 99.750 & 103.000 \\
\hline & 80.000 & 84.000 & & 104.000 & 104.000 \\
\hline & 80.000 & 84.000 & & 109.000 & 109.000 \\
\hline \multirow[t]{4}{*}{ May } & 85.500 & 88.000 & November & 114.000 & 117.000 \\
\hline & 87.500 & 86.000 & & 112.000 & 116.000 \\
\hline & 120.000 & 118.000 & & 117.500 & 120.000 \\
\hline & 127.000 & 126.000 & & 120.000 & 121.000 \\
\hline \multirow[t]{4}{*}{ June } & 120.000 & 120.000 & December & 121.000 & 122.000 \\
\hline & 106.000 & 115.800 & & 117.000 & 122.000 \\
\hline & 98.000 & 105.000 & & 115.000 & 121.000 \\
\hline & 102.000 & 104.000 & & 113.000 & 121.000 \\
\hline
\end{tabular}

SOURCE: Oil Buyers Guide, January 1978-December 1979. Petroleum Publications, Lakewood, New Jersey. 
NOTES FOR CHAPTER 2

1. For an introduction to consumer surplus, producer surplus and deadweight loss, see any intermediate microeconomics text, for example, Hirshleifer (1978).

2. See U.S. Department of Commerce, "Part 377, Short Supply Controls", Export Administration Regulations.

3. See U.S. DOE, ERA, Mandatory Petroleum Allocation Regulations; Emergency Adoption of Final Rule Providing Entitlement Benefit for Importation of Middle Distillates, $44 \mathrm{FR} 31162$.

4. Specifically this is represented by the fact that as long as $P_{\text {us }}>P_{r}$ holds, trade is allowed and the U.S. and ROW both face price $P_{O}$ (see Figure 3).

5. Note, we need not worry about the cost that U.S. producers face in exporting product, as exports are not allowed. If they were, then, of course, these costs would need to be included in determining the effective price for U.S. product in the world market.

6. Phelps and Smith (1977), p. 24.

7. See Kalt (1981), Chapter 4.

8. See Platt's Oilgram Price Report or Oil Buyers Guide for this comparison. 
9. We recognize that there exists a vigorous controversy among energy policy-makers over whether the world price of oil does in fact represent the actual social cost of the commodity to the American economy -particularly given our need to import. Paramount among these concerns is whether there is a national-security based external cost to consumption of imported oil which is not reflected in U.S. oil prices. These arguments imply that the selection of the world price as our benchmark for measuring U.S. prices may result in our considering efficient a U.S. price which is inefficiently low -- which fails to reflect some of the costs of imported oil consumption. If this is the case, then our analysis of the efficiency of the relationship between U.S. and world prices are below world levels, and less inefficiency resulting if they are above. Thus, our conclusion that U.S. prices were inefficiently low during 1979 becomes even stronger if true efficiency dictates that, due to an oil import premium, they should have lain above world prices. For a perspective on this issue, see Landsberg, et al. (1979). 
Chapter 3

ADAPTATION WITHIN THE U.S. MARKET

In this chapter we will analyze the process of U.S. market adaptation to higher world oil prices which occurs within the American oil market. That is, we will examine how individual firms, sectors of the oil industry, and consumers react to changes in the world price of oil (as it is filtered Llirough the marginal spot market). We will examine both the economic efficiency implications of the observed transition process and its distributional impact upon consumers and producers.

We first present an analytical framework for our analysis, and then apply it to the changes which took place in the U.S. market for oil during 1979.

\subsection{Analytical Framework}

\subsubsection{Effects on Price/Supply Decisions}

The response of a firm to an increase in the price of one of its inputs is to shift the mix of inputs used in the production process, increase the output price, and decrease the output supplied. These movements generally occur regardless of the competitiveness or noncompetitiveness of the industry (i.e., the movements are not of the same magnitude but are in the same direction for various market structures).

Recall from the previous discussion that the relevant cost of crude to the refiner is the price the refiner must pay for its marginal barrel of crude. Even if the average cost of crude is much lower than the marginal cost, the profitability of the last barrels of refined products the refiner produces is determined by the price the refiner pays for the last barrels of its crude input. A company that shows a massive increase in profits in the face of a 
supply shock -- as many comapnies did in 1979 -- is not necessarily price gouging or inefficiently responding to the changing crude situation. If fact, from an economic efficiency point of view, such increases in a firm's profits represent an efficient adaptation to higher input prices (that is, higher marginal prices). If the firm raised its price only to reflect the increased average cost caused by the higher marginal cost of crude (thus experiencing no increase in profits), the result would be less efficient. Consumers would see marginal prices that would be less than the cost of produced petroleum products. Thus, raising refined product prices by an amount reflective of the increase in marginal, rather than average, cost of crude represents the efficient reaction to more expensive crude oil.

If a refiner faces an increase in the cost of crude, the major input in the production process, how does that affect this firm's production, price, and output decisions? The refiner will attempt to produce a given level of output of refined products in the least-cost method, qiven the relative costs of the various inputs. As crude oil becomes more expensive relative to other input factors in the refining process, a shift is made toward more intensive use of the relatively cheaper input factors, such as capital, than previously occurred. However, this can happen only to a very limited extent in refining, as crude oil has a low elasticity of substitution with other inputs.

Due to crude oil's low elasticity of substitution, higher prices for crude are felt rather directly by refiners, increasing the cost of producing refined products. For any given output price, refiners will not supply as much as before. This can be represented by a shift in the industry supply curve. Output price increases and output declines. It is important to note that part of the increased cost is borne by the producer rather than being all passed on to the consumer. This results from the fact that demarid for 
refined products is reduced as prices rise, forcing producers to tradeoff higher prices against reduced sales in their attempt to raise the revenue necessary to cover their costs.

\subsubsection{Effects on Consumers}

Higher prices for refined products (or for any other good in the economy) will make consumers worse off than they were prior to the price increases. Their income will buy fewer total qoods and services than before. Some policymakers appear to have the belief that American consumers have the right to lowerthan-world prices for energy; ${ }^{l}$ thus, they advocate regulation of the domestic market, in the form of price controls on both crude oil and refined products. While this may be a politically popular position, as we have seen in Chapter 2, policies that constrain U.S. prices relative to those on world markets lead to a misallocation of resources. We have noted that the oil market is an international one; thus, as the rest of the world perceives the world spot price to be the relevant price for marginal supplies of oil, there is no reason for any different measure of the cost of oil to prevail among United States consumers.

If we accept that higher prices for oil products are necessary to inform consumers about the resource cost of the products they are using, what judgments can we make regarding the effects of these higher prices? From the point of view of economic efficiency, it is necessary that consumers feel the effects of these prices directly, in order that they may efficiently adapt to the new relative value of oil in the economy. However, from the perspective of social fairness and the distribution of wealth across consumers in society, there may exist grounds for concern as a.result of oil price increases. This concern, however, is clearly not over price levels themselves, but rather over the effects of higher prices on the incomes -- the purchasing power -- 
of various consumers.

It is inaccurate to conclude that any alteration in the supply or demand characteristics in the market may be seen as inherently embodying a problem for consumers. Rather, changes away from old behavioral norms, based on new, higher prices, are necessary. This judgment applies not only to price levels in the market, but to all facets of producer and consumer adaptation. Arguments are often advanced, for instance, that certain refined petroleum products are "necessities", especially home heating oil. The implications drawn from these arguments have often been that the price for the commodity can simply become too high in an absolute sense, requiring government regulation to lower it. It is simply false, however, to argue that quantity of any oil product needed by American consumers is independent of price. Rather, as the price of a good such as home heating oil increases, people begin conserving in its use through various methods: by insulating their homes, shutting off unused rooms, switching between energy sources, lowering their thermostats, etc. That consumers must face higher prices does not imply their absolute survival is threatened; rather, they must make tradeoffs in their consumption patterns, based on the new set of prices they face.

If the appropriate concern of policy-makers in times of oil price increases is not "need" or price levels themselves, how do we define the adverse nature of oil price increases on consumers? We define it in terms of economic equity, or fairness: efficient transition period prices may cause great harm to the welfare of many consumers; and policy-makers may, for humanitarian reasons, deem it necessary to aid them. Higher prices may push people who were on the edge of poverty into poverty-level existence, and those already genuinely impoverished even lower. In fact, the economic standing of all consumers, regardless of income level, will be compromised by price increases. The argument is often advanced, however, that low-income consumers are affected 
more adversely than those in higher income brackets by higher energy prices. The validity of this argument rests upon the methods by which energy expenditures and income are measured. Most studies conclude that the share of direct energy expenditures in income decreases as a function of income when income is measured by either total household income or total consumption expenditures (the latter does not include household savings or dissavings). However, severàl recent studies suggest that the share of direct and indirect energy expenditures combined (the latter refers to energy consumers through the purchase of goods and services) is essential.ly invariant as a function to total consumption expenditures. ${ }^{2}$ Thus, we might well argue for special programs for the disadvantaged for the simple reason that the damage they suffer due to high energy prices is unacceptable given their initial income state. However, it is less likely that arguments for special programs for these groups on the basis that they are made worse off proportionally by higher energy prices are apprupriale.

There has also been some concern that particular consumer groups are more affected by the higher energy prices than others. Geographical disparities in energy prices may indicate that certain regions of the country are hurt more than others by the higher prices. These price discrepancies can be traced to climate-based, seasonal patterns in demand and various aspects of the regulatory framework affecting domestic crude. ${ }^{3}$ In the absence of regulation, we shouldnot expect to see significant, sustainable geographical disparities (other than those allowed by transportation cost differentials) in prices. Rather, we would expect to see these disparities arbitraged away by jobbers and distributors buying in regions where demand is slack and prices relatively low, and transporting the refined products to areas where demand is peaking. (The role of arbitrage is discussed further in section 3.1.4.)

The question has also been raised in the public arena whether there may 
by a need to support producer groups who would otherwise go bankrupt due to higher cost energy. From the point of view of pure economic efficiency, the answer is generally no. Consider, for example, the agricultural sector. If, due to an increase in the price of productive inputs such as oil, the production and transportation of a food product exceeds the value of that product as measured by the price consumers are willing to pay, it is an efficient result to allow the food to go unharvested. If a firm in an industry goes bankrupt because its technology is more energy-intensive than that of its competitors, this result is not undesirable in terms of economic efficiency. In fact, it is necessary; it demonstrates that there is a need to switch toward less energy intensive methods of production as the price of energy increases relative to the price of other inputs. Similarly, it is not an inefficient or undesirable outcome for entire industries which are no longer profitable to go bankrupt due to higher oil prices. Rather such adaptation processes simply suggest that other things have come to be valued more highly than the affected industry's output.

If it is believed that, on grounds of fairness, certain consumer or producer groups should be shielded from the effects of higher prices, government intervention may indeed be called upon. But we should be cognizant of the fact that the justification for such intervention, in most cases, is found in our concern for the welfare of certain groups who are made worse off by the adaptation process rather than the broad public interest in economic efficiency. Such concern for the welfare of certain groups must not be confused with the notion of genuine market failure; it relates not to the economic efficiency or the process of market adaptation, but rather to our. concerns for those who suffer because of it. We also must be aware that proper policy approaches to income issues are by nature radically different than those used to address 


\subsubsection{The Role of Arbitrage}

In a market in which costs, supplies, prices, and expectations are in flux, there can often arise sharp differences in the demand for petroleum products among regions and consumers. The price differences that initially result from these differences in market tightness across regions are socially wasteful if not arbitraged away. This is because if there exist significant differences in price level among consumers or regions, all consumers can be made bettex off through trade with each other. The buying of a good in an area where demand is slack and prices are low and the subsequent selling of that good where the market is tight is known as geographical arbitrage. Arbitrage takes place as profit opportunities arise due to these interconsumer, interregional, or intertemporal market differences. As an example of geographical arbitrage, if the price of gasoline on the East coast rises above the price in the Midwest, it may pay some firms to transport supplies from the Midwest to the Lighter East coast market.

However, traditional buṣinesses may be somewhat hampered in effectivcly capitalizing on these kinds of opportunities because a variety of factors render them unable to react to day-to-day changes in the demand structure surrounding them. Paramount among these factors are long-term contractual commitments, i.e., supply relationships in which they have invested considerable capital. To alter radically these relationships in order to follow market dynamics in the shortterm would seriously affect these firms' long-term business interests.

What we must look for, in times of supply shocks, is evidence that some actors in the oil market are pursuing a strategy that capitalizes on the profit opportunities which arise from an unequal adjustment process. If we see evidence that any differences in price level among regions or consumer groups are quickly being dissipated, we can conclude that the efficiency of the market is not being hampered by inadequate opportunities for arbitrage. The spot market is the sector of the oil market that we would expect to play the major 
role in interregional and interconsumer arbitrage during times such as these because of the role it plays in meeting marginal needs. We would expect to see this spot market activity increase through increased activity by spot market brokers -- businesses not encumbered by long-term business commitments whose sole strategy is to broker oil between regions and consumers. We shall examine the changes in the level of activity of these actors in this market to determine whether a significant change in level of activity exists.

\subsection{Structural Adaptation: An Analysis of Market Behavior}

In this section, we shall examine available data relating to the U.S. market's structural adjustment process. Are firms adapting to the new and of ten sharp supply fluctuations in the market? Do we observe new firms entering to deal with aspects of adaptation such as arbitrage which were described earlier, or do existing firms meet these needs adequately?

The aspect of the dynamics of the American oil industry's conduct which will tell the most direct story about how firms are reacting to the changes in the U.S. market is their behavior with respect to arbitrage. As described, the actions of firms in arbitraging away differences in price among regions and consuming groups are the most dynamic evidence that industry actors are taking advantage of the short-term opportunities in the market which are created by unanticipated supply shocks. The sector of the market which we would expect to play the role of arbitraging during times of adjustment is, of course, the spot market because, as we described earlier, it serves as. the market conduit for immediate-need transactions. Theoretically, the best perspective upon activity in spot markets would result from the existence of quantitative data on the level of volumes of oil which pass through this sector of the market during any given time period. Unfortunately, no reliable 
estimates of actual volumes transacted through spot markets exist. Therefore, we must utilize the most reliable sources of information available for this analysis. These include numerous discussions with industry and trade publication sources and analysis and anecdotal evidence provided in the trade publications themselves.

Evidence from these sources suggests that since the beginning of the period in which the U.S. has experienced repeated world oil supply/price shocks the level of activity on spot markets has undergone a veritable explosion. Trading volumes on spot markets and the number of brokers doing business in these markets jumped twice in the 1970s, first in 1973-1974 and again in 1979. These were, of course, the periods in which the U.S. market was adapting to the sharpest changes in the world oil market. The number of spot brokers operating in New York and Houston, the two largest centers of spot trading, increased almost a thousand-fold over the ten year period from 1970-1979.4 This offers perspective regarding the role that arbitrage plays during market transition, and of the U.S. market's very marked shifts towards higher levels of broker activity during periods of change.

A second testament to the increased role of spot market and arbitrage in the U.S. market may be found in the manner in which major trade industry publications list price data. Prior to 1976, the major source of daily oil prices, Platt's Oilgram Daily News Service, did not track and list the spot transaction prices. However, beginning in 1976, Platt's began listing spot transaction prices, an editorial decision that was based on the increased importance (volume) of these transactions in oil markets as a whole. 5 This is a clear indication of the changing importance of spot (marginal) prices and arbitrage in the oil industry.

From the perspective of industry conduct, then, available evidence supports the conelusion that the U.S. oil industry is changing in its patterns 
of operation, and in some sénse its structure, in order to adapt to the shocks which it has experienced due to radical changes in world oil markets. The shifting of market operations towards firms in the sector of the market that most effectively meets marginal needs has been pronounced over the past decade. We now turn to an examination of whether this behavioral result is sufficient to ensure a completely efficient transition process as measured by pricing in U.S. markets. (A more detailed discussion of the activity in U.S. spot markets during the 1979 transition period is presented in Chapter 5).

\subsection{Price Adaptation: An Analysis of Market Performance}

In this section, we present the most important aspect of our empirical analysis. Pricing behavior constitutes the most basic measure of the efficiency of adaptation within U.S. markets, and is the measure of most relevance to U.S. petroleum consumers.

In order to judge the efficiency of the price increase process in U.S. markets over the short-term, we shall take the U.S. spot market as our base. As the world spot price serves as a benchmark from which to analyze the relative price levels in individual countries, so the U.S. spot price itself may serve as a standard by which to judge the efficiency of pricing within U.S. markets. The spot market within the U.S. serves as a benchmark because it is the source of marginal supply for U.S. consumers. As we have concluded in our earlier analysis, the price of marginal supply is the price at which an efficient market should function. This price represents the resource cost to society of a barrel of oil consumed, If oil products are readily available to consumers on American spot markets at spot prices, which we have shown to be equal to or below world prices, then other prices for oil in the econamy may be judged for efficlency relative to the marginal spot norm. 
Transactions on U.S. spot markets do not constitute the bulk of oil sales in the U.S. Rather, approximately 90 percent of all U.S. oil products are supplied through contract markets, i.e., through the mechanisms of longterm contracted relationships between buyers and sellers. It is in these contract markets, therefore, that efficiency in transition must be measured, utilizing the spot market as our basis of comparison. Most of the allegations about inappropriate behavior on the part of major U.S. firms during recent periods of oil crisis have revolved around their pricing patterns within the context of thse contract relationships. To gain a perspective upon how we would expect to see contract prices behave, relative to an efficient marginal norm, we must address ourselves first to the nature of product supply contracts within U.S. markets and to what the contract price paid for oil by contract buyers represents.

Supply contracts are long-term agreements by buyer and supplier which act as a vehicle for allocating and sharing risks -- costs that are inherent in the production and distribution system. Contracts provide risk and cost benefits to both the consumers and the supplier. To the buyer, possessing a legally contracted source of supply vastly reduces transaction costs and allows planning based upon a higher level of information regarding the availability and price of future supplies than would otherwise exist. For these sources of security, especially in a market with increasing uncertainty such as that in oil products since 1973, the consumer is usually willing to pay a slightly higher price for oil. The amount the consumer is willing to pay above spot market prices can be termed the contract-value premium. To the seller, contracts represent the lowering of transaction costs inherent in marketing plus the ability, through specified volume provisions, to approximate future demand patterns and thus predict demand flows. This predictive ability serves to aid many aspects of business such as inventory maintenance 
and seasonal stockpile management. Furthermore, when the contract carries the use of a brand name, the seller is building public-image capital, while the buyer (reseller) is purchasing the right to utilize the existing brand name capital of his business. (Branded sales are common in gasoline and diesel, but less so in heating oil, where customer image is more dependent upon service quality.)

Due to the restrictions of several pieces of federal legislation (notably EPAA and the Robinson-Patman Act), refiners for many years have been extremely wary of any appearance of price discrimination. Therefore, while we might expect that long term supply contracts would carry with them certain price guarantees, this is in fact not the case, Rather, prices are left unspecified in contracts. Contracts define the relationship between supplier and buyer primarily with respect to level of supply. The price horizon in oil product contracts is one-day; major sellers' contracts stipulate that the price fui any given delivery of fuel sperified in the contract is that price posted by the company for contract sales for that day in the region relevant to the seller. ${ }^{6}$ Interregional price discrimination is heavily avoided, as is interconsumer discrimination, due also to the provisions of the aforementioned legislation. Thus, in contract markets -- quite unlike spot -prices between regions do not show significantly more variation than that accounted for by the different costs of transportation. Nor do prices between consumers vary for such reasons as length of business relationship.

Given this description of contract provisions, we may now make some theoretical predictions regarding the behavior of contract prices during a period of dynamic oil market transition such as 1979. Specifically, we may relate their behavior to the trends observed in our measure of marginal market price, the spot market price. We would expect the cumulative impact of all the factors in the contracting process to yield a transition period contract 


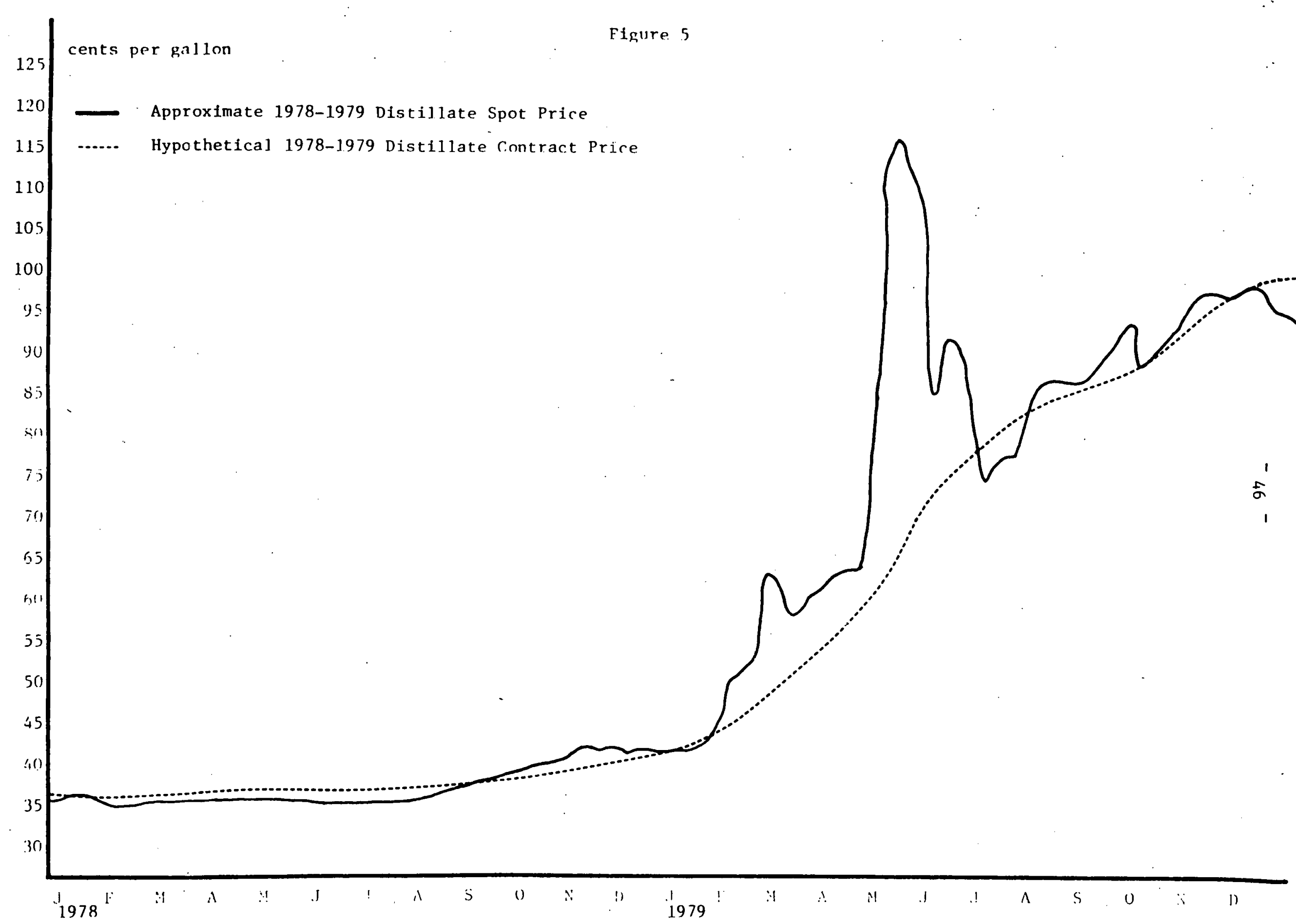


price which relates over time to spot price as we have drawn the relationship in Figure 5. This diagram presents a theoretical representation of contract prices sometimes lagging spot during the adjustment process, but such lags in pricing should be relatively short lived. Overall, we-would clearly not expect contract prices to show the same gyrations as spot prices. There is clearly enough shared responsibility between the two parties to the contracting agreement to promote some price-smoothing in the interests of predictability. Also, the contract market is generally not speculative, and therefore would not be expected to gyrate as sharply as spot, which reflects prices on a moment-by-moment basis. As Figure 5 suggests, once the market transition process is completed, we would expect a rough parity to exist again between spot and contract prices, after the contract price has been adjusted by the value of the contract premium.

Given that we would expect rough contract-spot price parity over the long run (adjusting for the contract value premium), we may state briefly the inefficiencies that would occur if we observed contract prices lying significantly above or below spot prices over time in the market for a petroleum product. The efficiency and welfare implications of a deviation from spot prices in other modes of oil sales within the U.S. are much the same as those discussed earlier regarding a disparity in U.S. and world spot prices. We will summarize these considerations here for the present discussion.

If the price charged in other sales arrangements is above the price in spot markets by a substantial margin, an inefficiency is indicated. If we see contract and posted prices well below spot prices, we may assume that sellers are charging an inefficiently low price for oil in the short-run. In both cases, there are distributional as well as efficiency consequences to observed pricing decisions. If prices are above spot (plus the contract-value premium), consumers are suffering a net welfare loss (relative to the distributional 
consequences of an equivalent exchange at efficient prices) and producers are enjoying a net welfare gain. If prices are below spot, then producers suffer the loss, and consumers realize the gain on all oil sold to them by traditional suppliers at less than the highest prices that would be had (i.e., spot prices). In both cases, a deadweight loss to society results.

We now turn to an analysis of product pricing patterns during 1979. Both controlled and uncontrolled product markets will be analyzed in order to isolate the effects that price controls have on the market transition process. We shaj.t examine the prices of products and their availability relative to demand during the years 1978-1979. This allows the observation of pricing tendencies in one year of relative market stability and one year of protracted market turmoil and change.

\subsubsection{Decontrolled Markets}

Of all major decontrolled petroleum products, distillate serves as the most relevant for the purposes of observation and aralysis. This is because, at 18 percent of all oil consumed in the U.S., it is the largest volume petroleum product traded in a market which is not subject to direct price restrictions. Moreover, distillate has been decontrolled for a time period sufficient to allow the forces of supply and demand to reassert themselver over the effects of previous controls (distillate has been exempt from controls since June, 1976). 7

Graph 3 and Table 3 show the average weekly price at which sales of distillate fuel oil took place under wholesale contract in New York Harbor during 1978-1979. and compares this contracted sale price with the average weekly price of spot wholesale product transactions in the same location during the same period. This comparison yields some interesting conclusions. In 1978, we observe exactly what we would expect in the juxtaposition of these two prices. 


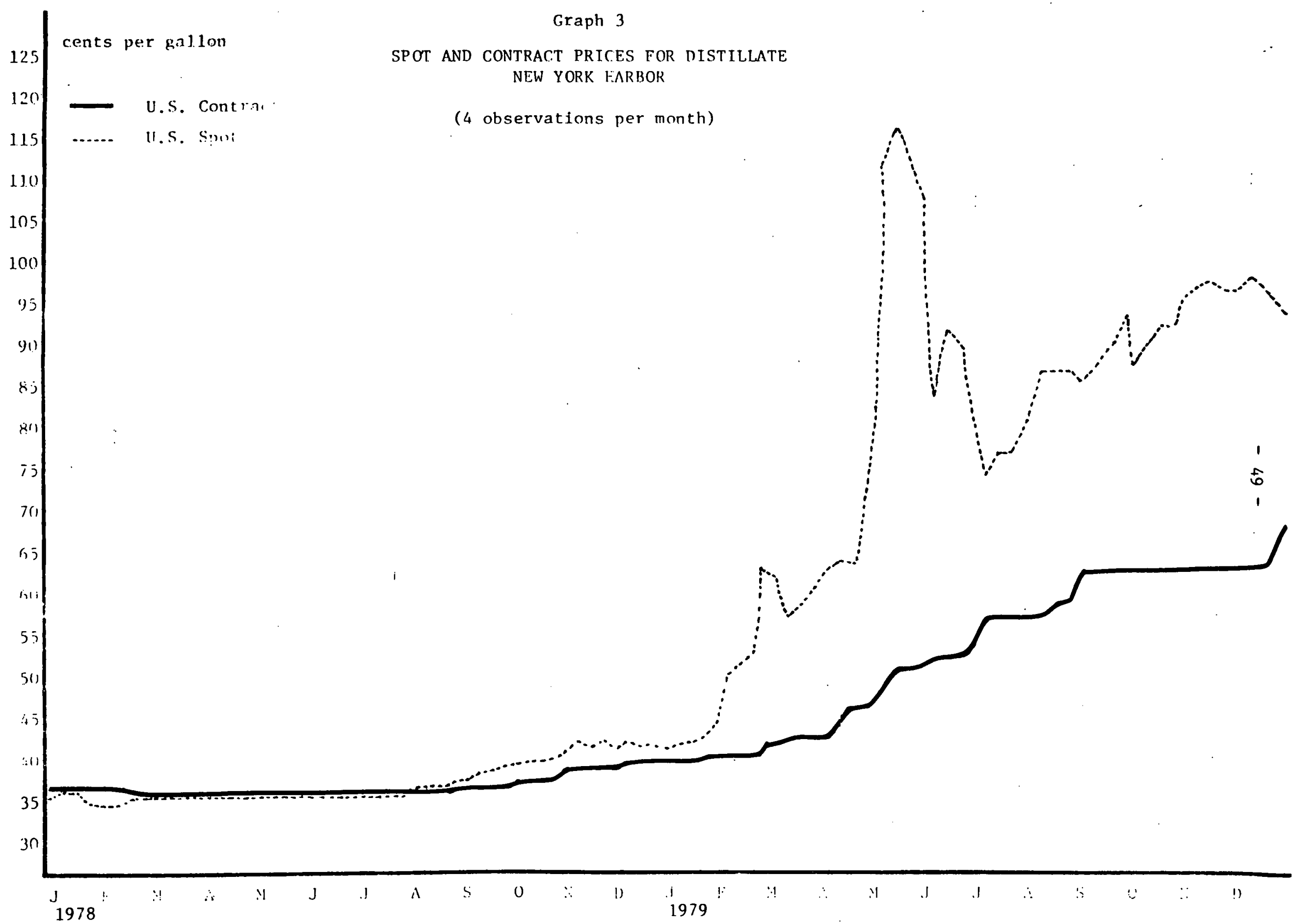

SOURCE: Oil Buyers Guide, January 1978-December 1979, Petroleum Publications, Lakewood, New Jersey. 
Table 3

AVERAGE CONTRACT AND SPOT PRICES FOR DISTILIATE

CENTS PER GALLON, NEW YORK HARBOR

( 4 observations per month)

1978

Month

January

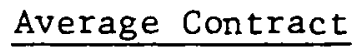

36.500

36.500

36.500

36.500

35.900

36.200

36.200

34.900
1978

\begin{tabular}{ccc} 
Month & Average Contract & $\frac{\text { Spot }}{\text { July }}$ \\
\cline { 2 - 3 } & 36.000 & 35.150 \\
36.000 & 35.300 \\
36.000 & 35.800 \\
& 36.000 & 36.000
\end{tabular}

February

36.500

36.500

36.000

36.000

March
36.000

36.000

36.000

36.000
34.800

34.900

35.000

35.500
August

36.000

36.000

36.000

36.500
36.350

36.550

36.600

37.250
37.700

38.000

38.200

38.850

\section{April}

36.000

35.400

September

36.500

36.500

36.500

37.500

35.700

35.650 October

37.500

39.000

36.000

35.550

37.500

39.250

36.000

35.500

37.500

39.625

36.000

35.500

38.500

40.200

May

36.000

35.370

November

38.500

41.500

36.000

35.100

38.500

42.375

36.000

35.350

38.500

41.750

36.000

35.370

38.500

42.375

June

$$
\begin{aligned}
& 36.000 \\
& 36.000 \\
& 36.000
\end{aligned}
$$

35.370

December

38.500

41.000

35.250

39.200

41.250

35.150

39.200

40.700

36.000

35.150

39.200

40.950 
TABLE 3 (continued).

1979

1979

\begin{tabular}{|c|c|c|c|c|c|}
\hline Month & Average Contract & Spot & Month & Average Contract & Spot \\
\hline \multirow{4}{*}{ January. } & 39.200 & 41.000 & July & 53.700 & 81.600 \\
\hline & 39.200 & 42.250 & & 56.000 & 73.000 \\
\hline & 39.200 & 42.000 & & 56.000 & 75.250 \\
\hline & 40.000 & 43.350 & & 56.000 & 75.250 \\
\hline
\end{tabular}

\begin{tabular}{|c|c|c|c|c|c|}
\hline \multirow[t]{4}{*}{ February } & 40.000 & 44.500 & August & 56.000 & 74.500 \\
\hline & 40.000 & 49.500 & & 56.000 & 79.000 \\
\hline & 40.000 & 50.750 & & 58.000 & 79.000 \\
\hline & 40.000 & 52.500 & & 58.000 & חח . 79 \\
\hline
\end{tabular}

\begin{tabular}{|c|c|c|c|c|c|}
\hline \multirow[t]{4}{*}{ March } & 41.500 & 62.750 & September & 61.000 & 78.000 \\
\hline & 41.500 & 59.250 & & 61.000 & 80.500 \\
\hline & 42.500 & 56.500 & & 61.000 & 83.500 \\
\hline & 42.500 & 57.250 & & 61.000 & 86.500 \\
\hline
\end{tabular}

\begin{tabular}{|c|c|c|c|c|c|}
\hline \multirow[t]{4}{*}{ April } & 42.500 & 59.000 & October & 61.000 & 80.500 \\
\hline & 44.000 & 61.000 & & 61.000 & 83.500 \\
\hline & 46.000 & 62.750 & & 61.000 & 85.000 \\
\hline & 46.000 & 62.500 & & 61.000 & 85.000 \\
\hline
\end{tabular}

\begin{tabular}{|c|c|c|c|c|c|}
\hline \multirow[t]{4}{*}{ May } & 46.000 & 70.000 & November & 61.000 & 88.000 \\
\hline & 48.000 & 81.000 & & 61.000 & 89.000 \\
\hline & 50.000 & 109.000 & & 61.000 & 90.000 \\
\hline & 50.000 & 114.000 & & 61.000 & 89.000 \\
\hline
\end{tabular}

\begin{tabular}{|c|c|c|c|c|c|c|}
\hline \multirow[t]{4}{*}{ June } & \multirow{4}{*}{$i$} & 50.000 & 106.000 & December & 61.000 & 89.000 \\
\hline & & 51.500 & 82.000 & & 61.000 & 90.500 \\
\hline & & 51.500 & 90.000 & & 61.000 & 88.000 \\
\hline & & 51.500 & 87.000 & & 64.000 & 86.000 \\
\hline
\end{tabular}

SOURCE: Oil Buyers Guide, Estimated Spot Cargo and Barge Prices, January 1978 December 1979 (Petroleum Publications, Lakewood, New Jersey). 
While spot prices varied to a slightly greater extent than contract prices during this year, reflecting greater volatility in spot markets, the price under contract stayed $1 c$ to $2 c$ per gallon above spot -- reflecting the value to the buyer of an assured source of supply -- and tracked the spot price fairly consistently. Beginning in January 1979, however, this trend changes radically. Spot prices undergo a dramatic increase -- reflecting the higher scarcity value of oil in the wake of the Iranian cutoff. They continue climbing in a fairly steady manner throughout the year, with several large discrete gyrations both up and down. These jumps reflect periods of dramatic change in world markets and U.S. governmental policy.

Contract prices do not exhibit what would be considered efficient behavior. U.S. contract prices for distillate consistently lag far behind spot prices and show little sign of catching up and approaching re-equilibration until March 1980 -- a full 15 months after the initial divergence. ${ }^{8}$ This behavior of prices implies that contract sellers of distillate oils, faced with no explicit government controls on prices in 1979, chose to hold prices artificially low in the U.S. market, throughout, and perhaps past, the period of transition.

Taking the spot price as the measure of the marginal cost of distillate to the nation in 1979 , Table 3 indicates that this value was often $20 \mathrm{c}$ per gallon above the price at which most contract sellers in the U.S. were supplying it in 1979. This difference suggests a major gap in the contract market between the amount that the industry was willing to supply and the amount that buyers demanded at the contract price. If there were no such gap, all demand could be satisfied (i.e., cleared) in the contract market, no demand would be registered in the spot market, and spot prices would drop to approximate parity with lower contract prices. With unsatisfied demand in the contract market, however, those sellers who do not raise price to current market-clearing. levels can be expected to institute methods of rationing the product they do make 
available among their customers by non-price means.

With more demand than supply, some method of allocating the supply is necessary. Normally, of course, price would be used to allocate the product by regulating supply and demand until they were in balance. In 1979, however, non-price methods of allocation arose. Product was distributed throughout much of 1979 through the use of allocation fractions; that is, through action by sellers to allocate existing fuel supplies among their customers roughly in proportion to customers' contract volume agreements and past demand patterns. Table 4 is a sumary of distillate allocation fractions imposed by various large companies, gathered from industry trade publications. The existence of these fractions, or non-price rationing of a product not under formal federal control, reinforces the pricing data in suggesting that most distillate sold throughout 1979 at contract was priced below the market-clearing price. If companies which traditionally supply a major portion of the contract market in distillate are induced to hold prices artificially low and are resorting to non-price rationing, we would then expect to observe a significant amount of unsatisfied demand. This, again, proves to be the case. Hearings held in 1979 by the Department of Energy and various Congressional committees on supply and price in diesel fuel are overflowing with cases of customers who were unable to obtain greater than 50 to 80 percent of their previous year's supplies from their supplier. ${ }^{9}$ of course, complaints about absolute price level are also often found in these accounts; but no evidence exists to show that prices from traditional suppliers were inefficiently or artificially high. Rather, the prices of these suppliers were higher, in an absolute sense, than the customers had paid in the past. And, indeed, evidence exists in these testimonies that the "high" prices consumers complained of being charged were actually still inefficiently low." They were well below the spot price in the appropriate region, which was in turn well below world levels. ${ }^{10}$ As 1 ong as 
spot product was available to those consumers who were unable to obtain their marginal supply needs from traditional sources, and as long as that spot product was available to them at prices not exceeding world spot levels, there was no absolute shortage. In all individual cases surveyed from the records of the 1979 hearings, spot product was available to meet marginal needs. However, such spot product was not always purchased by those who claimed to "need" more than was available to them at artificially low prices from their traditional sources. ${ }^{11}$ This makes evident the disparity between increased demand created by the artificially low prices of contract suppliers and the lower levels of actual market demand which were evident at current marginal, that is, spot prices.

It is clear that supply was being made available to consumers by producers at far below what the market would bear. This represented a tremendous transfer of wealth away from traditional distillate producers toward distillate consumers. Taking the difference between the yearly average contract price charged by resellers for distillate products and the average yearly New York spot price for the product and multiplying that difference by a preliminary estimate of the volume of distillate sold under contract during the year, we arrive at an estimate of total wealth transfers suffered by the distillate producing industry. In 1979 as a whole, we estimate that the producers in the distillate industry held prices sufficiently low that over $\$ 8.5$ billion were transferred from distillate suppliers to those lower in the distribution chain. 12

We would expect several groups to benefit from this wealth transfer. To the extent that lowered prices are passed on to ultimate consumers of oil products, they derive benefits. However, the wealth transfer can also be captured by resellers in the industry who can raise prices so as to clear the market. While this result directs much of the benefit of lower prices away from consumers, it is a preferable solution insofar as it presents consumers with 
Table 4

DISTILIATE ALLOCATION FRACTIONS - 1979, REFINERS

(Partial Listing - Fractions Reported

in National Trade Publications)

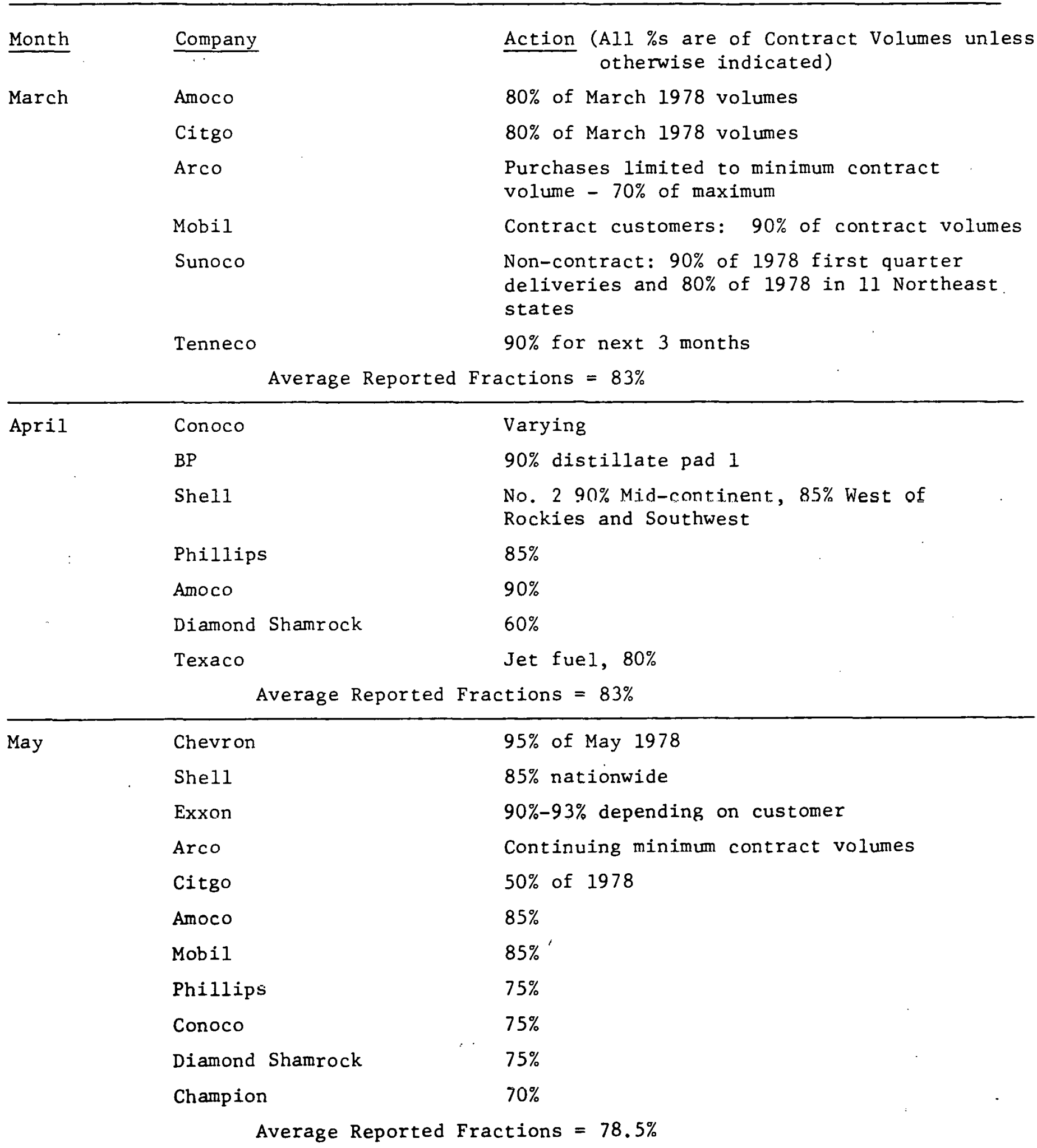


TABLE 4 (continued)

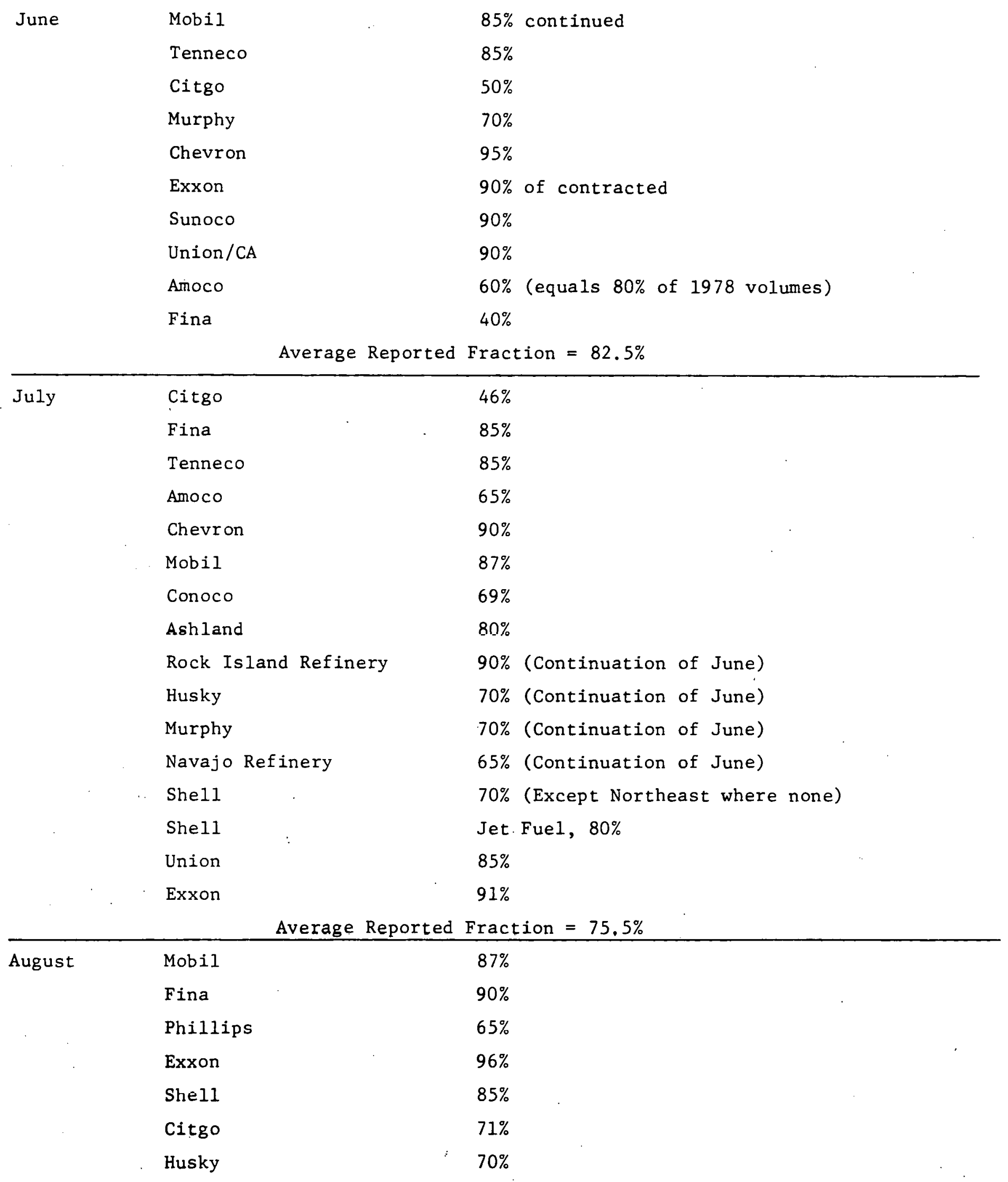


TABLE 4 (continued)

\begin{tabular}{lll} 
August & Diamond Shamrock & $85 \%$ \\
(continued) & Skelly & $75 \%$ \\
& Ashland & $80 \%$ \\
& Amoco & $70 \%$ \\
& Thunderbird & $70 \%$ \\
& & Average Reported Fraction $=.78 .7 \%$ \\
\hline September & Amoco & $70 \%$ \\
& Philips & $65 \%$ \\
& American Petroleum & $85 \%$ \\
& Husky & $70 \%$ \\
& Citgo & $71 \%$ \\
& Mobil & $93 \%$ \\
& & Average Reported Fraction $=75.7 \%$
\end{tabular}

SOURCE: Intermittent reports in Oil Buyers Guide, Oil and Gas Journal, and Oil Daily, March-September, 1979. 
efficient price signals and avoids the waste and arbitrariness of nonprice rationing mechanisms. We will examine what combination of these results transpired in the U.S. market in 1979 when we examine the pricing behavior of large and small firms in the upcoming pages.

It is clear that artificially low contract prices, coupled with nonprice rationing, were responsible for the public and governmental perceptions of absolute distillate "shortages" which were so noteworthy in the spring and summer of 1979. If prices had been raised to market-clearing levels (and thus had reflected the actual scarcity value of the distillate supply level that was available on world and U.S. markets), demand by all sectors would have fallen. Supplies would have increased, and there would have been no perception of shortages, only of higher prices. News commentators would have spoken about price increases so grave that people were actually refraining from purchasing as much as they used to -- exactly the response to increased scarcity, as reflected in higher prices, that we would expect from rational. individuals, and exactly the response necessary for an efficient adjustment of the economy to a world of increasingly scarce oil. Instead, with firms somehow induced not to raise prices in this efficient manner, the new marginal markets in oil, the brokered spot markets, served to satisfy excess demand from the contract market. Despite the availability of oil at the margin, many serious inefficiencies resulted from the price lags in contract markets. First, there undoubtedly occurred substantial interconsumer misallocation, with many consumers buying more oil than they would have, had they been faced with market-clearing prices. Further, a higher spot market price probably resulted from higher demand for spot market oil; if contracted prices had been closer to market clearing levels, spot prices would probably have been lower. ${ }^{13}$

In order to gain a perspective on which particular groups, if any, are the instigators of the artificially low contract prices in decontrolled products 
such as distillate, we must further break down the contract price data. This is done in Graphs 4 and 5 and Tables 5 and 6 which show product pricing by industry sector. These show the contract pricing of the two major distillate products at wholesale by major oil companies and small independent firms, and estimates of the wholesale contract price charged for all distillate products by the largest refiners. The data demonstrate that the major companies in the U.S. oil market, as judged by absolute size, constrained product prices severely through the transition period. Those in the independent sector, particularly small firms, priced in a manner closer to what the spot market would suggest to be market-clearing. It is further apparent from a comparison of the graphs that refiners lagged prices more than did other large companies.

While small independents are clearly pricing somewhat under spot prices over the short-term, the gap between majors' and refiners' contract prices and spot prices is considerable. Indeed, the difference between majors' and refiners' contract prices and independents' contract prices is also substantial. While there are some interesting fluctuations and variations in the pricing of majors evident in the two distillate products surveyed (which will be discussed in an upcoming section), it is clear overall from this data that major oil companies significantly underpriced during critical periods of 1979 .

Table 7 provides an estimate of the wealth transfer borne by major distillate refiners as a result of these lagged prices during 1979 . We calculate that the major companies lost almost $\$ 5.0$ billion of revenue in 1979 from underpricing the two major distillate products, relative to what they could have gained from pricing at market-clearing levels throughout the period.

\subsubsection{Controlled Product Markets}

The only major oil product that was still under the constraint of price 


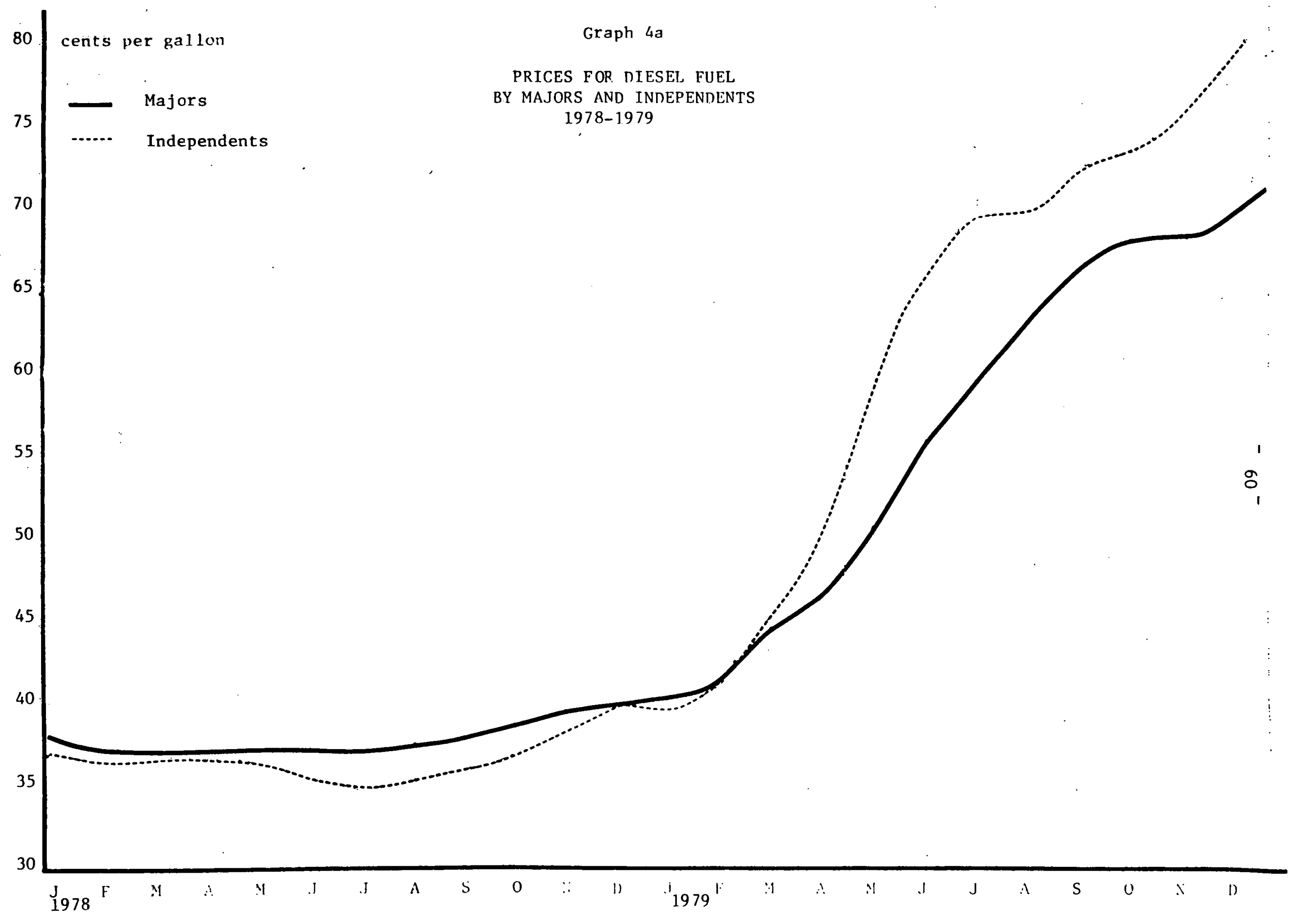

PRICES FOR DIESEL FUEL

1978-1979

SOURCE: Aggregation of DOE price data. From DOE survey of product producers and resellers. Aggregation performed by Office of Price Margin Analysis, Energy Information Administration, February, 1980. 


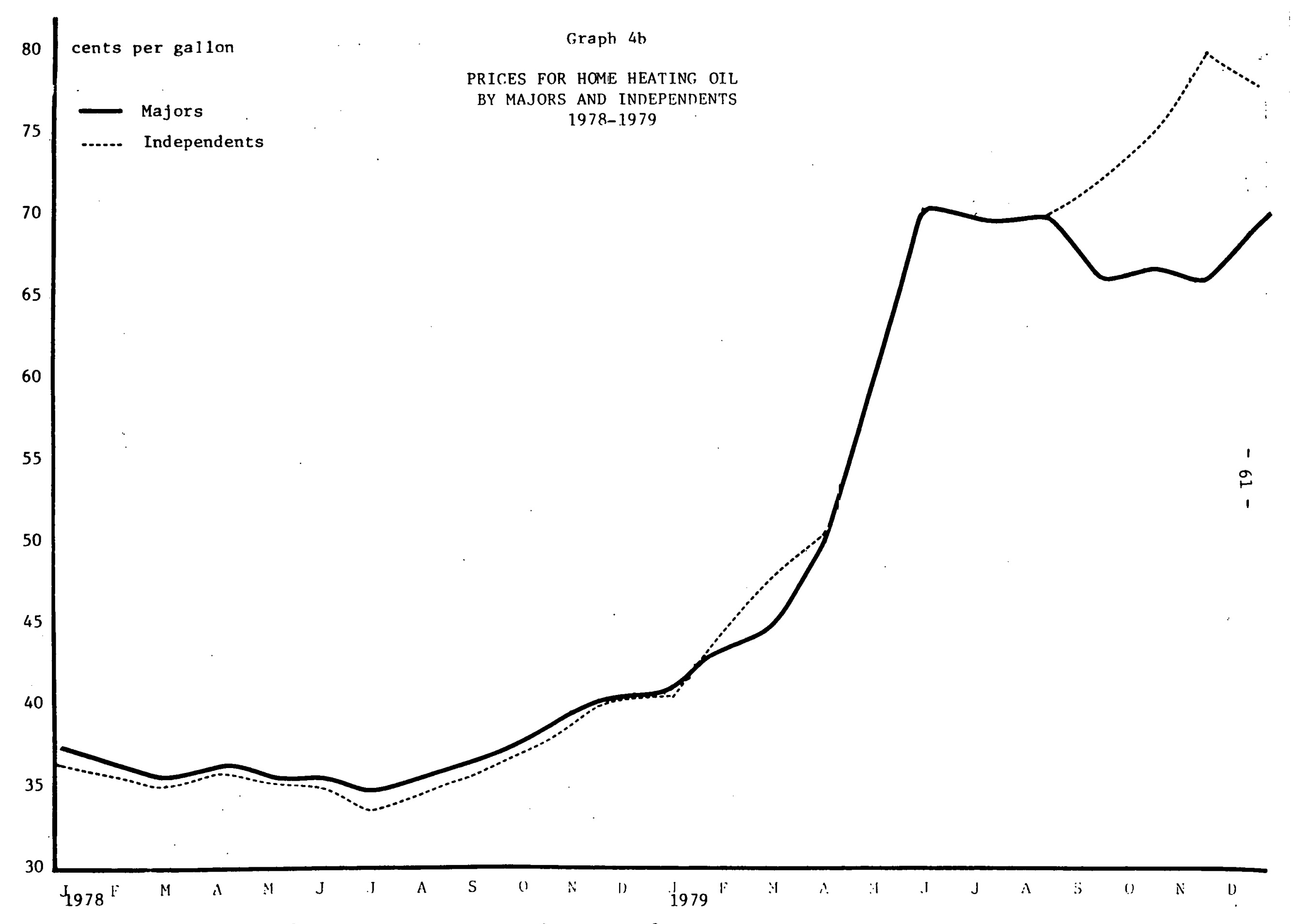

SOURCE: Aggregation of DOE price data. From DOE survey of product producers and resellers. Aggregation performed by Office of Price and Margin Analysis, Energy Information Administration, February, 1980. 
Table 5

PRICES FOR DISTILLATE PRODUCTS, MAJORS AND SMALL INDEPENDENTS

1978-1979

\begin{tabular}{|c|c|c|c|c|c|c|c|}
\hline Year & Month & Majors & Independents & Year & Month & Majors & Independents \\
\hline \multirow[t]{12}{*}{1978.} & Jan. & 37.5 & 36.6 & 1978 & Jan. & 37.2 & 36.5 \\
\hline & Feb. & 37.3 & $36.5^{\circ}$ & & Feb. & 36.7 & 36.2 \\
\hline & Mar. & 37.3 & 36.7 & & Mar. & 36.4 & 35.6 \\
\hline & Apr. & 37.2 & 36.5 & & Apr. & 36.5 & 35.5 \\
\hline & $\dot{M} a y$ & 37.3 & 36.6 & & May & 36.6 & 35.5 \\
\hline & June & 37.2 & 35.3 & & June & 36.3 & 35.3 \\
\hline & JuIy & 37.0 & 34.8 & & JuIy & 36.3 & 34.6 \\
\hline & Aug. & 37.3 & 35.0 & & Aug. & 36.5 & 35.4 \\
\hline & Sept. & 37.6 & 35.5 & & Sept. & 37.2 & 36.4 \\
\hline & Oct. & 38.0 & 36.5 & & Oct. & 38.2 & 37.6 \\
\hline & Nov. & 38.8 & 37.7 & & Nov. & 39.7 & 39.2 \\
\hline & Dec. & 39.3 & 39.3 & & Dec. & 40.2 & 40.2 \\
\hline \multirow[t]{12}{*}{1979} & Jan. & 39.9 & 38.8 & 1979 & Jan. & 40.8 & 40.9 \\
\hline & $\mathrm{Feb}$ & 41.8 & 41.3 & & Feb. & 42.9 & 44.3 \\
\hline & Mar. & 44.1 & 45.3 & & Mar. & 44.7 & 49.1 \\
\hline & Apr. & 46.6 & 49.4 & & Apr. & 50.8 & 50.8 \\
\hline & May & 50.5 & 59.0 & & May & 61.6 & 61.6 \\
\hline & June & 55.4 & 66.6 & & June & 71.5 & 71.5 \\
\hline & July & 58.7 & 69.9 & & July & 70.2 & 70.2 \\
\hline & Aug. & 63.4 & 69.4 & & Aug. & 70.7 & 70.7 \\
\hline & Sept. & 66.9 & 72.6 & & Sept. & 66.0 & 73.5 \\
\hline & Oct. & 67.3 & 72.9 & & Oct. & 66.2 & 74.9 \\
\hline & Nov. & 67.2 & 76.0 & & Nov. & 65.5 & 80.0 \\
\hline & Dec. & 69.1 & 80.0 & & Dec. & 68.8 & 78.7 \\
\hline
\end{tabular}

SOURCE: Aggregation of DOE price data. From DOE survey of product producers and resellers. Aggregation performed by Office of Price and Margin Analysis Energy Information Administration, February, 1980. 


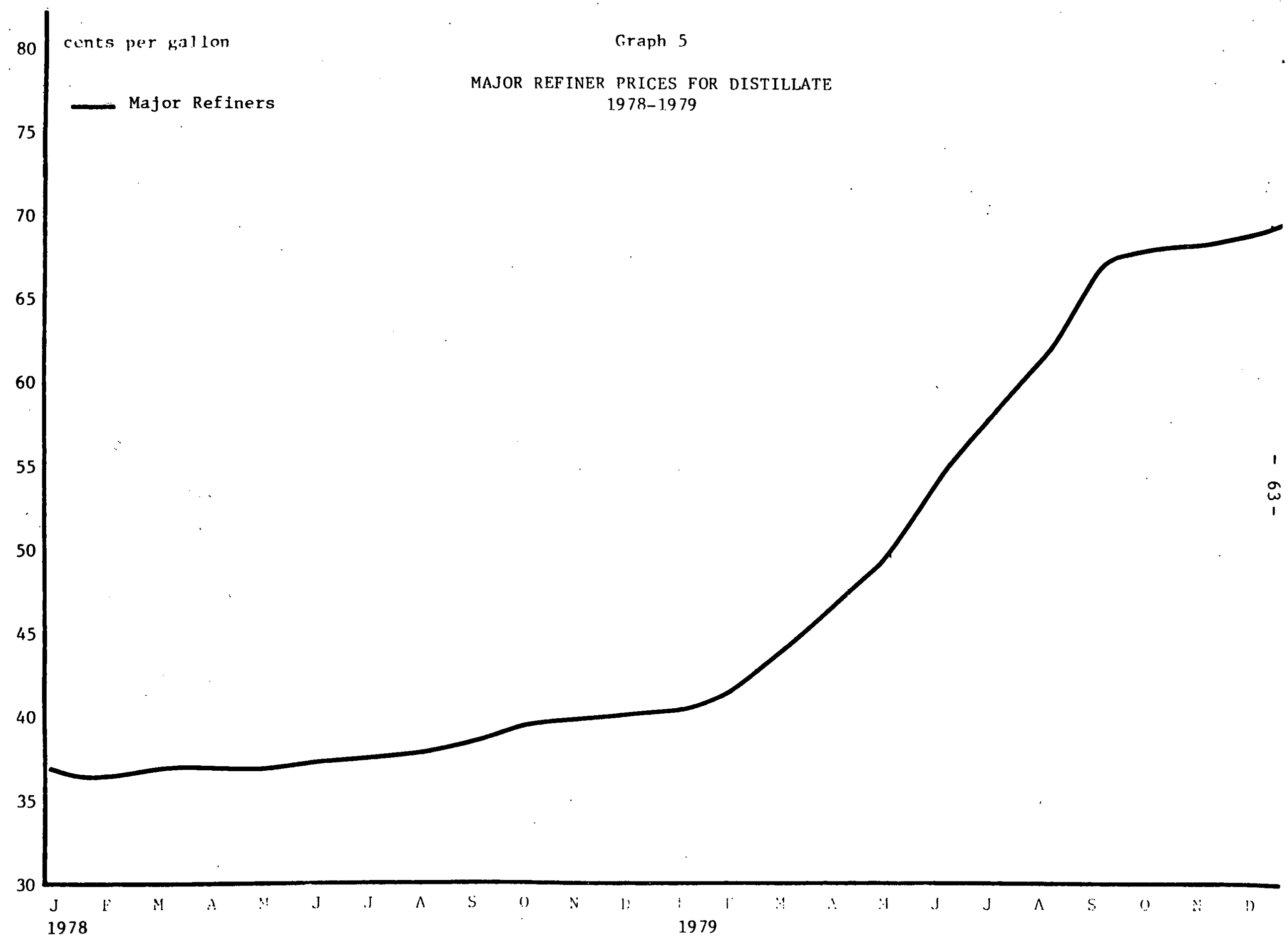

SOURCE: These prices represent the average of the individual company data reported in Table 10. 
Table 6

MAJOR REFINERS' AVERAGE MONTHLY PRICES

FOR DISTILIAGE, 1979

1978

January $\quad 36.80$

February $\quad 36.50$

March $\quad 36.20$

April $\quad 36.30$

May $\quad 36.30$

June $\quad 36.40$

July $\quad 36.50$

August $\quad 36.60$

September $\quad 37.20$

October $\quad 38.20$

November $\quad 39.40$

December $\quad 40.10$
1979

40.60

42.49

45.40

47.60

50.10

55.10

58.50

63.60

67.50

67.60

67.20

68.40

SOURCE: These prices represent the average of the individual company data reported in Table 10 . 
controls. in 1979 was gasoline, which was controlled at every level of the industry. A comparison of Exxon's contract price at wholesale for this product -- the only contract price data available to us during 1979.-- with concurrent spot prices demonstrates the extent of the price-increase lags which occurred in the contract gasoline market during this period. This may be seen in Graph 6 and Table 8. The gasoline market failed to clear -- there were gasoline lines -- during much of the late spring and early summer. ${ }^{14}$

The issue which this section will examine is whether it may be concluded that the price control constraint alone was responsible for these low prices and resulting shortages or whether there were other constraining influences at work in this market similar to those found in distillate. As a first approximation we can analyze this by determining whether gasoline prices were at their price-controlled maximums throughout the summer's shortage, or whether they were below ceiling levels.

Gasoline price controls have different structures and effects at different levels of the gasoline distribution network. At wholesale, the controls are based upon a full passthrough of increased costs, as measured relative to a base price and cost structure that is specific to each firm. These costs include, for refiners, the increased costs of purchases of refined product and costs of doing business, such as labor and marketing costs. The structure of retail controls mirrored the cost passthrough framework of the wholesale and refining sectors fran the beginning of controls in 1973 until the summer of 1979. However, beginning on August 1, 1979, the dollar-for-dollar cost passthrough work was abandoned at retail, and instead a gross margin rule was adopted. This rule allowed gasoline retailers to charge a maximum of 15.4c above average cost on each gallon of gasoline they sold (the gross margin is updated at regular intervals, and stood at $16.1 \mathrm{c}$ per gallon as of late 1980). 15 
Table 7

WEALTH TRANSFERS EXPERIENCED BY MAJOR OIL COMPANIES DUE TO LAGGED DISTILLATE PRICES, 1979

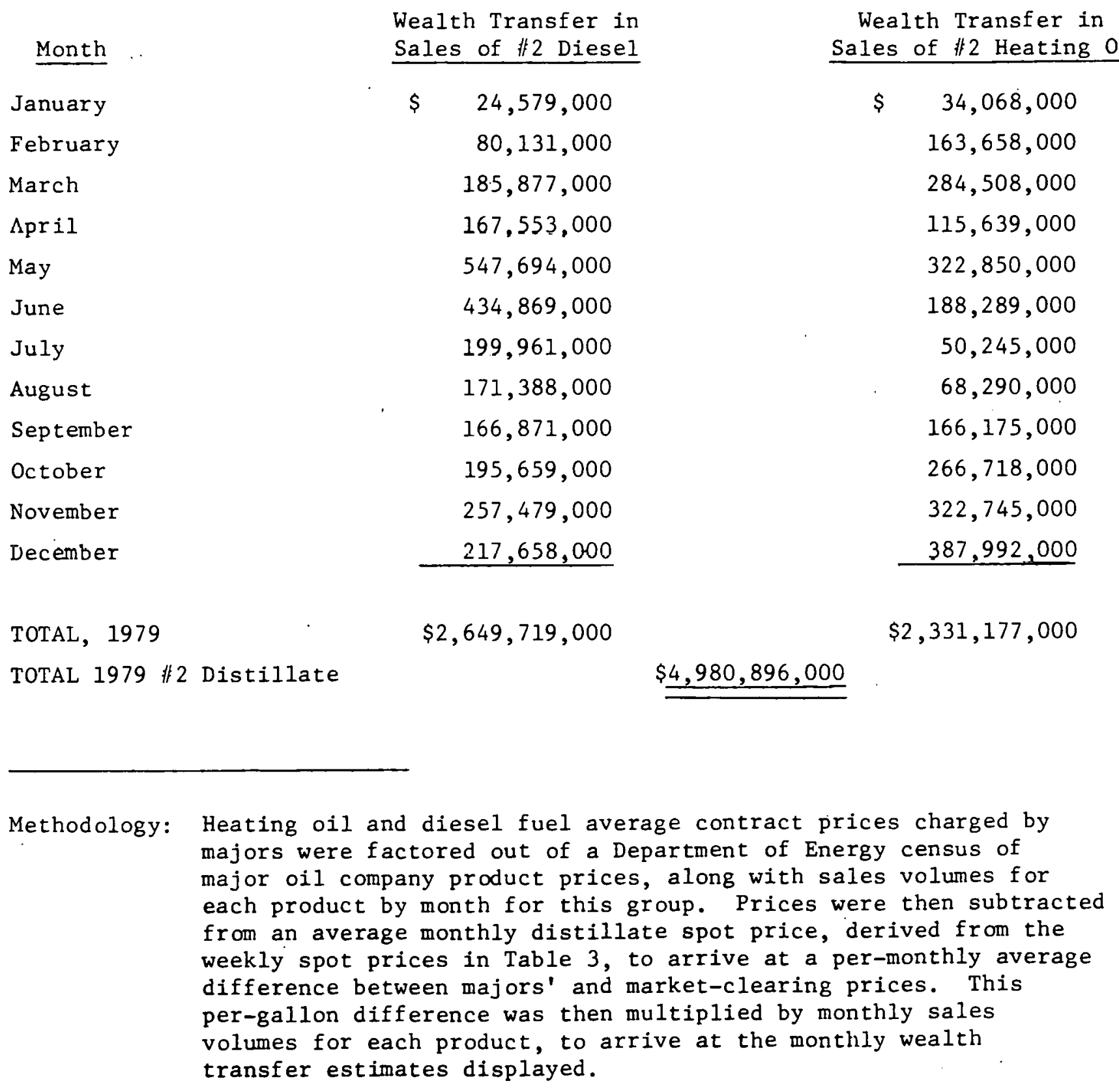




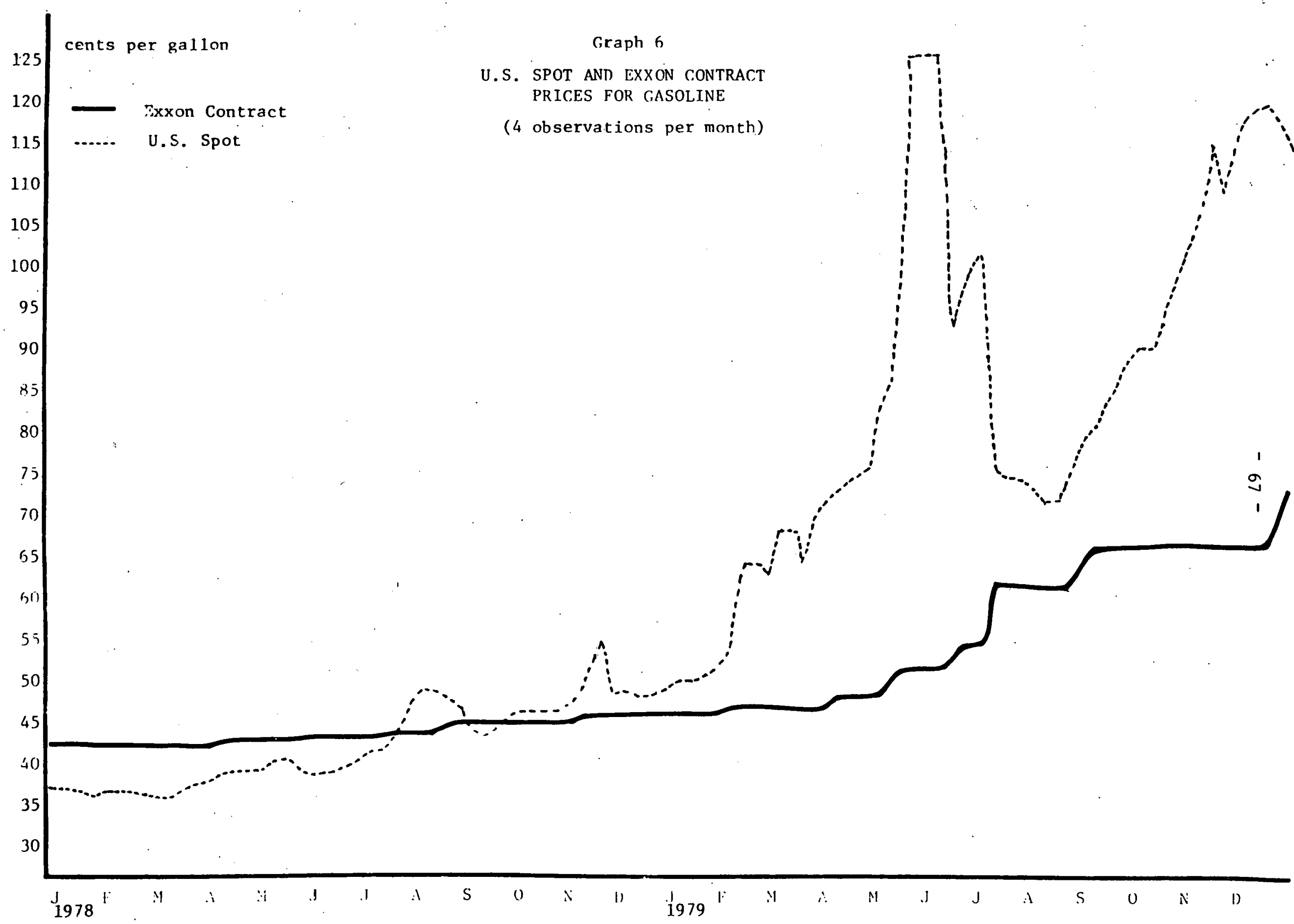

SOURCE: O11 Buyers Guide, January 1978-December 1979, Petroleum Publications, Lakewood, New Jersey. 
Table 8

U.S. SPOT AND EXXON CONTRACT PRICES

FOR GASOLINE, NEW YORK HARBOR

1978-1979

( 4 observations per month)

1978

1978

\begin{tabular}{|c|c|c|c|c|c|}
\hline Month & Spot & Exxon Contract & Month & Spot & Exxon Contract \\
\hline \multirow[t]{4}{*}{ January } & 37.10 & 42.30 & July & 42.00 & 43.50 \\
\hline & 37.10 & 42.30 & 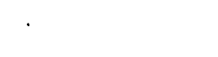 & 42.40 & 44.20 \\
\hline & 37.00 & 42.30 & & 44.00 & 44.20 \\
\hline & 36.30 & 42,30 & & 47.00 & 44.20 \\
\hline \multirow[t]{4}{*}{ February } & 36.80 & 42.30 & August & 49.50 & 44.20 \\
\hline & 36.80 & 42.30 & & 49.50 & 44.20 \\
\hline & 36.80 & 42.30 & & 49.00 & 45.20 \\
\hline & 36.50 & 42.30 & & 47.50 & 45.20 \\
\hline \multirow[t]{4}{*}{ March } & 36.60 & 42.30 & September & 45.00 & 45.20 \\
\hline & 36.60 & 42.30 & & 44.75 & 45.20 \\
\hline & 36.90 & 42.30 & & 45.10 & 45.20 \\
\hline & 37.30 & 42.30 & & 46.00 & 45.20 \\
\hline \multirow[t]{4}{*}{ April } & 38.00 & 42.30 & October & 46.25 & 45.20 \\
\hline & 38.80 & 43.00 & & 46.25 & 45.20 \\
\hline & 39.00 & 43.00 & & 46.25 & 45.20 \\
\hline & 39.30 & 43.00 & & 46.75 & 45.20 \\
\hline \multirow[t]{4}{*}{ May } & 39.50 & 43.00 & November. & 48.50 & 45.20 \\
\hline & 40.40 & 43.00 & & 50.25 & 46.20 \\
\hline & 40.50 & 43.00 & & 55.50 & 46.20 \\
\hline & 39.80 & 43.50 & & 49.00 & 46.20 \\
\hline \multirow[t]{4}{*}{ June } & 39.40 & 43.50 & December & 50.00 & 46.20 \\
\hline & 39.60 & 43.50 & & 49.30 & 46.20 \\
\hline & 40.00 & 43.50 & & 49.25 & 46.20 \\
\hline & 41.00 & 43.50 & & 50.80 & 46.20 \\
\hline
\end{tabular}


TABLE 8 (continued)

1979

Month

January

$\frac{\text { Spot }}{51.30}$

51.30

52.30

53.00

$\begin{array}{cl}\text { Exxon Contract } & \text { Month } \\ 46.20 & \text { Ju.1y } \\ 46.20 & \\ 46.20 & \\ 46.20 & \end{array}$

1979

\begin{tabular}{|c|c|c|c|c|c|}
\hline \multirow[t]{4}{*}{ February } & 55.30 & 47.20 & August & 75.00 & 63.90 \\
\hline & 65.00 & 47.20 & 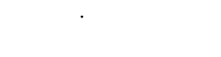 & 73.90 & 63.90 \\
\hline & 65.00 & 47.20 & & 74.00 & 63.90 \\
\hline & 64.30 & 47.20 & & 77.00 & 65.90 \\
\hline \multirow[t]{4}{*}{ March } & 69.50 & 47.20 & September & 81.00 & 68.90 \\
\hline & 69.00 & 47.20 & & 83.00 & 68.90 \\
\hline & 66.30 & 47.20 & & 86.00 & 68.90 \\
\hline & 71.00 & 47.20 & & 90.00 & 68.90 \\
\hline \multirow{4}{*}{ April } & 73.50 & 47,20 & October & 91.00 & 68.90 \\
\hline & 74.50 & 49.20 & & 91.00 & 68.90 \\
\hline & 75.50 & 49.20 & & 100.00 & 68.90 \\
\hline & 76.50 & 49.20 & & 104.00 & 68.90 \\
\hline \multirow[t]{4}{*}{ May } & 84.00 & 49.20 & November & 108.00 & 68.90 \\
\hline & 87.00 & 51.20 & & 116.00 & 68.90 \\
\hline & 126.00 & 53.20 & & 111.00 & 68.90 \\
\hline & 126.00 & $\because \quad 53.20$ & & 117.00 & 68.90 \\
\hline \multirow[t]{4}{*}{ June } & 126.00 & 53.20 & December & 119.00 & 68.90 \\
\hline & 115.00 & 53.20 & & $120: 00$ & 68.90 \\
\hline & 94.00 & 55.20 & & 118.00 & 68.90 \\
\hline & 103.00 & 55.20 & & 115.00 & $74.90^{\circ}$ \\
\hline
\end{tabular}

February

March

\begin{tabular}{|c|c|c|c|c|c|}
\hline \multirow[t]{4}{*}{ February } & 55.30 & 47.20 & August & $: 75.00$ & 63.90 \\
\hline & 65.00 & 47.20 & & 73.90 & 63.90 \\
\hline & 65.00 & 47.20 & & 74.00 & 63.90 \\
\hline & 64.30 & 47.20 & & 77.00 & 65.90 \\
\hline \multirow[t]{4}{*}{ March } & 69.50 & 47.20 & September & 81.00 & 68.90 \\
\hline & 69.00 & 47.20 & & 83.00 & 68.90 \\
\hline & 66.30 & 47.20 & & 86.00 & 68.90 \\
\hline & 71.00 & 47.20 & & 90.00 & 68.90 \\
\hline \multirow[t]{4}{*}{ April } & 73.50 & 47,20 & October & 91.00 & 68.90 \\
\hline & 74.50 & 49.20 & & 91.00 & 68.90 \\
\hline & 75.50 & 49.20 & & 100.00 & 68.90 \\
\hline & 76.50 & 49.20 & & 104.00 & 68.90 \\
\hline \multirow[t]{4}{*}{ May } & 84.00 & 49.20 & November & 108.00 & 68.90 \\
\hline & 87.00 & 51.20 & & 116.00 & 68.90 \\
\hline & 126.00 & 53.20 & & 111.00 & 68.90 \\
\hline & 126.00 & $\because . \quad 53.20$ & & 117.00 & 68.90 \\
\hline \multirow[t]{4}{*}{ June } & 126.00 & 53.20 & December & 119.00 & 68.90 \\
\hline & 115.00 & 53.20 & & 120.00 & 68.90 \\
\hline & 94.00 & 55.20 & & 118.00 & 68.90 \\
\hline & 103.00 & 55.20 & & 115.00 & 74.90 \\
\hline
\end{tabular}

Apri1

\begin{tabular}{|c|c|c|c|c|c|}
\hline \multirow[t]{4}{*}{ February } & 55.30 & 47.20 & August & $: 75.00$ & 63.90 \\
\hline & 65.00 & 47.20 & & 73.90 & 63.90 \\
\hline & 65.00 & 47.20 & & 74.00 & 63.90 \\
\hline & 64.30 & 47.20 & & 77.00 & 65.90 \\
\hline \multirow[t]{4}{*}{ March } & 69.50 & 47.20 & September & 81.00 & 68.90 \\
\hline & 69.00 & 47.20 & & 83.00 & 68.90 \\
\hline & 66.30 & 47.20 & & 86.00 & 68.90 \\
\hline & 71.00 & 47.20 & & 90.00 & 68.90 \\
\hline \multirow[t]{4}{*}{ April } & 73.50 & 47,20 & October & 91.00 & 68.90 \\
\hline & 74.50 & 49.20 & & 91.00 & 68.90 \\
\hline & 75.50 & 49.20 & & 100.00 & 68.90 \\
\hline & 76.50 & 49.20 & & 104.00 & 68.90 \\
\hline \multirow[t]{4}{*}{ May } & 84.00 & 49.20 & November & 108.00 & 68.90 \\
\hline & 87.00 & 51.20 & & 116.00 & 68.90 \\
\hline & 126.00 & 53.20 & & 111.00 & 68.90 \\
\hline & 126.00 & $\because . \quad 53.20$ & & 117.00 & 68.90 \\
\hline \multirow[t]{4}{*}{ June } & 126.00 & 53.20 & December & 119.00 & 68.90 \\
\hline & 115.00 & 53.20 & & 120.00 & 68.90 \\
\hline & 94.00 & 55.20 & & 118.00 & 68.90 \\
\hline & 103.00 & 55.20 & & 115.00 & 74.90 \\
\hline
\end{tabular}

\begin{tabular}{|c|c|c|c|c|c|}
\hline \multirow[t]{4}{*}{ February } & 55.30 & 47.20 & August & $: 75.00$ & 63.90 \\
\hline & 65.00 & 47.20 & & 73.90 & 63.90 \\
\hline & 65.00 & 47.20 & & 74.00 & 63.90 \\
\hline & 64.30 & 47.20 & & 77.00 & 65.90 \\
\hline \multirow[t]{4}{*}{ March } & 69.50 & 47.20 & September & 81.00 & 68.90 \\
\hline & 69.00 & 47.20 & & 83.00 & 68.90 \\
\hline & 66.30 & 47.20 & & 86.00 & 68.90 \\
\hline & 71.00 & 47.20 & & 90.00 & 68.90 \\
\hline \multirow[t]{4}{*}{ April } & 73.50 & 47,20 & October & 91.00 & 68.90 \\
\hline & 74.50 & 49.20 & & 91.00 & 68.90 \\
\hline & 75.50 & 49.20 & & 100.00 & 68.90 \\
\hline & 76.50 & 49.20 & & 104.00 & 68.90 \\
\hline \multirow[t]{4}{*}{ May } & 84.00 & 49.20 & November & 108.00 & 68.90 \\
\hline & 87.00 & 51.20 & & 116.00 & 68.90 \\
\hline & 126.00 & 53.20 & & 111.00 & 68.90 \\
\hline & 126.00 & $\because . \quad 53.20$ & & 117.00 & 68.90 \\
\hline \multirow[t]{4}{*}{ June } & 126.00 & 53.20 & December & 119.00 & 68.90 \\
\hline & 115.00 & 53.20 & & 120.00 & 68.90 \\
\hline & 94.00 & 55.20 & & 118.00 & 68.90 \\
\hline & 103.00 & 55.20 & & 115.00 & 74.90 \\
\hline
\end{tabular}

\begin{tabular}{|c|c|c|c|c|c|}
\hline \multirow[t]{4}{*}{ February } & 55.30 & 47.20 & August & $: 75.00$ & 63.90 \\
\hline & 65.00 & 47.20 & & 73.90 & 63.90 \\
\hline & 65.00 & 47.20 & & 74.00 & 63.90 \\
\hline & 64.30 & 47.20 & & 77.00 & 65.90 \\
\hline \multirow[t]{4}{*}{ March } & 69.50 & 47.20 & September & 81.00 & 68.90 \\
\hline & 69.00 & 47.20 & & 83.00 & 68.90 \\
\hline & 66.30 & 47.20 & & 86.00 & 68.90 \\
\hline & 71.00 & 47.20 & & 90.00 & 68.90 \\
\hline \multirow[t]{4}{*}{ April } & 73.50 & 47,20 & October & 91.00 & 68.90 \\
\hline & 74.50 & 49.20 & & 91.00 & 68.90 \\
\hline & 75.50 & 49.20 & & 100.00 & 68.90 \\
\hline & 76.50 & 49.20 & & 104.00 & 68.90 \\
\hline \multirow[t]{4}{*}{ May } & 84.00 & 49.20 & November & 108.00 & 68.90 \\
\hline & 87.00 & 51.20 & & 116.00 & 68.90 \\
\hline & 126.00 & 53.20 & & 111.00 & 68.90 \\
\hline & 126.00 & $\because . \quad 53.20$ & & 117.00 & 68.90 \\
\hline \multirow[t]{4}{*}{ June } & 126.00 & 53.20 & December & 119.00 & 68.90 \\
\hline & 115.00 & 53.20 & & 120.00 & 68.90 \\
\hline & 94.00 & 55.20 & & 118.00 & 68.90 \\
\hline & 103.00 & 55.20 & & 115.00 & 74.90 \\
\hline
\end{tabular}

Spot.

93.00

76.00

75.50

75.50

$63.9: 0$
Exxon Contract

55.20

63.90

63.90

SOURCE: Oil Buyers Guide, January 1978-December 1979, Petroleum Publications, Lakewood, New Jersey. 
In this control system, a supply-demand gap occurring at upper levels of the industry was exacerbated at retail, as the retail sector was prevented from raising prices to the level needed to eliminate the gap. Due to the structure of the controls, retailers also faced many disincentives to searching for and purchasing additional supplies from nontraditional suppliers in times of rapidly rising prices, which further exacerbated the shortage. 16 The result was that gasoline was underpriced, and retailers had to resort to methods of non-price rationing such as customer lines, poorer service, and shorter hours.

In order to gain the necessary perspective upon the constraint that was limiting gasoline price increases during 1979, it is necessary to examine in detail another aspect of the price control framework: banked costs. An examination of the trends in banked costs during 1979 will allow us to determine if refiners (the only sector of the industry for which banked cost data are available) were able tupass through the cost increases they incurred in 1979, or whether some constraint prevented them from doing so.

When a refiner incurred increased costs which the firm was unable to pass through immediately because the market would not bear higher prices, the company would then bank those unrecovered costs for possible future recovery. Figure 6 depicts the situation in which increased costs are constrained from being fully passed through -- the constraint being the level of market demand. 17 Prior to the increase in cost, which is depicted as shifting the firm's supply curve from $S_{0}$ to $S_{1}$ in Figure 6 , binding price controls were in place. That is, the controlled price $\overline{\mathrm{P}}_{\mathrm{O}}$, was less than the market-clearing price, $\mathrm{P}_{\mathrm{O}}^{\mathrm{C}}$. Suppose there is a cost increase of $\$ X$ per unit output. The new ceiling price is $\overline{\mathrm{P}}_{1}=\overline{\mathrm{P}}_{0}+\mathrm{X}$ and allows a full passthrough of increased costs over the base. As depicted in Figure 6, however, the new price ceiling is not 
binding (Figure 7 illustrates the other alternative). The market will only allow the price to rise to $\mathrm{P}_{1}^{\mathrm{c}}$. Notice that part of the increased cost is borne by the consumer and part by the producer. Consumers bear a cost of $\left(P_{1}^{c}-\bar{P}_{0}\right) Q_{1}^{c}$. The part that is borne by the producer, $\left(\bar{P}_{1}-P_{1}^{c}\right) Q_{1}^{c}$, is added to his bank for possible future recovery. This amount, $\left(\bar{P}_{1}-P_{1}^{C}\right) Q_{1}^{C}$, is shown by the area $\bar{P}_{1} G C P_{1}^{C}$ or equivalently by $\bar{P}_{0} F E\left(P_{I}^{C}-X\right)$.

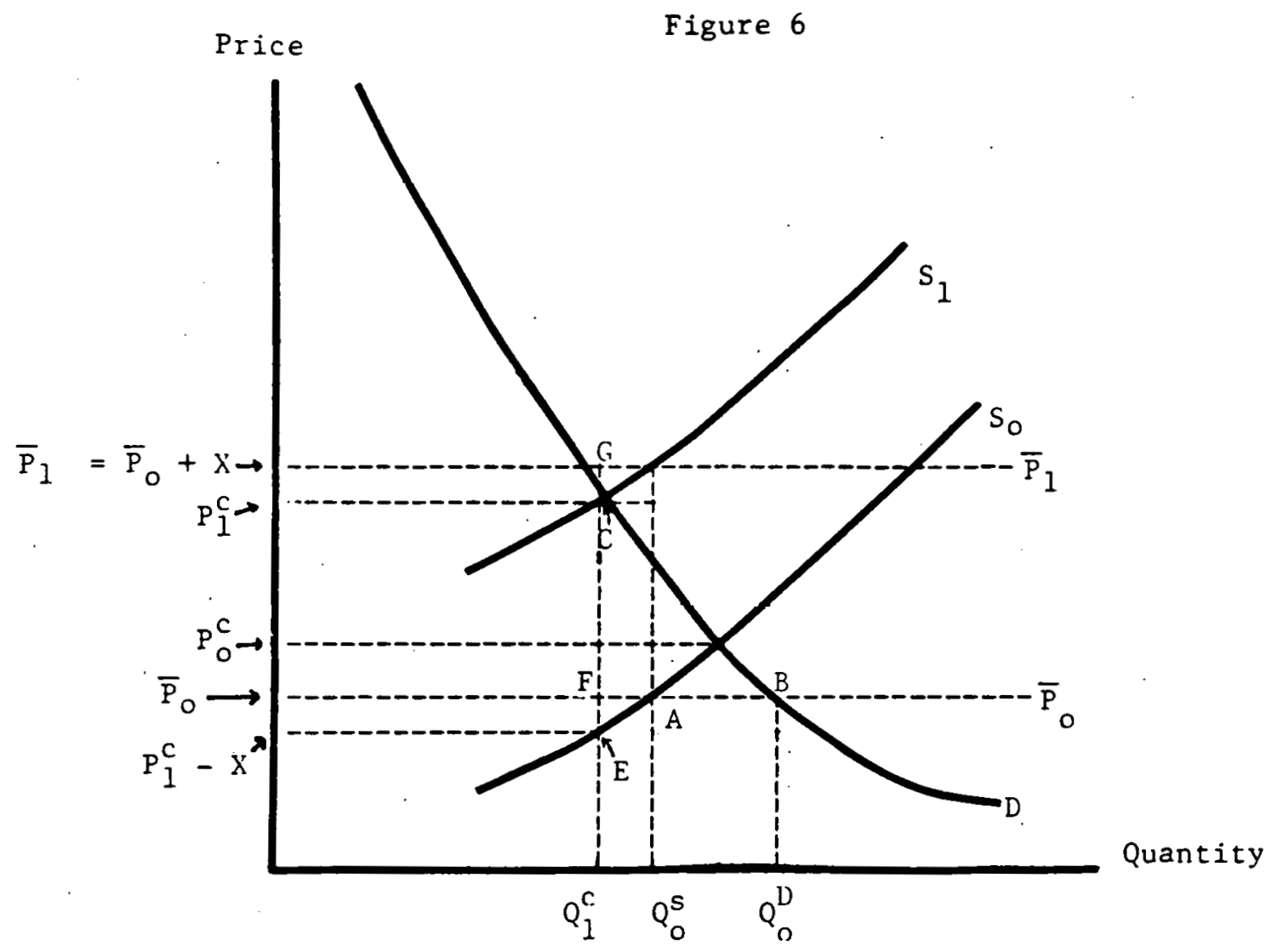

In a time of radically increasing costs, such as last year, we might expect a refiner to push those costs through in higher prices if able. As we have seen, however, at least some contract sellers of gasoline were not raising prices as much as the marketplace would allow, i.e., to approximate parity with spot prices. If this were due to price controls on contract gasoline, we would expect to see the exhaustion of, or at least no buildup in banked costs among refiners. This situation is illustrated in Figure 7 . The controlled 


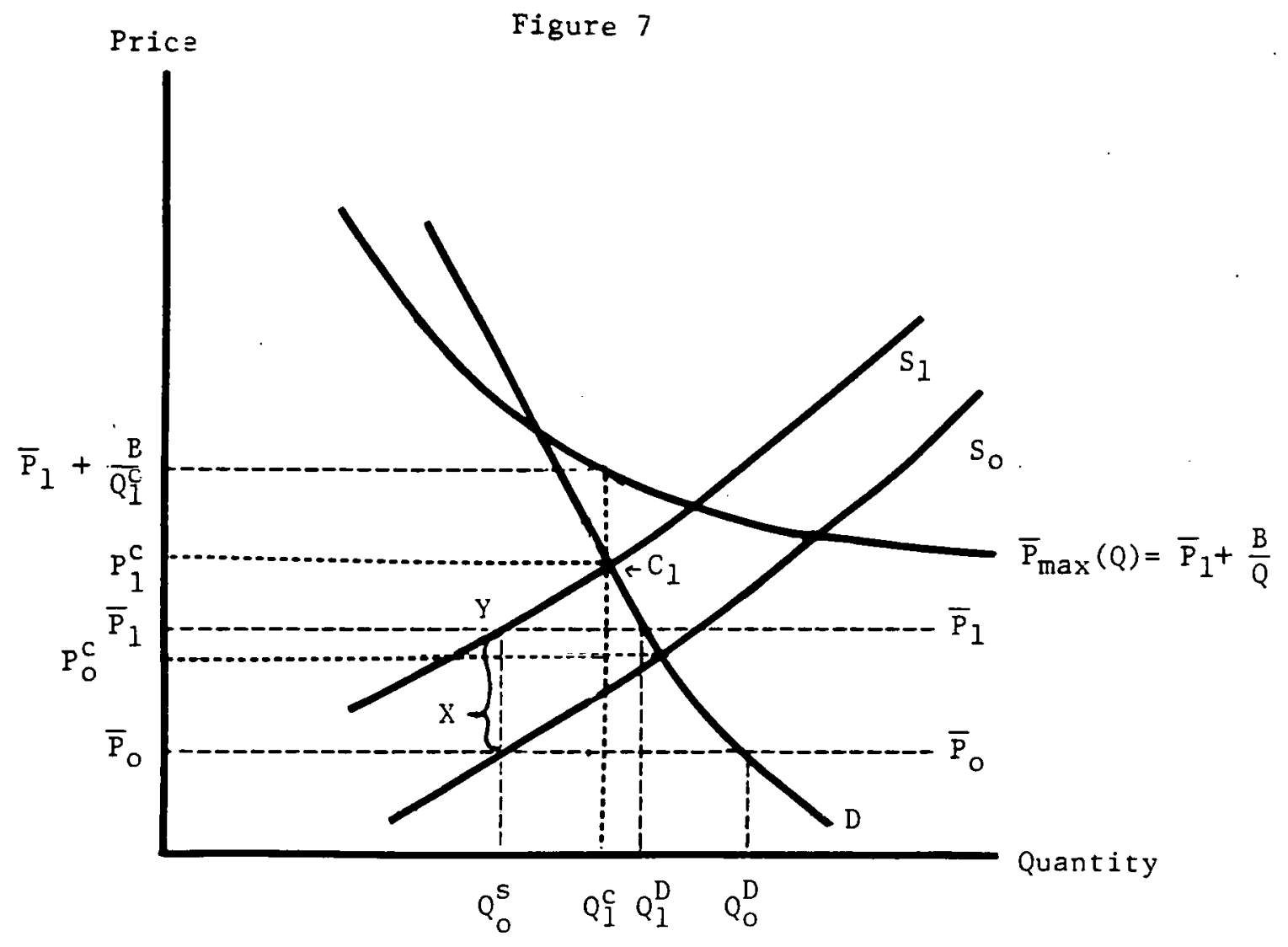

price, $\bar{P}_{O}$, is far below market-clearing, $P_{O}^{C}$. Excess demand (a supply shortage) of $Q_{0}^{D}-Q_{0}^{S}$ results. An increase in cost of $S X$ per unit causes a shift in supply to $S_{1}$ from $S_{0}$ and an increase in the price controlled ceiling to $\bar{P}_{1}=\bar{P}_{0}+x$. The price constraint is still binding in this case; thus, output (supply) remains the same (rather than derlining as in Figure 6), excess demand has decreased to $Q_{1}^{D}-Q_{0}^{S}$, and the increased cost, $Q_{0}^{S} \cdot X$, has been fully passed through to consumers (in Figure 6 part was borne by the producers and banked). Banked costs would remain the same. In fact, if the firm has banks of $B$ from prior time periods it could draw upon them in this situation. Given 
banks $B$ and the controlled price ceiling (with no bank drawdown) of $\bar{P}_{1}$ the maximum price allowed if the banks are completely drawn down, $\overline{\mathrm{P}}_{\max }$, depends on quantity $Q: \overline{\mathrm{P}}_{\max }(\mathrm{Q})=\overline{\mathrm{P}}_{1}+\frac{\mathrm{B}}{\mathrm{Q}}$. That is, available total banks, $\mathrm{B}$, get spread out over the quantity, $Q$, of the firm's sales. Thus, as sales increase the per unit allowed passthrough of banks, $\frac{B}{Q}$, declines. This is shown as the $\overline{\mathrm{P}}_{\max }(\mathrm{Q})=\overline{\mathrm{P}}_{1}+\frac{\mathrm{B}}{\mathrm{Q}}$ curve in Figure 7 . The situation depicted in Figure 7 is for B large enough so that the market clears by only partially drawing down banks. Banks would be drawn down by $Q_{1}^{c}\left(P_{1}^{C}-\bar{P}_{1}\right)$ and remaining banks would be $B-Q_{1}^{c}\left(P_{1}^{c}-\bar{P}_{1}\right)=\left(\left(\bar{P}_{1}+\frac{B}{Q_{1}^{c}}\right)-P_{1}^{c}\right) Q_{1}^{c}$. This need not be the case. If the banks are insufficient to allow the market to clear, then a shortage will result. Diagramatically, this simply means that the curve $\overline{\mathrm{P}}_{\max }(\mathrm{Q})$ intersects the supply curve $\mathrm{s}_{1}$ below $\mathrm{C}_{1}$.

An analysis of banked costs in gasoline during the months of "gasoline crisis" in 1979 indicates that some market constraint other than the price control framework itself was putting severe downward pressure on gasuline prices. While price controls certainly further exacerbated the problems in the gasoline market, our observations suggest that other forces were yet more restrictive. Table 9 summarizes the total banked costs in gasoline held by the twenty-nine largest U.S. refiners. These figures indicate that during those months of 1979 when artificially low prices caused the greatest problems in the gasoline market, these refiners were not bound in gasoline price by the price-control framework.

Table 9 shows that during the period of gasoline shortage, banked costs in gasoline were in fact increasing at a tremendous rate among these twenty-nine refiners moving from slightly over $\$ 1.1$ billion in February 1979 to over $\$ 3.1$ billion by September. Thus, binding price controls at the refinery level fail as an explanation for the 1979 gasoline shortages. This is reinforced by the evidence contained in the table that in years of relative price stability 
gasoline banks still depleted during the sumer months, as refiners priced so as to take advantage of the seasonal demand peak. Of course, this does not preclude the possibility that controls were binding at the retail level.

In distillate, artificially low prices charged by large firms did not result in shortages because of the existence of a marginal spot market comprised of brokers and independents and the lack of formal controls at the retail level. While there were complaints of the economic impact of high prices by distillate consumers last summer, there were no lines. In contrast, it is clear that the price and allocation control system in gasoline has, in several ways, created a barrier to that market's clearing in the presence of price lags by majors. First, the regulatory framework has restricted the development of a healthy brokered and independent spot market due to the disincentives to entry into this market posed by the control framework. Second, the control framework, based upon average-cost-passthrough with time lags, serves as a disincentive to the purchase of expensive, marginal supply. Third, an efficient result in the gasoline market might have been attained if retailers had simply been able to raise price to the point at which the market cleared, thus making up for controlcaused supply reductions at wholesale. The control framework, of course, prevented them from so doing. One retailer who attempted to pursue this latter goal, and thus tried to service the gasoline market at the margin, was Beacon Hill Gulf in Boston, Massachusetts. The station owner raised his prices in July of 1979 to market-clearing levels -- approximately $\$ 1.50$ per gallon. He was sent to jail, and fined the amount he "gouged" consumers by increasing his prices above price-controlled levels. 18

It should be noted that at $\$ 1.50$ per gallon -- approximately $70 \mathrm{c}$ above the then-current controlled price -- Beacon Hill Gulf was realizing substantial windfall gain during the period on the gasoline it obtained under contract. 
The result attained, however, was far preferable in an economic sense. Marginal supply was made available to consumers who did not have to wait in lines to obtain it. From the viewpoint of economic efficiency, it is beneficial to have a source of marginal supply available to the consumer at prices reflective of marginal costs of supply acquisition. A source of supply which may be obtained at a high price with no waiting in line is preferable to no such source if some consumers choose to purchase product from that source. If the cost to them of waiting in line for low-priced supply is actually higher when all factors are counted in, than is paying a higher price, the high price is preferable. Longer lines serve to increase the effective price paid by consumers for gasoline. The value of marginal-supply sources, as opposed to a controlled environment with lines, may be seen in a story that appeared in the Washington Post on February 14, 1973. At that time, price controls had become binding even without a vorld oil supply interruption. As a result, significant price differences existed between controlled U.S. and controlled foreign markets. Consequently:

\begin{abstract}
Mexicans are crossing into California to fill their tanks, while Californians are stealing into Tijuana to do the same. A :-exican ssasc: orner said his countrymer viere fici- into San Diego county, where gas is jette: quality and cheaper by $7 c$ per gallon. In Ciula Vista, on the U.S. side, a station owner said that Americans are driving into Tijuana because fuel isn't rationed and there are no waiting lines.
\end{abstract}

Clearly this demonstrates that the effective price of a product includes an evaluation of the non-price attributes of the product (such as waiting time) and that different consumers place different values on those attributes. In the next chapter, we advance a theory regarding the nature of the constraint that governed rates of price increase in domestic petroleum markets during 1979. 
Table 9

UNRECOUPED COSTS FOR REFINED PRODUCTS

FOR 29 LARGEST REFINERS

\begin{tabular}{|c|c|c|c|c|c|}
\hline Year & Month & $\begin{array}{c}\text { Motor } \\
\text { Gasoline }\end{array}$ & $\begin{array}{l}\text { Jet } \\
\text { Fuel }\end{array}$ & $\begin{array}{c}\text { Other } \\
\text { Products }\end{array}$ & Total \\
\hline \multirow[t]{12}{*}{1977} & January & 901 & 166 & 325 & 1,392 \\
\hline & February & 1,038 & 187 & 303 & 1,528 \\
\hline & March & 956 & 180 & 287 & 1,423 \\
\hline & April & 1,029 & 194 & 343 & 1,566 \\
\hline & May & 967 & 224 & 351 & 1,542 \\
\hline & June & 957 & $234^{\prime}$ & 344 & 1,535 \\
\hline & July & 869 & 210 & 391 & 1,470 \\
\hline & August & 764 & 279 & 455 & 1,498 \\
\hline & September & 784 & 186 & 500 & 1,470 \\
\hline & October & 879 & 248 & 511 & 1,638 \\
\hline & November. & 904 & 218 & 538 & 1,660 \\
\hline & December & 818 & 185 & 470 & 1,473 \\
\hline \multirow[t]{12}{*}{1978} & January & 1,055 & 101 & 420 & 1,666 \\
\hline & February & 1,265 & 198 & 435 & 1,898 \\
\hline & March & 1,065 & 175 & 378 & 1,618 \\
\hline & April & 1,013 & 170 & 400 & 1,583 \\
\hline & May & 849 & 186 & 500 & 1,535 \\
\hline & June & 718 & 180 & 562 & 1,460 \\
\hline & July & 713 & 136 & 449 & 1,298 \\
\hline & August & 353 & 74 & 461 & 888 \\
\hline & September & 554 & 155 & 491 & 1,200 \\
\hline & October & 627 & 131 & 701 & 1,459 \\
\hline & November & 709 & 102 & 540 & 1,351 \\
\hline & December & 532 & 94 & 791 & 1,417 \\
\hline \multirow[t]{12}{*}{1979} & January & 836 & 64 & 799 & 1,699 \\
\hline & February & 1,110 & 36 & 842 & 1,988 \\
\hline & March & 1,551 & NA & 837 & 2,388 \\
\hline & April & 2,067 & NA & 1,649 & 3,716 \\
\hline & May & 2,245 & NA & 1,848 & 4,093 \\
\hline & June & 2,737 & NA & 1,754 & 4,491 \\
\hline & July & 2,989 & NA & 2,087 & 5,076 \\
\hline & August & 2,865 & $\mathrm{NA}$ & 2,331 & 5,196 \\
\hline & September & 3,176 & NA & 2,384 & 5,560 \\
\hline & October & 3,158 & NA & 2,303 & 5,461 \\
\hline & November & 3,492 & NA & 2,302 & 5,794 \\
\hline & December & 3,724 & NA & 1,171 & 4,895 \\
\hline
\end{tabular}

SOURCE: Monthly Energy Review 
NOTES FOR CHAPTER 3

1. Major proponents of this view include Senator Edward M. Kennedy (DMassachusetts) and Congressman Anthony (Toby) Moffett (D-Connecticut).

2. For a review of the literature surrounding this issue, see Wright (1980), pp. 10-11 and 24-25. See also Landsberg et a1. (1979), pp. 80-81.

3. Major among the regulatory policies that canse these geographical disparities to persist is the Crude Oil Buy-Sell Program; see Verleger (1979).

4. Estimates on the level of brokered activity have been obtained from several sources. Included are executives active in the management of product distribution and sales for several large oil refining firms, and the editors of several trade-industry journals which formally report sales activity and pricing.

5. See representative issues of Platt's Oilgram Price Report pre- and post-1976. Conversations with Platt's editors have affirmed that this reasoning was behind the decision to include spot prices in 1976.

6. Examples of outlines of typical supply contracts are available upon request from most major refiners.

7. Federal Energy Administration, Mandatory Petroleum Price and Allocation Regulations: Exemption of Middle Dist1llate. Final Rule, 41 FR 24516, June 16, 1976. 
8. On March 17, 1980, Platt's Oilgram Price Report data indicated the New York Harbor spot price for \#2 distillate to be 73.50 c and the New York Harbor posted price at 76.00c. Given the value of the contract premium, this may be considered parity in these prices.

9. See, for instance, U.S. DOE Hearings on Special Rule 9: Amendment to Provide Middle Distillates for Agricultural Production. \#非A-R-79-25.

10. For some perspective on Midwestern posted prices, see Platt's Oilgram Price Report. We also obtained accounts of pricing patterns from various oil company and agricultural operators in the region.

11. See the Special Rule 9 Hearing Transcript.

12. To arrive at an estimate of the total wealth transfer away from U.S. distillate producers in 1979 , it was necessary to utilize adjusted 1978 figures for U.S. distillate consumption as a surrogate for 1979 production. Due to unavailability of the latter data, 1978 consumption figures were adjusted for imports and for an approximation of the effect of higher prices on demand. This 1979 estimate was then multiplied by the average difference during 1979 between contract and spot distillate prices. While the estimate thus attained is far from perfect, it does give us a persepctive upon the magnitude of wealth transfer that lagged prices caused.

13. This is because the lower the price of contracted oil relative to spot, the greater is the disincentive to sell on the contract market, thus the lower the allocation fractions in contracted markets. But the lower the allocation fraction, the greater is the amount that must be secured from 
the spot market. This greater demand for spot product increases the pressure on the spot market, and this pressure results in higher prices for spot product than might otherwise occur.

14. References to gas lines were widespread in both television and the printed news media. See, for example, May, June and July issues of Time Magazine, the Washington Post, and The New York Times.

15. For a more complete description of the price control framework in gasoline, see Volume 1 of Commerce Clearing House, Energy Management Series.

16. The disincentive to purchase of additional supplies in times of rapid price increases stems from the average cost-based nature of cost passthroughs. Average cost passthroughs ignore the average cost/marginal cost divergence which the firm faces when deciding on the profitability of additional supplies. The profitability of the additional supplies is determined by the marginal cost, not average cost, of those supplies.

17. As a guide to understanding Figures 6 and 7 , the following should be noted: Subscripts 0 and $I$ refer respectively to the two time references chosen with zero denoting the base period and one referring to the altered state. Four superscripts are used: "C", "D", "S", and "-", which refer to various controlled and uncontrolled situations. A "C" denotes the competitive (uncontrolled) solution in which case supply equals demand. A "-" (bar) superscript denotes a controlled price, that is, a price ceiling. In price controlled situations, if the ceiling is binding, supply will not equal demand and the quality supplied is denoted with the superscript "S" and that demanded is denoted by a " $D$ ". 
18. U.S. District Court, District of Massachusetts, Criminal Number 79-314-2. The owner's conviction is currently under appeal before the Temporary Emergency Court of Appeals. Docket number TECAl-7. 
Chapter 4

POLITICAL PRESSURE ANALYSIS OF

INTRA-U.S. PRICING PATTERNS

We have observed major inefficiencies in the pricing of the two most widely consumed petroleum products in times of market transition. This inefficiency is the result of the observed tendency for firms in the industry to charge prices below market-clearing levels during periods of world crude oil supply constriction. This tendency is most serious among refiners and, particularly, oil companies. Marginal suppliers in uncontrolled petroleum markets behave in a manner which assures that the markets clear. Incontrolled products, however, the underpricing trend exacerbates the inefficiencies inherent in the price control framework and results in a market seriously hampered in adjusting to new world and U.S. market conditions.

This study now turns to the task of devising a theoretical explanation that accounts for the pricing patterns observed in oil product markets. We note at the outset that more empirical work is needed on the actual pricing strategies of firms in these markets. Modeling the incentives and disincentives perceived by individual firms over time, and examining the exact relationship of firms' prices to their average and marginal levels, will yield a more precise picture of the causes of the pricing patterns governing U.S. refined product markets. We begin the theoretical analysis, by examining the validity of two somewhat related hypotheses regarding oil industry pricing strategy that have been advanced by policy-makers over recent years. The first is that oil company pricing is simply based on average rather than marginal costs and that, as a result, low major company prices simply reflect the fact that these firms procure most of their product from cheaper sources. This has been particularly 
alleged for member corporations of Aramco. The second is that these companies are pricing below each other in an attempt to expand their market shares, or otherwise gain a competitive advantage with regard to one another during the transition process.

While the average-cost-based pricing theory has been advanced to explain pricing patterns in various industries, observational data suggest that it does not describe the typical behavior of firms in the petroleum industry. ${ }^{1}$ The theory of average-cost-based pricing is behavioral in nature and, in essense, hypothesizes that firm managers will attempt to approximate the "right" price for their product through a markup above the average cost of production because they possess imperfect information regarding the market. This behavior is more likely to occur the greater the degree of stability and complexity (strong product differentiation, etc.) in the market.

The greater the stability of the market, the greater will be the stability of the relationshlp belween average and marginal cost. Further, the greater the degree of complexity in the market, the more difficult it is to determine prevalent cost and demand conditions, and thus, the more likely are average-costbased rules to be used as surrogates.

It is clear that those conditions conducive to average cost pricing are not met in the oil industry. Complexity of the sort that obscures the marginalaverage relationship seems minimal in this industry, where it appears that the marginal nature of spot markets and the effect of marginal supply availability and price on firms' ability to meet supply obligations is evident to most industry actors. Further, the notable lack of stability in this market over the last several years would lead firms to rely less heavily on average-costbased rules. The oil industry actors are apparently too sophisticated and the market is too dynamic for its managers to conform to the behavioral norm of average-cost-based pricing. Of course, it may indeed be the case that the pricing 
of certain firms in the industry does approximate their average costs (or standard markups over their average costs) in periods such as 1979. This is not explained, however, by the hypothesis that this is the intent of the actors in the industry. Rather, it is the result of certain preceived incentives that exist in the marketplace that lead otherwise marginal-cost-pricing firms to deviate from their usual behaviọ.

The second, market share-based theory regarding the strategy of oil firm during periods of market transition rests upon several questionable assumptions regarding oil industry market structure and the interactions of firms which arise in response to this structure. Many policy-makers have voiced the belief since 1973 that interests in the oil market are such that oil companies engage in predatory conduct vis-à-vis one another during periods of adjustment and uncertainty. Specifically, with regard to pricing activities, one theory suggests that price cutting may occur between firms as those firms jockey for competitive advantage in the market. ${ }^{2}$ The two most often-voiced allegations that arise from this belief are: 1) that major firms act in such as way as to squeeze independent. oil companies out of the market; and 2) that they attempt to increase their share of the market with regard to their competitors. In both of these views, price becomes a weapon, and price deviations allow the firm the opportunity to expand its market territory and its influence over market activities.

The most critical aspects of the independent marketers' argument have been addressed in Section 3.1.3. In the present context, "market control" theories, we shall call them, suffer from a misunderstanding of the economist's use of the term "competition".

"Competition" to the layman suggests an image of inter-rival competition. Therefore, to define an industry as "workably competitive" carries the implication that firms compete with each other, sparring in the marketplace. The economic definition of competition, however, carries certain implications that are the 
opposite of those that policy-makers generally perceive it to have. In the economic sense, the generally accepted conclusion that oil markets are workably competitive means that firms in the oil industry generally do not perceive an ability to influence, their structural position in the market vis-à-vis their competitors by altering prices. The textbook definition of the competitive form does not suggest that the firm will "joust" with its rivals in the arena in order to gain a competitive advantage. Rather, simply put, quite the opposite is the case. Competitive firms perceive themselves as able to sell any amount of the commodity which they provide at the price demanded in the marketplace. If a competitive firm is forced for some reason such as political pressure to lower its price below the rest of the market, the result will be a decrease in its output, and thus a shrinkage in its market share (because, in general, marginal costs are expected to rise as output rises). ${ }^{3}$

The sort of intercompany price maneuvering and strategizing, which some policy-makers suggest characterizes the oil industry, is not competitive behavior in the economic sense, but is defined as oligopolistic behavior. Rivalry rather than competition is the term economists use to describe such behavior. This interdependent behavior generally stems from a market so concentrated as to be inadequately competitive, with so few sellers controlling such a large part of the market that their pricing decisions direction affect each other's market standing. According to the bulk of available economic research, the U.S. oil, refining, distributing and marketing industry is not oligopolistic in nature. ${ }^{4}$ Thus, while firms as large as those in this industry are not completely ignorant of each other, it is not expected that the individual firm's market position with respect to its rivals dominates or even significantly influences its short-term pricing strategy.

In short, average cost and market control theories of the pricing behavior of firms in the oil industry do not adequately explain the incentives that 
result in the transition-period market behavior investigated above. In this chapter, we advance an alternative theory regarding the origins and nature of this pricing behavior. This theory is based on the increasing politicization of oil markets that has occurred in concert with the oil price increases of the last decade. It suggests that the oil market conditions observed in 1979 stem from the emergence of a market whose sellers are subject to more or less overt political pressures that constrain them from raising price beyond certain levels. Sellers in the market price so as to balance the costs of acting contrary to political pressure against the returns from higher prices. The perceived costs of acting against the political constraint by raising prices include: the increased probability of product recontrol; the tightening of existing controls; threats of congressional action to break up the oil industry; threats of expropriative taxes; and damage to the seller's public image by policy-makers who have access to the media.

In Section 4.1 we develop a model to describe the pricing restraint that dominated petroleum product pricing in 1979. In Section 4.2, we examine specific facets of that model in some detail, paying special attention to the interactions that tie the various components of the model together. In Section 4.3, we summarize the main results of the model developed in 4.1 and 4.2 .

\subsection{A Model of the Political Pricing Constraint}

Figures 8 and 9 provide a representation of the model we believe describes the pricing constraint affecting firms in the oil industry during periods of world supply constriction. Figure 8 presents the elements of this model, while Figure 9 offers a complementary view in flow-chart form. The latter outlines primary functional ties as well as secondary relationships, both of which are discussed in this chapter.

The degree of induced restraint a firm shows in its price increase decision 
is determined by two primary factors: 1) the firm's political visibility; and 2) the amount of political pressure generated against the industry as a whole and against the firm itself. We propose that both visibility and political pressure are needed to create a genuine constraint in firm pricing. Either alone does not appear sufficient to cause prices to diverge from their efficient market-clearing levels.

The third major element of the model is the influence of those groups who capitalize on a firm's potential visibility and consumer anger for their own gain. These groups -- politicians, regulators, and the media -- can be termed the "catalysts" of the oil market They act to give form and definition to both the political pressure felt by the firm and the firm's degree of public visibility. Regulators and politicians form the mechanism that translates public dissatisfaction (which we term consumer pressure) with higher prices and/or shortages into enactment and enforcement of punative rules, regulations and laws (political pressure). The media in turn, realizes private gain by catering to consumer preferences by molding and coalescing the public's view of individual firms and the industry as a whole. This translates benign and undirected consumer anger into effective consumer pressure.

The capitalization that is sought by these groups represents entirely rational behavior. These actors, like any others, behave in the manner that best maximizes their own returns given their position in relation to market and political conditions. No negative or perjorative implications are attached to the description of the behavior of these groups. Without the behavioral tendencies that exist among them, the various factors which serve to determine a firm's public visibility would remain simply innocuous facts. Without these catalysts, firms would not feel compelled to constrain price as the pressure of individual consumers would pose no credible threat to them. 5

A varlety of primary factors affect the individual firm's visibility, a 
Figure 8

A PRICING CONSTRAINT MODEL

Degree of Pricing Constraint: PC

$P C=f(V, C)$

Where, $f$ is the firm's decision

function given firm visibility,

$\mathrm{V}$, and effective consumer pressure

(also termed political pressure), $C$.

\section{Catalysts:}

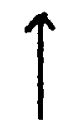

1. The Political Community

2. Regulators

3. The Media

determine visibility, $\mathrm{V}$, and political pressure, $C$, from

$a_{\mathrm{v}}, b_{\mathrm{v}} \ldots$ and $\mathrm{a}_{\mathrm{c}}, \mathrm{b}_{\mathrm{c}} \ldots$

respectively:

$$
v=g\left(a_{v}, b_{v} \ldots\right),
$$$$
\mathrm{C}=\mathrm{h}\left(\mathrm{a}_{\mathrm{c}}, \mathrm{b}_{\mathrm{c}} \ldots\right) \text {. }
$$

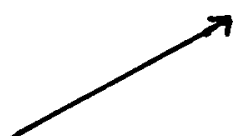

Components of Visibility: V

$a_{V}$ Firm size

$b_{v}$ Absolute profits

$c_{v}$ Increase in profits

$\mathrm{d}_{\mathrm{v}}$ Profit rate (rate of return)

$e_{v}$ Activity in the regulatorypolitical-public arena

$f_{v}$ Type of firm, e.g., "refiner"

NOTE: For simplicity, Figure 8 is. depicted for a "general" firm. For the firm-specific model, see Figure. 9.

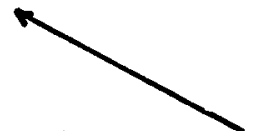

Components of Consumer Pressure: C

$a_{c}$ Rate of price increase

$b_{c}$ Absolute size of price increase

$c_{c}$ Consumers' state of perception

$d_{c}$ Demand cycle for the product

$e_{c}$ Organization of demanders

$f_{c}$ Perception of shortage

$g_{c}$ Response to drawn-out price increase.

$h_{c}$ Secondary response to firm visibility 
Figure 9

FLOWCHART OF PRICING CONSTRAINT MODEL

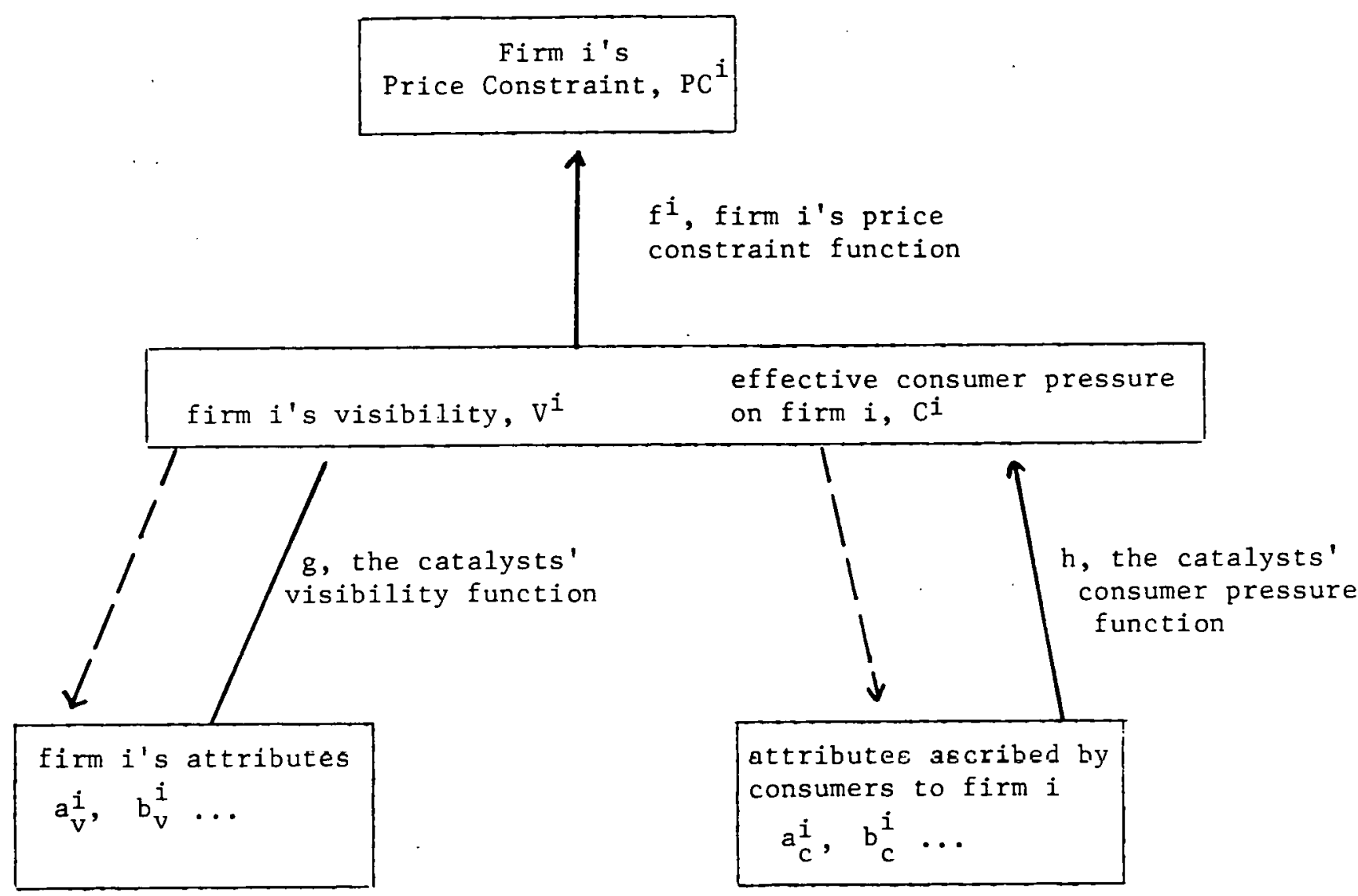

NOTE: Firm attributes tend to be firm specific. Some consumer attributes are applicable industry-wide, for example, $a_{c}^{\frac{1}{c}}-e_{c}^{i}$ in Figure 8 , while others may apply to specific firms, as $f_{c}-h_{c}$. For the former $a_{c}^{1}=a_{c}^{j}, \ldots, e_{c}^{i}=e_{c}^{j}$ for all firms $i$ and $j$ in the industry. 
partial list of which is given in Figure 8. Clearly, no one factor determines the firm's overall visibility and different components in the visibility function, $g$, receive different emphasis for different firms. The task of determining the actual functional form of " $g$ " in Figures 8 and 9 is difficult, if not impossible, given the problem of collinearity that exists among various components. Despite this, it is instructive to examine the roles each of these components can play. in determining a firm's visibility.

The most obvious factor in determining a firm's public image is firm size. The long American tradition of mistrust of bigness in economic affairs provides an effective theme for the pressure catalysts. A second factor determining visibility is firm profitability. Different measures of profitability are used by the catalysts, depending on which will have the most impact in any given situation. The amount of exposure the firm has in public hearings of various types, as well as the firm's advertising activity, also have an effect on the degree of visibility experienced by a firm. Note that this exposure may depict the firm in a positive or negative light; however, whatever the original situation, the visibility is increased. Last, the type of firm and its scope of activities may affect its visibility; companies with retail outlets, for example, are likely to be more visible than companies that only sell crude oil.

In contrast with firm visibility, the amount of political pressure emanating from the consumer side probably arises primarily as pressure applied to the industry as a whole and only secondarily as pressure applied against spectfic firms. The major factor that contributes to increased consumer pressure and, thus, to increased political pressure is, understandably, higher prices for the product. Public discontent is also greater in the face of price increases when the demand for the product is high: heating oil price increases in midsummer generate less anger than equivalent increases in midwinter. Furthermore, if demanders are well-organized, they can more easily obtain the attention of 
the politicians, regulators, or media. Consumers' perception of what is normal and abnormal in the market in such matters as pricing also determines the pressure consumers exert; and it is important to note these perceptions may easily change with time. For instance, consumer anger will tend to be greater over initial price increases than over similar increases which occur after a priceincrease trend has been established. On the other hand, consumers may increase their dissatisfaction if prices are still rising long after the real or perceived cause of the price rise has ceased. This catches firms which lagged prices during the disruption in a bind, for while their price lagging strategy made them less susceptible to public attack during the disruption, they then must continue raising prices in order to catch up. Further, pressure against the industry or a firm is likely to increase in response to either political or media-based reports about the industry or the firm that increase visibility. Finally, consumer pressure will be increased by shortages: shortages necessarily imply consumer-borne shadow prices in excess of quoted prices.

\subsection{Description of Pricing Constraint Factors}

In this section, we discuss in more detail the pricing constraint model outlined above. Each component of the model is described, and its ties to other parts of the model are introduced. Examples are drawn from the market turmoil of 1979 to illuminate the theory.

The various components are discussed sequentially. However, it is important to keep in mind the manner in which any specific part of the model interacts with the rest. In Section 4.2.1 we discuss the top end of the model, the pricing conctraint itself (denoted $f$ in Figures 8 and 9 ). We also present firm specific data showing the ultimate result of the pricing constraint during 1979. This data is discussed in detail in subsequent sections. Next, in Section 4.2.2, we discuss the crucial role the catalysts play in this market. 
Their role is important because, in our terminology, they turn consumer pressure into credible political pressure. Section 4.2 .3 examines the firm's side of the market; specifically, the components and interactions that lead to a firm's visibility. Section 4.2 .4 presents an analysis of consumer pressure and the various components that comprise it. Finally, insights into the pricing constraints feit in price-controlled markets are offered in Section 4.2.5.

\subsubsection{The Pricing Constraint}

We may view the firm's pricing decision function (denoted $f$ in Figures 8 and 9 ) as the firm's profit maximizing decision, constrained by a probability of undesired political consequences. The firm essentially makes its price lag decision based on a risk analysis of alternative price constraint scenarios. The firm calculates the optimal tradeoff between the increased profits and the increased risk of regulatory retribution, both of which become greater the higher the firm raises its prices.

It is important to note that the visibility and political pressure components of the price constraint function enter in an essentially multiplicative fashion. Either component on its own is generally not sufficient to constrain effectively a firm's prices. If a firm perceives its public visibility as minimal, then political threats have less credibility -- political threats hold returns for politicians or regulators only when they cater to some public demand. In the presence of low visibility, the firm acts as an effective free rider. In other words, a firm with low visibility depends on the price lagging behavior. of high visibility firms to shield it from retributory actions that it would otherwise risk from its decision not to lag prices. Conversely, if a firm perceives that political pressure is nil, that is, if visibility does not induce credible threats from the political community or regulators, then it will not feel compelled to lag prices. 
The price response that we would expect from oil companies during times of steeply increasing world oil prices, given the goal of establishing the optimum tradeoff between maximizing short-term profits and minimizing the probability of regulatory retribution, is to lag prices in oil products. This lag serves as a buffer between the world oil market and the American oil-consuming public. The amount and duration of price-lag could be expected to be dependent upon the size of the world oil market's price increase and the length of the period over which the increase takes place.

Tables 5 and 6 above show the pricing trends of major refiners and independent sellers of distillate during 1978 and 1979. Table 10 presents further breakdowns of price data among major refiners. Again, relative to an efficient spot norm, significant lags are shown. Table 11 offers the size statistics for the firms presented in Table 10. These tables, as well as Tables 5 and 6 , provide a sufficiently detailed perspective on pricing trends within the industry to allow detailed examination of the facets of the pricing constraint, where it originates, and how it operates. These examinations are presented in Sections 4.2.2 through 4.2.5 utilizing the data presented in these tables.

\subsubsection{The Catalysts}

Three groups, which are actors in the political marketplace, constitute the catalysts between consumer anger over higher prices and the pricing actions of firms. Without the presence and observed activity patterns of these groups, public anger over price increases might not be focussed on oil companies at all, and certainly would have few if any tangible effects on oil price decisions, however intense that anger might become. Of the three groups, two constitute the mechanical link between public anger and higher prices. These are the political and regulatory communities. The third group -- the media -- performs the crucial functions of linking prices increases to firm responsibility and of 
Table 10

\section{POSTED WHOLESALE PRICES \\ \# 2 OIL, NEW YORK CITY, \\ 1978-1979}

( 4 observations per month)

\begin{tabular}{|c|c|c|c|c|c|}
\hline Month & Exxon & Mobil & Sunoco & Amoco & Citgo \\
\hline \multirow[t]{3}{*}{ January } & 36.50 & 37.00 & 37.05 & --- & 36.85 \\
\hline & 36.50 & 37.00 & 37.05 & -- & 36.85 \\
\hline & 36.50 & 37.00 & 37.05 & -- & 36.86 \\
\hline \multirow[t]{4}{*}{ February. } & 36.50 & 37.00 & 37.05 & -- & 36.85 \\
\hline & 36.50 & 37.00 & 36.55 & -- & 36.85 \\
\hline & 36.00 & 36.50 & 36.55 & --- & 35.85 \\
\hline & 36.00 & 36.50 & 36.55 & --- & 35.85 \\
\hline \multirow[t]{4}{*}{ March } & 36.00 & 36.50 & 36.55 & --- & 35.85 \\
\hline & 36.00 & 36.00 & 36.55 & --- & 35.85 \\
\hline & 36.00 & 36.00 & 36.55 & --- & 35.85 \\
\hline & 36.00 & 36.50 & 36.55 & --- & 35.85 \\
\hline \multirow[t]{4}{*}{ April } & 36.00 & 36.50 & 36.55 & --- & 35.85 \\
\hline & 36.00 & 36.50 & 36.55 & --- & 35.85 \\
\hline & 36.00 & 36.50 & 36.55 & --- & 36.10 \\
\hline & 36.00 & 36.50 & 36.55 & -- & 36.10 \\
\hline \multirow[t]{4}{*}{ May } & 36.00 & 36.50 & 36.55 & -- & 36.10 \\
\hline & 36.00 & 36.50 & 36.55 & --- & 36.00 \\
\hline & 36.00 & 36.50 & 36.55 & --- & 36.50 \\
\hline & 36.00 & 36.50 & 36.55 & --- & 36.50 \\
\hline \multirow[t]{4}{*}{ June } & 36.00 & 36.50 & 36.55 & -- & 36.50 \\
\hline & 36.00 & 36.50 & 36.55 & -- & 36.50 \\
\hline & 36.00 & 36.50 & 36.55 & --- & 36.50 \\
\hline & 36.00 & 36.50 & 36.55 & --- & 36.50 \\
\hline
\end{tabular}


TABLE 10 (continued)

1978

\begin{tabular}{|c|c|c|c|c|c|}
\hline Month & Exxon & Mobil & Sunoco & Amoco & Citgo \\
\hline \multirow[t]{4}{*}{ July } & 36.00 & 36.50 & 36.55 & --- & 36.50 \\
\hline & 36.00 & 36.50 & 36.55 & --- & 36.85 \\
\hline & 36.00 & 36.50 & 36.55 & --- & 36.85 \\
\hline & 36.00 & 36.50 & 36.55 & -- & 36.85 \\
\hline \multirow[t]{4}{*}{ August } & 36.00 & 36.50 & 36.55 & --- & 36.85 \\
\hline & 36.00 & 36.50 & 36.85 & --- & 36.85 \\
\hline & 36.00 & 36.50 & 36.85 & $-\cdots$ & 36.85 \\
\hline & 36.50 & 36.50 & 37.25 & --- & 37.75 \\
\hline \multirow[t]{4}{*}{ September } & 36.50 & 37.00 & 37.25 & --- & 37.75 \\
\hline & 36.50 & 37.50 & 38.25 & --- & 37.75 \\
\hline & 36.50 & 37.50 & 38.25 & --- & 37.75 \\
\hline & 36.50 & 37.50 & 38.25 & --- & 37.75 \\
\hline \multirow[t]{4}{*}{ October } & 37.50 & 37.50 & 37.25 & --- & 38.75 \\
\hline & 37.50 & 37.70 & 38.25 & --- & 38.75 \\
\hline & 37.50 & 38.20 & 38.25 & --- & 38.75 \\
\hline & 38.50 & 38.20 & 38.25 & -- & 39.45 \\
\hline \multirow[t]{4}{*}{ November } & 38.50 & 39.20 & 39.35 & --- & 39.45 \\
\hline & 38.50 & 39.70 & 39.35 & --- & 40.15 \\
\hline & 38.50 & 39.70 & 39.35 & --- & 39.95 \\
\hline & 38.50 & 40.20 & 40.70 & -- & 39.95 \\
\hline \multirow[t]{4}{*}{ December } & 38.50 & 40.20 & 40.70 & -- & 40.45 \\
\hline & 38.50 & 40.20 & 40.70 & --- & 30.45 \\
\hline & 39.20 & 40.80 & 40.70 & -- & 40.45 \\
\hline & 39.20 & 40.80 & 40.70 & -- & 40.45 \\
\hline
\end{tabular}


TABLE 10 (continued)

1979

\begin{tabular}{|c|c|c|c|c|c|}
\hline Month & Exxon & Mobil & Sunoco & Amoco & Citgo \\
\hline \multirow[t]{4}{*}{ January } & 39.20 & 40.80 & 40.70 & --- & 40.45 \\
\hline & 39.20 & 40.80 & 40.70 & -- & 41.45 \\
\hline & 39.20 & 40.80 & 40.70 & -- & 41.45 \\
\hline & 40.00 & 41.30 & 40.70 & --- & 41.45 \\
\hline \multirow[t]{4}{*}{ February } & 40.00 & 41.80 & 40.70 & --- & 41.45 \\
\hline & 40.00 & 42.80 & 43.50 & -- & 41.95 \\
\hline & 41.50 & 42.80 & 43.50 & --- & 43.45 \\
\hline & 41.50 & 43.80 & 44.50 & --- & 43.35 \\
\hline \multirow[t]{4}{*}{ March } & 41.50 & 44.80 & 45.50 & --- & 45.25 \\
\hline & 44.00 & 45.80 & 46.65 & 46.10 & 45.40 \\
\hline & 44.00 & 45.80 & 46.65 & 46.10 & 45.40 \\
\hline & 44.00 & 46.80 & 47.90 & 46.70 & 45.40 \\
\hline \multirow[t]{4}{*}{ April } & 44.00 & 46.80 & 48.90 & 46.85 & 46.40 \\
\hline & 44.00 & 46.80 & 48.90 & 46.85 & 46.40 \\
\hline & 45.50 & 46.80 & 50.40 & 47.85 & 49.40 \\
\hline & 47.50 & 47.80 & 50.40 & 48.85 & 50.16 \\
\hline \multirow[t]{4}{*}{ May } & 47.50 & 47.80 & 51.40 & 50.55 & 50.16 \\
\hline & 47.50 & 48.80 & 52.40 & 50.55 & 51.65 \\
\hline & 49.50 & 48.80 & 52.40 & 50.55 & 50.60 \\
\hline & 50.50 & 48.80 & 51.25 & 51.80 & 53.35 \\
\hline \multirow[t]{4}{*}{ June } & 51.50 & 49.80 & 60.00 & 58.10 & 60.40 \\
\hline & 57.50 & 55.80 & 60.00 & 60.10 & 62.40 \\
\hline & 57.50 & 58.30 & 60.00 & 60.10 & 62.40 \\
\hline & 57.50 & 57.30 & 58.85 & 59.25 & 59.35 \\
\hline
\end{tabular}


TABLE 10 (continued)

1979

\begin{tabular}{|c|c|c|c|c|c|}
\hline Month & Exxon & Mobil & Sunoco & Amoco & Citgo \\
\hline \multirow[t]{4}{*}{ July } & 54.50 & 53.80 & 60.00 & 58.10 & 60.40 \\
\hline & 57.50 & 55.80 & 60.00 & 60.10 & 62.40 \\
\hline & 57.50 & 58.30 & 60.00 & 60.10 & 62.40 \\
\hline & 57.50 & 57.30 & 58.85 & 59.25 & 59.35 \\
\hline \multirow[t]{4}{*}{ August } & 57.50 & 60.80 & 62.10 & 64.40 & 64.40 \\
\hline & 57.50 & 62.30 & 63.45 & 63.55 & 63.35 \\
\hline & 57.50 & 63.30 & 64.50 & 66.90 & 66.40 \\
\hline & 59.50 & 64.80 & 66.50 & 66.90 & 68.40 \\
\hline \multirow[t]{4}{*}{ September } & 62.50 & 64.80 & 66.50 & 66.90 & 74.40 \\
\hline & 62.50 & 64.80 & 66.50 & 66.90 & 74.40 \\
\hline & 62.50 & 64.80 & 68.50 & 69.40 & 74.40 \\
\hline & 26.50 & 64.80 & 68.50 & 69.40 & 74.40 \\
\hline \multirow[t]{4}{*}{ October } & 62.50 & 64.80 & 68.50 & 69.40 & 72.90 \\
\hline & 62.50 & 64.80 & 68.50 & 69.40 & 72.90 \\
\hline & 62.50 & 64.80 & 68.50 & 69.40 & 72.90 \\
\hline & 62.50 & 64.80 & $6 \dot{8.50}$ & 69.40 & 72.90 \\
\hline \multirow[t]{4}{*}{ November } & 62.50 & 64.80 & 68.50 & 69.40 & 72.90 \\
\hline & 62.50 & 64.80 & 68.50 & 69.40 & 69.90 \\
\hline & 62.50 & 64.80 & 68.50 & 69.40 & 69.90 \\
\hline & 62.50 & 64.80 & 68.50 & 69.40 & 69.90 \\
\hline \multirow[t]{4}{*}{ December } & 62.50 & 64.80 & 68.50 & 69.40 & 70.72 \\
\hline & 62.50 & 64.80 & 69.50 & 69.40 & 70.72 \\
\hline & 65.50 & 66.80 & 71.50 & 73.40 & 70.72 \\
\hline & 65.50 & 66.80 & 71.50 & 73.40 & 70.72 \\
\hline
\end{tabular}

SOURCE: Oil Buyers Guide, East Cost Terminal Price Summary, January 1978December 1979. Petroleum Publications, Lakewood, New Jersey. 
Table 11

COMPARISON OF FIRM SIZE TO

AVERAGE 1979 DISTILLATE PRICING PATTERNS

\begin{tabular}{|c|c|c|c|c|c|}
\hline Firm & $\begin{array}{c}\text { Size-Volume } \\
\text { of Sales } \\
(\$ 000) \\
\end{array}$ & 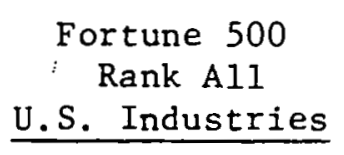 & $\begin{array}{l}\text { Ordinal } \\
\text { Size Rank } \\
\text { In Sample } \\
\end{array}$ & $\begin{array}{l}\text { Average } \\
1979 \text { Price }\end{array}$ & $\begin{array}{l}\text { Ordinal Rank } \\
\text { of Average } \\
\text { Price for Sample }\end{array}$ \\
\hline Exxon & $79,106,470$ & 1 & 1 & 55.9 & 1 \\
\hline Mobil & $44,720,908$ & 3 & 2 & 57.4 & 2 \\
\hline Amnsn* & $1.8,610,347$ & 10 & 3 & 60.7 & 3 \\
\hline Sunoco & $10,666,000$ & 20 & 4 & 60.9 & 4 \\
\hline Citgo ** & $6,276,500$ & 47 & 5 & 62.3 & 5 \\
\hline
\end{tabular}

\footnotetext{
* Standard Oil of Indiana

$\star *$ Citics Service
}

Methodology for Prices: Refiners average posted prices by week were averaged to obtain an estimated average 1979 price. Price series used for averaging is displayed in Table 10, and begins with the second March observation, as the data series across refiners are incomplete prior to this date.

SOURCES: Fortune Magazine, May 5, 1980

Oil Buyers Guide, March - December, 1979

Price data from Table 10 
providing a forum through which the organizers of consumer interest groups operate.

\subsubsection{The Media}

The media plays the primary role in disseminating information to the public about the operation of oil markets. For the purpose of the model of political pressure examined here, it is the manner in which the news media reports oil price stcries that creates the link between oil price increases and oil Indusley culpatility. Without attributinn by the media, the oil price increase news of 1979 , for instance, might have had no major American villains in the public perception. It appears that the media can capitalize on the public's readiness to blame U.S. oil companies for increased prices by calling attention to the oil market situation without providing reasoned judgments regarding the causes of U.S. oil industry actions. Accurate representations of the market conditions which lead to results such as price and profit increases are often eclipsed by the attention focussed on the results themselves. Repeated media demands for "justification" by oil company executives for price and profit increases belies a tendency for a "good guy/bad guy" view of economic events, as well as a presupposition of causality, if not culpability.

News media behavior appears to reflect the interaction of three factors. First, and most importantly, it is clear that the news media have economic incentives to cater to the entertainment value inherent in a news item that affects such a vast number of Americans. They appear to play oil market disturbance stories in such a manner as to capitalize on consumer demand for drama and morality plays. Since dispassionate and detailed information on the true nature of oil price increases is of little use to the typical consumer, media firms which provide such information are likely to be at a disadvantage in the competition for audience. Second, the market served by most media firms, 
particularly television firms is a market of consumers. Consequently, media firms with a consumerist approach are often at a competitive advantage. Third, because consumerism sells in the media marketplace, the news analysts most likely to prosper are often those that are motivated by genuine pro-consumer sentiments and that possess many of the same misunderstandings of the nature of economic behavior as consumers themselves, e.g., believing that U.S. oil companies can somehow be "forced" to lower prices without damage to their industry or to the economy as a whole. Note that all of these conclusions about media behavior flow directly from economic incentives and in no way impinge the motives of media firms.

\subsubsection{The Political Community}

Among politicians, there appears to be a perference for gradual increases in oil price levels. Gradual increases carry less political fallout. Indeed, graduation in oil price changes has been a key part, if not the cornerstone, of federal energy policy since Phase II of the Nixon Administration's price control program. ${ }^{6}$ Gradualism, moreover, is consistent with economic models of political behavior. 7

The nature of the American political marketplace is such that the politician must remain to some significant extent responsive to constituents in order to remain in office. Thus, as actors in the political process, politicians must be quite responsive to the widespread public discontent with the U.S. oil industry -- discontent that is heightened during periods of rapid price increase. The oil companies have demonstrably had much to fear from the political: results of an ill-informed and angry American public. Beginning with the EPAA price and allocation control framework in 1973, a long list of regulatory and legislative efforts has been aimed at the industry in response to higher petroleum product prices. In addition to EPAA, EPCA, and ECPA, Initlatives and threats which have emanated from Congress and the executive 
branch over the past several years include:

- Regulation of heretofore unregulated sectors of and activities in the industry (such as the proposals for controlling refinery production levels and yields which were made by DOE in 1979).8

- Recontrol of decontrolled products (such as distillate, as was proposed in 1979)?

- Tightening of existing controls (such as the proposals for the elimination of cost banks in gasoline which were made in Congress and DOE in 1979). 10

- Vigorous prosecution for "violations" of arcane regulations (such as stepped-up prosecution for "price-gouging" in controlled products). 11

- Threats of congressional action to legislate alterations in the corporate structure of oil industry (such as the vertical and horizontal divestiture legislation that has been introduced in several post-1973 Congresses). 12 :

- Threats of legislative restriction on the future structural characteristics or behavior of firms in the oil industry (such as legislation introduced in 1978 and 1979 to prevent U.S. oil companies from participating in the development of nonoil energy sources). 13

Clearly, this partial list of threats to the oil industry's well-being has been sufficient to induce industry actors -- at least, those highly visible. ones -- to take actions to avert these or other similar measures. Given their cause, political threats are best dissipated through pricing patterns designed to minimize public anger during times of sharp world oil price increases.

\subsubsection{The Regulators}

The regulator can be viewed as the agent charged with carrying out the broad policy goals laid out by the politicians. In this task, the regulator has considerable discretion. In fact, there are several initiatives a regulator may take which aid the politician in the restraining of oil price increases, of which two predominate. First, the regulator has an ongoing interaction with firms in the oil industry. As a consequence, regulators of teri possess information regarding industry operation that is not readily available to politicians. 
in developing anti-industry threats. Second, the effectiveness of any policy initiative is in large part due to the zeal of regulatory implementation. For instance, the increased incidence of "overcharge" prosecution by DOE in 1979 was a function of regulatory effort rather than of policy making. ${ }^{14}$ Thus, by providing information to the political community and increasing or decreasing the vigor of regulatory enforcement, the regulatory community can have a strong impact upon the credibility of the political threat. This imbues the regulators with some power in determining the effectiveness of politicians' threats, and thus with substantial opportunity to maximize his or her personal capital in the process.

\subsubsection{Price Guidelines of the President's Council on Wage and Price Stability:} A Case Study of the Catalysts in Action.

Many policy makers, business analysts, and economists have expressed the strong belief that the major interference with free-market pricing patterns in oil markets during 1979 stemmed from the constraints on price increases embodied in the guidelines set forth by the President's Council of Wage and Price Stability (COWPS). Several economists (e.g., Jacobs, 1980) have analyzed the COWPS guidelines and related them to 1979 oil pricing patterns in some detail; the conclusion has been that the guidelines have accounted for many of the odd and otherwise unexplainable relationships between prices in different products. ${ }^{15}$ What remains is to examine how the COWPS guidelines fit into a political pressure theory of market pricing.

To understand the relationship between COWPS and our political pressure theory, it is necessary to examine why COWPS served as a constraint in the market at all. For what is remarkable about the guidelines -- particularly regarding our theory -- is that they had significant effect, given their voluntary nature. Apparently the outgrowth of a political goal to dampen price increases, the Council's guidelines did not constitute légally binding 
regulations. Certain penalties ensued if they were violated, but violation did not result in the sort of criminal penalties that stem, for example, from violating EPAA price control guidelines. It was the nature of the perceived violation penalties under COWPS that render the guidelines so pertinent to our theory.

Violation of COWPS guidelines brought only one statutory penalty: the Council could recomend to the Federal office of Procurements that the violator be denied new federal contracts in excess of $\$ 5$ million (there was no retroactive authority over these contracts, only the perogative to recommend the: dismissal of new awards). ${ }^{16}$ This authority -- exercised only a couple of times in 1979 -- was minimal in scope overall. According to the Office of Procurements, no contracts were denied during 1979 on the basis of COWPS recommendations. ${ }^{17}$ Where, then, does the Council's power to influence pricing decisions of large American corporations stem from? We suggest that this power is in fact political in nature, and that COWPS simply represents the focussed embodiment of all facets of our theory regarding the role and behavior of catalysts in the market. Although it may, in a sense, be thought of as another catalyst, it seems more reasonable to view COWPS as an institutional outgrowth of political pressure. COWPS came into existence in order to give one of the catalysts -- the political community -- a vehicle with which to catalyze public discontent and create, selectively, firm visibility. COWP' strong interplay with both the political and media communities throughout 1979 suggests that its primary power was based in generating an effective political-pressure threat to firms. Thus, COWPS represented an institutionalized exemplification of the manner in which the political marketplace generates friction against price Increases.

Two examples will demonstrate the political nature of the coWPS constaint. 
These examples, derived from discussions with COWPS officials, provide a perspective upon the strength of the purely political threat embodied in COWPS, and juxtapose this with the minimal level of threat embodied in the statutory authority of the Council over the granting of contracts.

The first of these examples involves Mobil Oil Company, which on April 3, 1979 was issued a warning by COWPS that it was in violation of the guidelines. Mobil officials took no action either to petition for exemption or to come into compliance before they were publicly listed in violation. Rather, Mobil publicly refused to recognize officially the Council and the guidelines -- even refusing to send attorneys to negotiate with the COWPS staff. COWPS' retaliatory action, as one official put it, was to "let the President know he could be very helpful in carrying the ball on this." 18 The official went on to describe the result.

From the time we notified the President of Mobil's noncompliance and refusal to cooperate, at every press conference and in every public forum, he never failed to mention Mobil. I know that in the two press conferences he held in the month after notification, he called Mobil un-American and irresponsible -- without, either time, being asked about the case. He just brought it up on his own -- he was terrific.

Within the month Mobil was at the negotiating table with us -asking us to call our dogs off, because they couldn't stand the negative publicity. 19

This example clearly demonstrates both the nature of COWPS' ability to enforce its guidelines and how completely this ability rests upon political rather than statutory power. It is clear that the statutory power over contracts which COWPS possessed was not a significant deterrent to the company, as in its initial refusal to cooperate, Mobil could be expected to have weighed the penalties of the funding freeze in formulating 1t. Only when politicallybased pressure was applied did Mobil decide that it was in its interest to comply with COWPS -- that is, it decided to constrain its price increases based upon the political pressure they faced. 
The second case involves a less well-known oil company, Amerada Hess. ${ }^{20}$ In this case, the results are slightly more complicated, but serve to shed more light on the balance between COWP' statutory and political authority. In mid-1979, Hess was found in violation of the guidelines, and like Mobil, the company refused to come into compliance. COWPS issued a recommendation to the Office of Procurement to disallow a contract between Hess and the Department of Defense (DOD) for jet fuel, However, the Procurement Office overrode the COWPS recommendation, citing "national security considerations." Thus, COWP' limited statutory authority was overridden by another federal agency which left Hess facing no direct financial or legal penalties for continued violations of the Council's guidelines. However, in the wake of these developments, as one cowPS official tells it, the following events took place:

We started putting the word out -- quietly, through friends in the press, so as to avoid intergovernmental friction -that there was this boondoggle between Hess and DOD, that Hess was profiteering on its oil products and that DOD was protecting them from gnvernment pressure. Stories started popping up -- and, despite the fact that Hess was violating our guidelines without any real penalty, they came in to negotiate. They complied. 21

This case is yet more interesting than that of Mobil. Hess, although large, is not a well-known oil company; and it seems clear that its low profile is an integral part of its corporate strategy. Thus, in this case, CoWP' political retribution created publicity that was doubly negative for the company because, unlike the effects of COWPS' publicity in the Mobil case, many who read reports of Hess's supposed irresponsibility were forming their first impression of the firm.

In short, the COWPS guidelines offer a clear embodiment of the catalyst function in political price constraint. COWPS provides an institutional fulcrum for credible threats beyond the scope of the Council's statutory authority. Indeed, the price constraint strength of the Council appears to have emanated 
overwhelmingly from its evidently large degree of informal power within the political market process.

\subsubsection{Summary}

Three groups -- the media, the political community, and regulators -together constitute the catalysts in bringing about the effective political pressure that induces certain oil firms to lag in their price increase decisions during periods of sharp upward price pressure. The media's treatment of the price-increase phenomenon turns generalized public anger into directed consumer pressure. The policy-making community, in response to this pressure, restricts or at the very least threatens to restrict various aspects of oil industry behavior in retribution for higher prices. Regulators abet the anti-industry policy process to maximize their own capital with the Council on Wage and Price Stability providing the most striking recent example.

\subsubsection{Determinants of a Firm's Visibility}

Factors on the supply side of the marketplace are used by the catalysts to create the political visibility of firms in the industry, and the industry as a whole, in times of market change. For any given amount of political pressure, this visibility in turn determines the degree of price lagging practiced by the industry as a whole and by individual firms in particular. The characteristics described in this section are generally firm-specific; however, it should be noted that many of the factors in fact have spillover effects on the political visibility of the entire industry.

The decision to lag prices is a firm-specific decision, based on each firm's perception of its own visibility in combination with the degree of effective consumer pressure. Each firm possesses attributes that are combined by the catalysts -- particularly the media -- to create an Individual, firm- 
specific amount of political visibility. The following factors appear to play important roles in creating a firm's political visibility:

- firm size and scope

- firm profitability, including:

- absolute profits

- increase in profits

- profit rate

- activity in the regulatory-political-public arena

of these factors, some, such as firm size, are relatively fixed in character over the short term and are thus predictable and relatively constant in their effect on visibility. Others, such as profitability or activity in the public arena are obviously very volatile, and alter the firm's visibility and thus, ultimately, its pricing decisions over time. It should be noted that the entire array of firm attributes which we have listed are clearly important in determining the firm's visibility. It would be difficult, if not impossible, to determine the actual importance of any specific attribute given the collinearity that it shares with many of the other attributes. For example, Exxon, the largest industrial corporation in the world, with a 1979 sales volume of over $\$ 79$ billion has, as a result of its size, a much larger absolute level of profits than other petroleum corporations. Exxon's visibility increases in the face of reports about its absolute profits. However, given its size, Exxon may actually have experienced a lower profit rate (i.e., rate of return) than other firms in the industry. In this situation, it is difficult to determine which factor actually determined Exxon's 1979 visibility: absolute profitability, absolute size, or both.

\subsubsection{Firm Size and Scope}

Tables 5, 6, 10, and 11 offer support for the assertion that the size of the firm is a major factor in determining its political visibility, and thus 
its level of pricing restraint. Tables 5 and 6 also indicate that refiners appear more constrained in pricing than other actors in the industry.

Perhaps one reason there has not generally been politically-based pricing in industries other than oil that have undergone major price increases in recent years is that those industries generally have firms which are of a much smaller size than firms in the oil industry. The size of some oil industry members relative to other firms is seen by the placement of oil firms within the Fortune 500 list as shown in Table 11. When other commodities have undergone large price increases in the American economy during the last two decades, the industries, characterized by firms which play a smaller and therefore less visible role in the American economy, have generally escaped public notice. Agriculture is a prime example of this phenomenon. When meat prices double, consumers seem to exert little effective attention toward meat producers. Meat producers simply do not loom large in the public consciousness in the way that Exxon, Mobil and other large U.S. oil firms do.

Table 10 presents posted prices charged by five individual refiners at wholesale for distillate in New York Harbor during 1978 and 1979. (These are the individual company data which were aggregated to produce the average large refiner prices in Table 6.) These data suggest that, within the refining sector, size is clearly the overriding determinant of the extent of political pressure felt by a firm. Table 11 shows the relative size rankings of the five oil companies in Table 10 and compares these size rankings with the average price charged for distillate by the firm in 1979. The data show that the two largest companies, Exxon and Mobil, maintain significantly lower prices than the other three throughout the year, and the smallest firm, Cities Service, maintains the highest price. Further, throughout the sample, the size rankings perfectly match average price rankings. 
Given the consistency of the data presented in Tables 10 and 11 , it is probably safe to assume that other large refiners will be pricing in a manner similar to that shown in Tables 10 and 11 . Given this assumption, a comparison of Tables 5 and 6 offers a view of the difference between refiner pricing and pricing of all participants in the wholesaling sector during 1979. In Table 5, we see heating oil and diesel fuel prices of major wholesalers; in Table 6 , average distillate prices for the five refiners surveyed in Table 10. As the refiner prices in Table 6 form a subset of the major sellers figure in Table 5, it stands to reason that those non-refining wholesalers whose prices are also averaged into Table 5 should be substantially above the final Table 6 average prices, as the volumetrically weighted average of these refiner and wholesaler prices is higher than those of the refiners alone.

It should be noted that the comparability of these data series is limited. The price series in Tables 5 and 6 are gathered by different sources, sampling from different firms, and utilizing different survey methodologies. Further, prices in Table 5 are specific to the two major distillate products, while those in Table 6 represent an average price among the sellers surveyed for all distillate at wholesale. Nonetheless, comparison of these two series suggests that refiner prices represented the lower end of the price spectrum in oil products during 1979 .

Why do refiners appear relatively more constrained in their pricing decisions in periods such as 1979? There are probably several elements at work which combine to create the net political visibility which refiners feel; however, absolute corporate size seems the major determinant. Refiners -- all except a small number of very marginal independent refiners -- tend to be far larger corporations than even the biggest actors further down the distribution chain in the oil industry. ${ }^{22}$ several of the attributes that affect refiner visibility are obviously size-related, such as the number of people whom the large firm's. 
actions affect, directly and indirectly. Other factors that may at first appear to relate more closely to other firm attributes such as structure or marketing strategy are, in fact, simply reflections of firm size. An example of this is the fact that refiners deal extensively in national and intemational, as opposed to state or regional, oil markets.

Large firms thus appear to be indulging in a rational tradeoff between the costs of an increased risk of government regulation stemming from price increases and the maximization of profits. As the Vice President of one major company stated in July of 1979 :

We're treading the knife edge in distillate pricing -increasing price just as far as we think it's feasible to without getting re-regulated. If you look at companies bigger than us, they're increasing prices still more slowly; while our customers are buying from us at $75 \mathrm{c}$ and turning around and selling two days later -- sometimes back to us -- at 90c. We're losing a lot of money; but frankly, if I ever got re-regulated in distillate, I'd have to get out of the business. It just wouldn't be profitable for me to stay in. 23

In a situation in which firm size clearly has a great deal to do with firm visibility and thus the level of constraint felt in pricing, we might expect to see small firms acting as free riders, their small size and relative invisibility allowing them to price at market-clearing levels. Notwithstanding this expectation, some pricing constraints were apparently felt by small members of the oil industry during 1979, as a comparison of independents'. prices for distillate products (Table 5) with distillate spot prices (Table 1 or 3) indicates. Among small firms, there appears to have been a prevalent perception that price increases that were not average-cost-justified qualified as "gouging" and that "gouging" was illegal. This perception suggests that information concerning the actual legal and regulatory framework in the market is imperfect among smaller members of the industry. Further, the price control framework which previously dominated the industry has resulted in a set of perceived incentives 
and restrictions among some small businesses which continue to affect adversely their behavior after the regulatory framework itself has been removed. (Without the legal framework of controls, there are no formal prohibitions on pricing for decontrolled oil products.) Moreover, this informational problem has in some instances been promoted and exacerbated by public officials issuing threats centered around high prices and "gouging". 24

Many independent diesel sellers appear to have refrained from purchasing and reselling spot market diesel due to both imperfect information on legal and regulatory matters and considerable direct pressure and threat from consumer groups, notably the trucking industry. Indeed, the case of independent diesel sellers appears to represent an instance in which large size was not required to generate visibility; a highly concentrated consumer group was able to bring effective pressure to bear without the mediation of catalysts. There are many instances in the hearings held on Special Rule 9 in which independent industry members appeared genuinely confused over the rate at which they could raise prices and how the price/supply relationship worked in the market. ${ }^{25}$ Moreover, there were widespread reports among owners and operators of independent diesel truckstops that truckers had threatened pickets, forced shutdowns, and of ten physical brutality if prices were raised to a level at which sellers could afford to sell marginal supplies (that is, spot supplies). 26

\subsubsection{Profits}

We have listed three types of profitability data in Diagram 11 which may cause a firm to experience increased political visibility. It is not the reality of these data, but rather their appearance, which we believe creates harmful 
impacts on firms. During times of concern about oil markets, otherwise benign profitability data may be inflammatory in the hands of the catalysts. Faced with limited time or space for news stories and cognizant of the low entertainment value inherent in a presentation of detailed analysis of corporate data, the media has catalyzed negative political visibility by its presentation of data pertaining to the oil companies' profits.

Oil firm profitability was discussed during 1979 not in terms of profit rates per se, as is appropriate when comparing profitability across industries and across time periode, but in terms of percentage increases in absolute profits and absolute levels of profits. This provided a focal point for consumers' anger over steeply rising prices. Consumers tend to view profits as coming directly out of their pockets -- as, of course they do. Thus, they tend to direct their anger against the companies which they perceive as making the most money at their expense. Consumers do not generally understand the causes and need tor increased prlces during periods of rapidly rising marginal input costs. Nor do they understand the resulting increases in profits that arise when there is a sharp marginal-average input cost divergence. Nor do they understand that these price and profit increases, given a concomitant world-market price increase are unavoidable if economic efficiency is to be maintained. ${ }^{27}$ The media generally does not provide consumers with information about the oil companies' real rate of profits, i.e., their return on equity, corrected for inflation and in comparison with the profit rates of other industrials. It was, for instance, generally not reported that the large increases in profits in 1979 were, in fact, increases relative to the low profits of 1975 through 1978. Less public anger might have been directed against oil companies in 1979 if it had been made clear by the news media that the increases in profits that occurred that year barely brought oil company profitability for 1974-1979 into line with the average profitability of U.S. industrial companies. 
For example, on April 23rd, 1979, CBS broadcast a news item on its evening news program regarding the newly-announced first-quarter profit increases of major oil companies. ${ }^{28}$ Although a large number of firms had announced their increases as of this data, CBS chose to air the data on three, and gave prominant play to only two. In Exxon's case, data were presented so as to show earnings in terms of raw dollars; and these represented a huge absolute amount. Further, the manner in which the story was presented left unclear whether that amount -- $\$ 955$ million -- represented the increase in earnings over 1978, or total earnings for that quarter in 1979. Of course, the latter was the case. Further, it was not made clear that the reason for the high earnings was simply that the firm itself is very large in terms of sales and assets, and that such a dollar-amount of profits might not represent an abnormal return for a firm of its size. Rather, this absolute amount was reported so as to seem virtually criminal. It should be noted that by an alternative definition of profitability, the increase in rate of profit, this particular firm was low by industry standards for that quarter; and was, in fact, below the industry mean. It is clear that the most sensational aspect of the firm's altered financial situation was emphasized by the media. The. conclusion cannot be escaped that this presentation -- both in terms of the particular firm selected and the aspect of profitability data selected -- was made in such a way as to have damaged the firm's and the industry's public image.

In the case of Occidental Petroleum, which was also given heavy play in the CBS story, profits were presented in terms of the rate of increase over the previous year -- with no indication of what effect this increase had on the firm's actual overall profitability rate. It was reported that Occidental had announced earnings "nearly triple" those of the first-quarter of 1978. In this case, what was not reported was that in dollar terms this did not represent a huge or startling amount, as Occidental is a relatively small 
corporation. In fact, its total-dollar profits for that quarter placed it 16 th among American oil refining firms with earnings of $\$ 88$ million.

The partial reporting of these two firms' financial situation, combined with the exclusion of other data and background, constitutes reporting designed to entertain by creating an adverse atmosphere surrounding oil company profitability. Discussions with consumers have shown that such stories left at least some of the American public perceiving that actual corporate rates of profit among companies such as 0ccidental were $300 \%$, as opposed to the true picture of $300 \%$ rates of increase.

In 1979, as this example demonstrates, two aspects of profit data were most widely used in the creation of firms' and the industry's public image: absolute dollar levels of profits and increases in levels of profit. We must note, however, that in protracted periods of world ofl market price increase, absolute rates of corporate profit could also become major public-image constraints, were they to rise to levels significantly above those in other U.S. industrial enterprises.

\subsubsection{Firm Activity in the Political-Regulatory Arena}

Several factors generate the hypothesis that a firm's activity in the political, policy, and regulatory arenas serve to focus attention upon it and thus to increase its political visibility. Firms in the oil industry vary considerably in their participation in, and thus their visibility within, the policy process. Many oil companies are active in this arena, attempting to influence the regulatory and legislative process as it affects the oil industry. As a general rule, firms undertake this sort of activity when they perceive that the climate of policy-making is such that without their participation, the resulting legal and regulatory framework could do more damage to their particular endeavors. However, within this generalization arise marked differences between 
firms, obviously tied to differences in their level of risk-aversion and corporate strategy. Some firms are willing to gamble upon the plus-andminus effects of a high political profile when potential returns are relatively low, while others will only do so when the rewards -- or the costs of not opposing policy activity -- are very high.

As example of the effect of firm participation in the policy process upon its political visibility, and ultimately its pricing constraint, may be found in an exchange which occurred in 1979 between Mobil and the Carter Administration. During the first week in May, Mobil came out in opposition to the Carter Administration's crude oil decontrol policies -- the only major U.S. oil company to do so at the time. This engendered an immediate wrathful reaction from within the Carter Administration. ${ }^{29}$ On June 1, this anger became public and President Carter publicly called Mobil "the most irresponsible corporation in America." The accusation was front-page news in the New York Times the following day and played prominently on network news that evening. 30

The price series for Mobil is displayed in Table 10. Through the beginning of the year, it runs consistently above that of the larger Exxon -- the expected response, given the size differential of the firms. However, in the second week of May, Mobil's price drops below Exxon's and remains consistently below until the third week in July. The date at which Mobil's price drops below that of Exxon corresponds exactly to the time when Mobil began to feel adverse Administration reaction to Mobil's position on decontrol. This suggests that the markedly increased political visibility which Mobil generated through the. active espousal of its anti-decontrol position resulted in a perceived need by Mobil to follow a more restrained pricing strategy for the following two months. In philosophical terms, it is somewhat sobering to consider that the conclusion arising from this section is that, to some degree, dissent from government policies can incur huge costs for a company -- so large that the 
firm may feel forced to "lay low." Mobil seems to have paid dearly in the form of millions of dollars of lost revenues for its disagreement with the Carter Administration. The company's officials apparently perceived that the potential costs of governmental punishment, in the form of increased regulatory pressures, prosecution threats, and other political retribution, were sufficient that the company took immediate steps to offset the adverse visibility that its policy position had generated. They clearly perceived that these costs would outweight the considerable costs of the increasingly lagged prices that were utilized to lower the firm's visibility.

In summary, three primary variables -. firm size, profitability, and firm activity in the policy process -- are utilized by the catalysts to create the political visibility which affects particular firms and the oil industry as a whole. We now turn to an examination of the factors which together comprise consumer pressure -- that is, the variables on the demand side of the market -and their interaction with politiciane and regulators.

\subsubsection{Determinants of Effective Consumer Pressure}

As was the case on the supply side, there are several factors which engender consumer anger at the oil companies. This anger, transformed by the catalysts, creates politically-based consumer pressure which ultimately leads to the pricing restraint seen in the market. It must be re-emphasized that, as with supply-side variables, the existance of the factors detailed here does not automatically lead to an effective constraint on prices. Rather it is the existence of the catalytic political and regulatory communities, which turn general public anger into genuine legal threat, that transforms consumer pressure into political pressure.

Consumer pressure is generally directed at the industry as a whole, although there are secondary, Interactive effects which in some instances serve to make 
consumer pressure firm-specific. Examples of firm-specific factors are $\mathrm{f}_{\mathrm{c}}$, $g_{c}$, and $h_{c}$ in Diagram 11 (shortage perception, response to drawn-out price increase, and secondary response to firm visibility); their interactive nature is discussed later in this section. We examine in detail four genres of variable which we believe to be of paramount importance in determining consumer pressure, and thus ultimately political pressure. These are: the nature of price increases, product demand cycles, organization of consumer groups, and consumer perceptions.

\subsubsection{Price Increases}

The reactions of consumers of oil products to higher oil prices forms the basis of the political pressure felt by oil industry actors during times of rapid price increase. The economic standing of many American consumers and industries is closely tied to the consumption of oil products. For these firms and individuals, large increases in oil prices mean losses in welfare. This ensures that any major change in the price of oil will likely stir a great deal of public discontent. Public reaction against higher prices would not take the form of antipathy toward the U.S. oil industry if the public correctly understood the market situation faced by domestic oil firms during periods of world supply cutback. In their role as price-takers on world oil markets, U.S. firms are not the instigators of price increases, and thus are an inappropriate target for public ire during periods of world oil market disturbance.

The public, generally ignorant of the economics of a supply-demand economy, evidently has a very imperfect understanding of the root causes of the oil price increases they have experienced in recent years. Most centrally, they do not understand the crucial price-determining role of marginal input costs. Moreover, they do not understand that product prices reflect society-wide supply and demand factors, rather than the designs of any individual actors in the 
market. The media have tended to exacerbate and capitalize on informational imperfections. Rather than presenting an analysis of the root causes of higher prices, news organizations have directed the public's attention and anger at the prices themselves, and at the American firms who are charging, or "setting," those prices.

The tendency to blame U:S. oil companies for price increases may stem not only from the sort of imperfect information problem just described, but also from a rational calculation on the part of consumers as to where to direct their anger at higher prices. Consumers and consumer representatives in the policy process may recognize that directing their attention toward outside sources more responsible for price increases, such as the oil exporting nations, does not generally create a direct impact upon U.S. oil price policies. These groups, frustrated by a lack of political potency in world market decisions, direct their anger toward those firms over which they possess more control. The medid aydill apjear to exacerbate and capitalisc on thie tendency, often inciting the public to blame U.S. corporations while doing little to highlight the relationship between U.S. pricing policies and OPEC price hikes or world spot market disturbances. Other catalysts appear to aggrevate this confusion by refraining from providing explanations, in lay terms, of the underlying causes of the higher prices seen by the consumer. Again, it must be noted that regulatory and political catalysts play a crucial role by directing anger into credible anti-oil company threats.

Two aspects of price increases have often been utilized by the catalysts to direct consumer anger and focus political pressure. The first of these is the absolute size of the price increase. Obviously, the larger the increase is in absolute terms, the greater is the level of public discomfort it engenders, and the greater is the potential pressure which may be focussed by the catalysts. Second, rates of price Increase have been utilized by the catalysts to make price 
increases appear more striking than they actually have been when viewed in absolute terms. An oil product price increase of $5 \%$ in a month -- especially if translated into an annualized increase of $80 \%--$ generally seems more startling than the same price increase when viewed in other terms. Such a $5 \%$ increase in distillate in late 1979 would have equated with a less startling 4c per gallon absolute increase in price.

In markets which are not clearing, the visible consequences of disequilibrium serve to create a great amount of public anger. Moreover, shortages are seasonal enough that catalysts can readily utilize them to turn public anger into political pressure. In 1979, the combination of the price/allocation control framework with the price-lagging strategy of major oil companies created a non-clearing market in gasoline. As a result, such nonprice rationing methods as lines and allocation rules (e.g., the odd-even purchasing rule) became fairly widespread. Consumers may perceive lines, allocation rules, and other facets of non-clearing markets as product unavailability in an absolute sense. However, it is important to understand that, in fact, their anger at these elements stems from the fact that the net effect of a non-clearing market is sharply higher shadow prices. Lines, for instance, involve the sacrifice of the valuable time of the consumer. The shadow price of oil is than the pump price plus the value of sacrificed time. Consumer anger over this aspect of price increases, while generally directed across the industry, may also be directed at specific firms, if those firms tend to nonprice ration more than others in the industry.

\subsubsection{Consumer Expectations}

A second major factor in determining the level of public anger created during periods of market disruption is the state of consumer expectations regarding normal versus abnormal market conditions. During the initial 
transition away from relative oil price stability, consumers' expectations have not caught up with the changing market, and increases in prices are noticed with more concern. However, once price increases have worked into general consumer expectation, anger over increases tends to diminish. Thus, companies might lag prices with the expectation not only that they will minimize immediate public conern, but that future price increases will be more and more readily tolerated.

An example that illustrates consumers' changing expectations is given by an analysis of retail gasoline during 1979 and $1980 .^{31}$ This example also illustrates the problems involved in determining the ultimate effect that any specific component of consumer pressure has on the overall level of consumer pressure. In January 1980, the largest monthly increase in recent history was recorded in the retail price of gasoline. Prices increased by seven percent, yet there was relatively little public outcry. A much greater amount of public prcssure had been exerted througlioul 1979 in reaction to increases of much smaller size. In part, the lack of public interest in the January 1980 price increase was due to revised consumer expectations as to what constituted a "normal" price increase, as, by January of 1980, rapidly increasing gasoline prices had come to be perceived as a market norm. However, other factors are also of obvious importance in this situation. Gas lines during May, June and July of 1979 clearly caused a large part of the consumer anger apparent during those months. In further comparing the 1979 and 1980 situations, it must be noted that the January 1980 price increase occurred during the seasonal trough in demand for gasoline. (For a discussion of this aspect of consumer pressure, see the next section.) The collinear occurrence of these various facets leaves no read1ly available methods for determining the relative importance exerted some significant force. 
Consumers' expectations may have both positive and negative effects on consumer pressure, and, ultimately, on firm pricing. Consumers' changing expectations allow refiners to continue increasing prices without incurring significant political costs after the initial period of public reaction against price increases has passed. This is a factor that refiners must take advantage of, because any strategy of lagging prices below efficient levels dictates that prices must continue to increase over a longer period than that in which the actual turbulence in world oil markets occurs, in order to regain parity. For example, world oil markets had essentially re-equilibrated by the late summer of 1979, following the December 1978 Iranian disturbance. However, the wholesale contract gasoline prices of U.S. majors were still increasing in March of 1.980, not yet having achieved parity with U.S. or world spot prices.

While changing expectations may allow'refiners to increase prices during later periods with less public resistance, there is a negative aspect to this drawn out price increase. Consumers experiencing latter-period price increases may note that there is no immediately evident reason for them. Post-crisis price increases, then, may engender suspicion among consumers. Gasoline station operators, and those in oil-intensive industries such as agriculture, are examples of those who have voiced resentment and suspicion over the 1980 catch-up price increases. As one gasoline station operator put it:

Last year they blamed it on Iran. Well, this year there's nothing to blame it on and they're still raising prices on me. They're just trying to get rich and drive us all out of business. 32

This comment encapsulates the double-edged nature of the price-lagging strategy. In the short-term, in the absence of a massive public education program, refiners face few options other than price-lagging. But the strategy certainly creates costs of 1 ts own, in terms of long-term negative public and business perceptions that may come back to haunt the industry. 


\subsubsection{Product Demand Cycles}

The amount of public attention focussed on the market for any individual oil product is related to the demand cycle for that product. In times of heavy product use, or when such a time is imminent, the public is more aware of the market situation of the product than when the product is in relatively low demand: In periods of relatively high demand, this increased public attention causes heightened consumer pressure in response to price increases. This, in turn, influences the pricing pattern for the product, as our model would indicate. This trend may be seen by observing the resellers for the two major distillate products, diesel fuel and home heating oil. These are shown in Graphs $4 a$ and $4 b$, and in Table 5.

Prices for both diesel fuel and home heating oil among major and independent sellers begin the period of market transition at rough parity. Independents then raise their prices for both products at roughly equal rates, to roughly equal levels. This is the price increase pattern that we wuld expect from observing historical pricing patterns in these products, which are functional substitutes; their differing demand cycles have led in past years to price discrepancies of a maximum of 1 to 2 cents per gallon in different seasons. Majors' pricing trends for both products follow a markedly different pattern than independents. Prices for diesel among majors increase at a slower rate than those of independents, with that rate of increase fairly constant through- out the year. Heating oil prices charged by majors, by contrast, follow a yet more markedly different pattern than that followed by diesel. The prices of majors lag behind those of independents during the first quarter. In AprilAugust they achieve parity, but then drop significantly in September and remain relatively constant for the remainder of the year.

This pattern of price increase by majors supports the assertion that public attention and pressure upon prices is a function of consumer sector demand 
cycles. Diesel fuel is in relatively stable demand throughout the year -reflecting its major use in commercial/industrial transportation processes -with a relatively small demand increase due to agricultural use in the summer months. By virtue of this, the political visibility of the product, and thus the constraint of pricing, would be expected to remain relatively constant throughout the year. Thus, the constant and stable rate of lag in pricing that we do in fact observe was not surprising. Heating oil, by contrast, is clearly subject tó seasonal demand fluctuations -- a sizable majority of the year's total consumption of the product occurs in the months from October through March. ${ }^{33}$ In keeping with the model of demand-derived consumer product visibility, we observe a pricing lag through the tail end of the 1978-1979 heating season, commensurate with the product's visibility during this time. Then, from April to July, major companies were far less constrained in pricing behavior and, in fact, were able to increase prices as fast as independents. But in August of 1979, with the high-demand heating season in sight, and increasing political unrest over the prices of petroleum products, the White House and Congress brought remarkably intense political pressure to bear on the majors in the industry in an attempt to keep prices down. ${ }^{34}$ The result is clear from the data: heating oil prices among refiners were actually forced down into rough parity with lagged diesel prices, where they remained for the duration of the high-demand season. 35

\subsubsection{Consumer Group Activity in the Pollcy Process}

Many consuming sectors have formal lobbying entitities. When threatened by oil price increases, these groups bring direct pressure to bear on the catalysts, increasing political pressure. Pressure from these groups usually centers around prices and supply of a single petroleum product, often in a particular consuming sector or region of the country. Therefore, this factor 
is likely to be particularly effective in inducing price restraint by specific firms within specific sectors of the domestic petroleum industry. We provide a detailed analysis of the effect of organized consumer-group pressure on distillate market pricing in 1979 in Chapter 5 of this study.

\subsubsection{Secondary Response to Firm Visibility}

Consumer pressure, and thus political pressure, is generally directed towards the industry overall, that pressure being made viable by the political and regulatory communities. The firm-specific pricing constraint results from the combination of this general pressure with the firm-specific pressure created by the firm's visibility: the less visible a firm is, the more likely it is to free ride on the price restraint of other firms. Although it is not a primary effect, we note that some direct firm-specific consumer pressure may arise in response to the firm's visibility. For example, Mobil's anti-decontrol pronouncement not only caused some degree of increased firm visibility due to its participation in the political process, but the political and media attacks on that company also caused some degree of increased anger to be directed exclusively at Mobil by consumers.

\subsubsection{Pricing Constraint in Controlled Markets}

The model of pricing constraint developed above is not peculiar to unregulated markets. In controlled markets, the corporate concern which breeds reaction to political pressure and engenders a price lagging strategy relates not to recontrol but to more stringent control. In gasoline, the only major product still controlled as of 1979 , we have seen that price controls have been. sufficiently flexible to allow ceiling prices that were generally above narketclearing levels during the post-embargo period. This flexibility has prevented gasoline lines from occurring more of ten and has allowed most sellers to behave 
as if formal controls did not exist when formulating pricing policy. ${ }^{36}$ Consequently, lagged prices in gasoline in 1979 (see Table 8 and Graph 6) were the result of attempts to minimize the political pressure for the imposition of more restrictive, binding controls. Many examples of threats of more restrictive gasoline price controls may be found in 1979. There was much discussion within DOE; at DOE hearings, and in Congress, of eliminating the applicability of the banked-cost passthrough regulations during crisis periods, so that firms could not "take advantage of the shortage" by increasing prices more than could be justified by current average cost increases. Further, there was obviously hope within the oil industry that if pricing during 1979 appeared "responsible," gasoline price controls might be lifted in the near future. It would seem that refiners, particularly major ones, were thus absorbing large cost increases in hopes of, like prisoners, receiving "time off for good behavior."

Interestingly, given the incentives to lag prices, and the potential for political retribution for high prices, the control framework in gasoline may not have been a completely negative factor for refiners, although it was for the economy as a whole. As major firms lagged prices more than control ceilings during 1979, the existence of the price controls themselves gave these firms something to focus public and political blame upon. Similarly, resentment about latter-period, catch-up price increases may have been somewhat defused by the public perception that these price increases were "legal" -- that is, were taking place within the confines of the price-control framework. Refiners, if pressed by politicians or others in the public arena, could point out the regulatory legitimacy of their actions to exonerate themselves.

The control framework was certainly a crippling hindrance in the market as a whole. It prevented, as noted above, a market-clearing short-term price solution during periods of severe refiner price-lag. However, as 1979's pricing patterns indicate, the U.S. oil market has become so politicized that 
major firms and refiners are de facto controlled even when they are free from all formal pricing restraints. Formal control programs may be something of an advantage to firms. At least, the control program demonstrably became a bargaining tool in the political process during 1979 and was utilized to deflect some of the heat away from major refiners.

\subsection{Summary}

The market pricing patterns that emerged in uncontrolled oil products during the market turmoil of 1979 are not easily explained by standard textbook models of marginal cost-based pricing. Further, in controlled products, the binding constraint on the market operation was not the price and allocation control framework, as increases in banked costs over the period show. The model presented here offers a plausible explanation for firm pricing patterns during this period. This model is obviously still in an imperfect state with the precise form of the various functions yet to be determined. llowever, it appears to aid considerably in understanding the behavioral patterns exhibited during the particular kind of market change observed in oil during 1979.

It would appear that a model of the type developed here will remain a necessary tool for explaining pricing patterns during transitional periods in industrial markets characterized by extremely large and visible firms, whose products are utilized by a wide cross-section of the consuming public. Theories of regulation have for some years dealt with the incentive changes that occur with direct regulatory intervention in the marketplace. However, as the case of oil pricing in 1979 demonstrates, the existence of political and regulatory bodies with sufficient scope to regulate, coupled with the expanded influence of the media, can combine to create a binding constraint upon pricing in U.S. markets even without formal regulatory action. This suggests the need to alter our thinking about the manner in which markets in oil and other highly visible products will respond to times of market realignment. 
NOTES FOR CHAPTER 4

1. For a discussion of full cost pricing, see Scherer (1980), pages 184-190.

2. The jargon that is used in economic circles for such behavior is predatory pricing; for a discussion of predatory pricing, see Scherer (1980), pages 335-340.

3. This idealized view of the market ac purely competitive is, of course, only for descriptive purposes. However, in reality, markets rarely conform exactly to the conditions of a purely and perfectly competitive market. As a result, economists must often rely on a less stringent measure of competition, that of workable competition. For a discussion of workable competition see Scherer (1980), pages 41-44. Among the criteria for workable competition listed by Scherer wh1ch deal with priciug are "firms should strive to achieve their goals independently, without collusion," and "there should be no unfair, exclusionary, predatory or coercive tactics" (page 42).

4. See Note 1, Chapter 1.

5. For an excellent exposition on the theory of bargaining and the need for credible threats, see schelling (1980).

6. See Bohi and Russell (1978) for a background on the Nixon Administration's policies in oil. 
7. See Peltzman (1976) and Owen and Braeutrgam (1978).

8. See U.S. Department of Energy, Economic Regulatory Administration, Proposed Rule to Establish Mandatory Production Levels for Middle Distillates. 44 FR 46244.

9. There were numerous proposals in Congress to decontrol distillate products during the 1979 shortage. See, for instance, the amendment offered by Congressman Peter Kostmeyer to the fiscal year 1980 DOE Authorization Bil1, HR 3000 .

10. Many discussions of this surfaced in ERA during 1979. Communications with the authors, June-August, 1979.

12. See, for example, HR 3346, the Petroleum Industry Competition Act: To Restore and Promote Competition in the Petroleum Industry and for Other Purposes, 96th Congress, First Session, 1979. This bill prohibits any firm from engaging in activities in more than one of the following sectors: petroleum production, refining, or marketing.

13. See, for example, HR 508: The Energy Competition Act: To Promote Competition in the Production of Coal, Uranium, and Geothermal Energy, 96th Congress, First Session, 1979. Also HR 4733, The Petroleum Corporation Holdings Act of 1979: To Prohibit Major Petroleum Producers, Refiners and Marketers from Acquiring, Owning or Controlling any Business, or Interest Therein, Which is Outside of the Petroleum Industry. For another slant on this 1ssue, see S 1246 Energy Ant1-Monopoly Act, which prohibits any oil company holding over $\$ 1$ billion in assets from acquiring any 
other oil firm holding over $\$ 50$ million in assets. U.S. Senate, 1979 . None of the above bills has passed the Congress. However, they represent a fraction of the total number of bills introduced during 1979 seeking to restrict or penalize the activities of major oil companies.

14. See Case Records, Office of Enforcement, in the Office of Special Counsel, Economic Regulatory Administration, DOE. Note that while we would expect to see some increase in regulatory enforcement efforts in a year of market change such as 1979 , we in fact observed increased enforcement not only in current cases but in ones prior to 1979. This suggests the use of retroactive enforcement as a threat.

15. See Jacobs (1980). See further Scherer (1980) pages 480-481.

16. See Jacobs (1980).

17. Conversation with the Contracting Office, Office of Procurements, September 1980. Records of federal contracts awarded and denied may be found in this office, while the COWPS recommendations regarding contract denials may be found on file within coWPS.

18. Conversation with COWPS official, September, 1980. The President's accusations against Mobil may be found in his April press conference; and the dates of Mobil's listing and delisting with COWPS are on file in the agency and available from the cowPS Office of Public Affairs.

19. Ibid. 
20. The elements of this case are on file with the same sources as in Note 18 , above.

21. Conversation between COWPS official and the authors, September, 1980 .

22. As of' 1976 , all of the 20 largest oil companies in the United States, as measured by total annual sales volume, were refiners. The 20 th ranked company was one-tenth of the size of the largest, Exxon. Thus, it is clear that the largest independent wholesaler in that year was yet smaller.

23. Communication:with the authors, July 17, 1979.

24. Discussions with the offices of several state attorneys general, including that of Massachusetts, indicate that these agencies took several steps in reaction to the price increases of 1979 which would rightly be interpreted by retailers as threats. All of these revolved around the sharply higher new market price for oil. The Massachusetts Office, in particular, was investigating during one period in 1979 whether retailers could be brought to court under the Massachusetts Consumer Protection Law simply for giving insufficient warning to customers before raising prices.

25. For evidences of this supply/price misunderstanding, see the Special Rule 9 Hearings Transcript. For a particularly illuminating case, see the testimony of Mr. Horace Kimball, Vice President, Telum Corporation, pages $14 \dot{3}-159$.

26. It seems apparent that there existed many such threats throughout 1979. Specifically, a collection of reports of these problems is on file with 
the Independent Truckstop Operators Association. On file are reports by individual owner-operators of intimidation, such as threats to close down stations by force, and newspaper articles from the spring and summer of 1979. These articles detail both the existence of such intimidations, in the market and numerous examples of trucker instigated violence against truckstop operators.

27. This of course places no emphasis on the equity issues involved in these price and profit increases. For a discussion of the efficiency/equity distinction, see Chapter 5.

28. CBS Evening News broadcast, April 23, 1979. Transcript available from CBS Archives, New York, New York.

29. Statement by William P. Taudulareas, President and Chief Operating Officer of Mobil Oil Corporation, before the Mobil Stockholders meeting of May 3, 1979, Kansas City, Missouri. That the anger of the Carter Administration was immediately communicated to top Mobil officials -even before the President's public comment referenced in Note 30 below -has been documented by discussions with sources within DOE.

30. New York Times, page 1, June 2, 1979.

31. See wholesale gasoline prices in the appropriate issues of U.S. Department of Energy, Monthly Energy Review and Monthly Petroleum Product Price $\underline{\text { Review. }}$

32. Discussion in Cambridge, Massachusetts, with independent gasoline station 
owner, April, 1980. For a further discussion of the myopic nature of consumer expectations, see Scherer (1980), page 215.

33. Data on national heating oil consumption by month are available from the EIA-9 Home Heating Oil Price Survey administered by the Office of Prices and Margins, Energy Information Administration, Department of Energy.

34. The most notable instances of this pressure were a series of White House meetings with representatives of the twelve largest major oil companies. In addition, hearings before various congressional comittees, which were reported in the national media, focussed upon the heating oil problem and the refining industry's response to that problem.

35. Note that while this price drop is not reflected in our refiner price data, the refiner data are not specific to heating oil but rather combine prices for all of distillate. Thus, we would expect the pricing patterns of other products to obscure that of home heating oil in these data to some degree.

36. It also, of course, has allowed the buildup of firms' banks as market demand constrained firms from passing through the full amount of cost increases. 


\section{Chapter 5}

\section{ANALYSIS OF 1979 OIL MARKET PROBLEMS}

AND POLICY RESP ONSE

At: this stage, we have accomplished three of the four major tasks that we embarked upon. We have presented a detailed empirical picture regarding the efficiency of U.S. oil market pricing during periods of world oil market shock and transition. We have also reached conclusions regarding the availability of marginal supply in various controlled and decontrolled product markets -- that is, whether, regardless of pricing patterns exhibited in the market overall, the markets were clearing at the margin. Finally, we have advanced a theory regarding the causal origin of the pricing patterns we have observed in these markets. The task still remaining is to pull together these conclusions regarding the market's function into a positive discussion of the problems that we believe exist in the market during periods such as 1979 . In addressing this issue, we approach our analysis from several perspectives. First, we separate the problems that occur in these markets into two categories: those relating to the efficiency of the market and those relating to the impact of higher oil prices upon the well-being of consumers and oil companies. Concerning the former of these problems, if the market evidences a breakdown in pricing and allocating goods in the most optimal manner across society, efficiency considerations may suggest intervention in the market to alter the signals consumers and producers perceive. The latter of these problems involves considerations of economic fairness in society: how wealth is distributed across consumers and producers, and what policy-makers perceive as a fair sharing of the burden imposed on all consumers due to the reduction in their real purchasing power caused by higher prices. 
The second perspective we take, once we have distinguished efficiency and fairness problems observed in the market, involves a comparison between actual problems and the public's and policy-makers' perceptions of these problems. Throughout the most recent period of American market turmoil, there was clearly much misunderstanding regarding the nature of the changes and problems that were occurring. Price increases, gasoline lines, and other facets of the adjustment process with differing causes, cures and implications for judging the market's workability were rolled up in the public arena into an inseparable, ill-defined lump termed "oil market crisis". It is important for our ability to cope with future crises that light be shed up on the relationship of these general misperceptions to the real market situation.

Third, we examine the nature of the government's policy responses to the actual changes occurring in the market and to the public's perceptions of those changes, e.g., were government regulatory initiatives in 1979 directed in such a way that programs actually addressed the efficiency and distributional issues that existed in the market? As we briefly noted, and will expand upon in this chapter, efficiency and distributional concerns demand very different types of institutional response. We thus need to define the appropriate governmental response to the general problem types we find, and examine the record to see if policy has arisen in response to the reality of market crises or to the illusions fostered by the prevalent misperceptions of those crises. We will thus be able to draw conclusions regarding the propriety of governmental response to the crisis of 1979 and, inferentially, to suggest some guidelines for policy action in the face of future world oil market crises.

\subsection{Definition of Market Problems}

In this study, we have stated the efficiency/fairness dichotomy several times. Let.us review it quickly here and comment on the policy implications 
of the two types of market problems.

Generally, two types of economic problems, those relating to economic efficiency and those relating to fairness in the distribution of income, may occur within markets and among market participants in a transitional period such as in oil markets during 1979. Although efficiency problems may well have distributional implications, the differences between these two categories of problems are such that their efficient redress is generally through separate means.

\subsubsection{The Problem of Economic Efficiency}

How do we define marketplace efficiency problems, their effects and their cure? Our primary concern in market transition, as we have seen throughout this paper, is that U.S. prices should adjust to reflect world prices so that an optimal response by U.S. consumers and producers to the reality of higher prices is possible. In this way, the U.S. economy will demand the optimal amount of oil as U.S. consumers will receive the correct signals regarding the actual value of oil. If an efficiency problems exists in a market, the price charged in the market does not represent the real resource cost and social value of the commodity. If oil is priced above its marginal cost, demand is less than is socially optimal. Conservely, if oil is priced below its marginal cost to society, it will be over demanded by consumers.

In terms of economic efficiency, the adaptation process is working if all products are allocated, by price, to their most highly valued use in soclety. Those who value the use of a given amount of oil at less than the price that clears the market -- those who are unwilling to pay the higher price for oil -must make do with less. The maximization of total U.S. economic wealth dictates that the nation utilize the resources available to it in the most efficient manner possible. A prerequisite is to allow price to reflect the true cost 
of oil to society and to require consumers to make consumption choices based upon that price level.

What are the visible signs of a problem of market inefficiency? Whenever U.S. product prices in major markets, particularly the contract market, remain significantly below spot prices, efficiency problems exist. Similarly, whenever some sellers in a market price at other than the market-clearing price, efficiency problems exist. In addition, efficiency problems exist when markets actually fail to clear; that is, when there is unsatisfied demand in the market. In this situation, nonprice forms of rationing the product, such as lines, will appear.

We have seen instances in recent years of inefficiently low oil market prices. What is the correct method of dealing with this kind of genuine market inefficiency? This type of problem demands redress through a correction of the market process. The process, as reflected in the price of the product, is causing consumers to face the wrong market signals. Further, governmental responses that merely attack some visible results of the efficiency problem, without attacking the basic price inefficiency itself, should not be seen as correcting the market distortions to any significant degree. For example, many times during both 1973 and 1979, in a market in which prices were too low and actual shortages of product developed, the government's response was to direct a change in allocation priorities. ${ }^{1}$ Such actions do not address the efficiency problems created by the shortage, but rather only redistribute the benefits of the lower prices between consumer groups. Some groups will be made better off, due to higher allocation fractions, but they are made so at the expense of the other groups whose supply of inefficeintly low priced product diminishes. Thus, the burden of the shorage is transferred among consumer groups rather than alleviated. The appropriate remedy, if the source of market inefficlency is a deviation of market prices from their efficient norms, is to take action which allows price to reach efficient levels. 


\subsubsection{The Problem of Economic Equity}

As described in Section 3.1.2, all users of petroleum products suffer real losses in income when oil prices rise, as any given amount of money will not buy as many petroleum products as it previously would. A change in the price of a commodity as central to our economy as oil produces major upheavals and alterations in the mode of operation of virtually all facets of our economy. We may expect to observe three classes of consumers hurt by these transformations. The most obvious of these is the passive consumer of oil products whose relative economic standing in society is appreciably worsened by his reduced purchasing power in the face of higher fuel prices. A second less obvious class of consumers who lose from rising prices is businesses that depend upon a continued supply of cheap oil. A third, and related class, consists of those businesses such as auto producers that produce products that are used in conjunction with oil. Many sectors of American industry will undergo radical change, and some may in fact cease to exist altogether when taced with the reality of higher oil prices. It must be clear from our foregoing analysis that in terms of economic efficiency, this result may not be inappropriate. Rather, such adjustments must happen for our society to adapt. Patterns of commerce and transactions which were constructive and profitable in the past may simply no longer be profitable due to the altered state of the market. The change will necessarily be painful for some. There are certainly arguments that action should be taken to aid those most severely hurt by the altered economic situation, but it must be recognized that these arguments are ultimately based upon considerations of fairness and equity rather than economic efficiency in the adaptation process.

The distributional consequences of a rapid increase in the price of oil can be severe, and there are certainly convincing cases which can be made -- and which we would make -- that some form of relief should be 
channeled to those hurt by altered market conditions, when political realities: dictate. The appropriate method for granting relief is one which does not interfere directly with the efficiency of the adaptation process. That is, interference with the net price of the oil products themselves or the consumption choices made by consumers faced with higher oil prices should be avoided. For instance, it is better from an economic efficiency and consumer welfare point of view to provide a low income consumer with $\$ 100$ in direct aid rather than allowing that consumer to purchase oil at an artificially low price, sufficient to yield the same total amount of effective aid.

Direct financial aid to those consumers deemed severely hurt by oil price increases constitutes the least distorting method of correcting the distributional problem. Such aid helps these consumers or consumer groups to cope with the impact of increased oil product prices by augmenting their income, while not altering the oil price level for them or other consumers. Aid, cleariy, should never be tied economically to the particular kind of fuel which has created the adverse impact on the consumer. By economic tying, we mean that the aid is associated, either directly or indirectly, with the use of the fuel. An example of a direct fuel-aid tie is illustrated by a direct subsidy on pergallon consumption of the product; an example of indirect tying is represented by a lump-sum subsidy which is only available to those consumers who actually consume oil products (e.g., the lump-sum of money is given to anyone with an oil burner). ${ }^{2}$ Any such tying will encourage over-consumption of fuel by recipients of such aid.

We now proceed to analyze the problems extant in controlled and decontrolled product markets during 1979 in order to render a judgment regarding the nature of the perceived market problems during this period. Given the analysis in this section, we may then suggest the remedies appropriate to the types of market problems that we have observed. Following this, in Section 5.3, we 
compare the actual remedies undertaken by policy-makers to our efficient benchmark, and determine whether the Department of Energy, policy-makers, and the public were perceiving problems correctly and undertaking appropriate policy in response to those problems.

\subsection{Empirical Examination of Market Problems in 1979}

\subsubsection{Controlled Products}

As we have shown, in the major controlled product, gasoline, genuine problems of market efficiency were evident in 1979. In gasoline, the coupling of price lagging with the control framework resulted in actual shortages of the product at various times during the year. Sufficient supply of gasoline was not available at the market price to satisfy demand; and a relatively large amount of industry-wide nonprice rationing resulted. Public perceptions of "supply problems" were quite accurate, although the cause was not often understood. In fact, the two- and three-hour gasoline lines in May and June of 1979 represented huge "shadow," or actual resource-cost, prices for gasoline. Many gasoline consumers were correct to perceive that, for them, gasoline had become completely unavailable. This was not due to a lack of supply, but because the combined costs of waiting in line and pump price exceeded the benefits these consumers derived from gasoline consumption.

That the control framework in this major consumer product created grave inefficiencies in the market has been well understood for some time. Several authors have performed extensive analyses on this framework. ${ }^{3}$ Therefore, we will not examine the control framework in detail here. We will note two aspects of the generally-held conclusions regarding the framework which we believe are particularly pertinent. First, product controls only become binding during periods of rapld world oil price increase. It would seem that the intent of the policy-makers who designed the controls was to "soften the blow" of oil 
price increases during the transition process. ${ }^{4}$ But the existence of binding controls during periods of transition tend to make consumers worse off. Twohour gasoline lines in a number of large metropolitan areas during the summer of 1979 represented huge welfare losses for consumers, as well as net efficiency losses to society.

Second, it seems clear that it is the control framework, and not the market itself which has led the huge errors in public information and expectations regarding world oil market crises. Both in 1973-1974 and 1979, a control framework bound prices in the most widely consumen oil product (gasoline) and thus created shortages in that product. As a result, most consumers and policymakers have the expectation that a world market supply cutoff will result in an absolute supply-demand gap -- a shortage -- in U.S. markets. of course, absent intervention, consumers would simply have to adjust to higher gasoline prices, not cope with a supply-demand imbalance.

This incorrect perception liás lecome almoat a crippling encumbrance ton appropriate reaction from the public and government to a world supply shock. Talk of "emergency conservation measures," "emergency allocation priorities," and other forms of market intervention to counter expected shortages dominate policy discussions in response to world market turmoil, as a cursory reading of popular news journals from these periods demonstrates. If the true nature of the distributional problems created by price increases were not masked by the shortages and inefficiency which the control framework has clearly caused, policy might better resolve the equity issues inherent in price increases. The price and allocation control response to the problem of higher prices represents the classic example of damaging efficiency in an attempt to address what are primarily distributional concerns.

Many of those who have demonstrated the most profound concern for the plight of the less fortunate have fallen into this trap, believing that basic economic 
signals can somehow be changed or controlled to benefit those needing income aid and assistance. ${ }^{5}$. The service they do for the less advantaged would be greatly increased were they to understand that their attempts to cure these distributional problems through market intervention, rather than through more direct income transfers, ultimately adversely affect the entire American economy -- including those whom they seek to aid -- by decreasing the total wealth available from the American economy.

\subsubsection{Decontrolled Products}

In decontrolled products, we have seen evidence that contract prices, particularly those of major refiners, lagged substantially below efficient marginal prices throughout 1979. This certainly created allocative inefficiencies in so far as some consumers, if faced with the efficient price in contract product, would doubtless have consumed less. Ultimately, however, economywide inefficiencies were moderated by a well functioning market for marginal supply. The infrequencies of lines in decontrolled products suggests that, due to active use of product spot markets, these markets cleared at the margin. However, we have not yet examined this claim in any detail. Many prominent policy-makers and members of the distillate consuming sector voiced belief through 1979 (and continue to hold the belief today) that product availability was a problem during this period. ${ }^{6}$ Many contended that product was often absolutely unavailable in the market and that real shortages did exist. We turn now to an examination of these claims, using as evidence records on one of the period's most intense distillate problems, May 1979, and the region of the country most affected during this period, the Midwest.

The most extensive policy hearings in which the problems of distillate supply were addressed were those surrounding the Economic Regulatory Administration's (ERA) implementation of Special Rule 9 on May 16, 1979. This rule was an emergency supply directive which mandated allocation priorities in 
distillate products (see Section 5.3.1). ${ }^{7}$ These hearings, held in Washington on May 18 and 19, 1979, occurred at a point of intense public concern about the dislocation they perceived in the primary distillate markets. The transcript from the hearings demonstrates that many consumers complained to ERA that a sufficient supply of distillate was not available to them. This complaint was taken at face value by many within DOE. A close reading indicates that major suppliers, who traditionally met a huge proportion of these consumers' needs, were indeed establishing allocation fractions in diesel. These were generally in the neighborhood of 50 to 95 percent of base-period levels of maximum contract volumes, as seen in Table 4. However, posted prices for diesel from the major suppliers throughout the West and the Midwest were roughly in line with the major seller diesel prices presented in Table $5 .^{8}$ Thus, what these consumers were actually faced with was a shortage of diesel from majors at artificially low prices.

The transcript indicates that spot market supplies were available to these purchases during this period throughout the Midwest and West at prices not substantially different from those observed in coastal spot markets. 9 To be sure, spot prices sometimes approached twice contract prices during this period -particularly in June, as was seen in Graph 3. Nevertheless, the fact that some distillate consumers chose not to consume spot diesel may be interpreted as a consequence of the price-elasticity of demand for diesel fuel. Consumers who refrained from buying spot product indicated by so doing that the change in relative valuation between oil and their output product was such that the cost of diesel made some marginal level of their business unprofitable. If so, this absention represented an efficient reallocation of societal resources in the face of new market prices. Increased oil prices were forcing appropriate adaptation by these sectors.

Transcript testimony from the Special Rule 9 hearings shows graphically 
the equation between the general perception of product unavailability and the reality of high prices -- prices many consumers believed were too high to constitute "real" market prices. Several of those testifying made the true nature of the "unavailability" issue unusually clear, linking the issue of "unavailability" directly to their inability to afford available spot product. ${ }^{10}$ This testimony provides the most illuminating perspective upon the nature of the supply crisis experienced by diesel purchasers in the spring and summer of 1979 .

The following exchange between Mr. Barton R. House, Acting Deputy Administrator of ERA, and Mr. Horace Kimball of Telum Corporation, the largest operator of independent diesel truckstops in the West, demonstrates this:

MR. KIMBALL: You will find enclosed a list of our 1978 suppliers and the amount of diesel supplied to us the first four months of 1978 and 1979. Please note that our shortages from these suppliers are a record of continual decline, In January, it was 19 percent; February, 26 percent; March, 33 percent; and April, 42 percent; and, as of yesterday, down to 51 percent ... like Mr. House has said, yes, there is product on the spot market. But does he know what the spot market right now in diesel fuel is in New York Harbor?

MR. HOUSE: Ninety-three cents.

MR. KIMBALL: That is right. Ninety-three cents ... I think that about sums up what we have. We have given you a list of our suppliers for these three months to give you a little background ... We go out on the open market and, normally, buy on the rack price system, filling in with the spot system.

But, as this gentleman has told you, with this spot market completely out of sight, we have nowhere else to go. We can't go to the spot market ... the spot price was so much higher. than the rack price that we really couldn't get any. 11 
Thus, sectors adversely affected by higher prices perceived their "need" as an absolute one. In their view, the market was not working because their need could not be met at traditional prices in traditional ways. But the existence of efficiently priced spot product available to these actors indicates that their problem was not an efficiency or market problem and should not have been addressed through market mechanisms. To state this and, thus, categorically to condem certain kinds of solutions to the problem, neither belittles the true nature of the problem nor implies that action should not be taken to address $1 \mathrm{t}$.

While it may have been the case that many demanding relief from high prices based on efficiency arguments did so with honorable motives, it should nonetheless be policy-makers' function during these periods to possess sufficient information regarding the market to undertake policy action without relying on the often incorrect information given them by interested parties seeking favors.

\subsection{Governmental Response}

Has governmental response to the problems that we have observed in controlled and decontrolled markets been timely and of the proper construction? We shall examine each type of market separately to render judgments on the propriety and efficiency of the observed governmental response.

\subsubsection{Controlled Products}

It appears that the response to the real problems of shortage caused in 1979 by price and allocation controls was complicated by the basic political reality of consumer pressure which we have discussed in Chapter 4 . The only government response which could have truly alleviated the nature of the market problem was to rescind controls. This would have left consumers angry at 
higher prices, but would have removed the huge and visible costs of dysfunctional markets.

Within the existing framework of price and allocation controls, ERA's attempt to mainpulate the system of controls in response to particular crises in gasoline constituted a basically sound initiative given the political constraints. .Price controls, during the 1979 adjustment periods, were binding only in specific, limited areas of the country, particularly urban areas. This was reflected in a pattern of localized shortages -- efficiency crises -rather than a nationwide one. Consumer anger directed at the Department over gas lines was the outgrowth of a genuine efficiency problem; and DOE's reaction -- to attempt to alterallocation priorities so that the affected markets came closer to clearing -- probably represented an efficiency gain. ${ }^{12}$ This conclusion only holds if product redirection does not result in the creation of shortages in new areas, which, during 1979 , it generally did not. ${ }^{13}$ It must be understood, however, that this kind of band-ald approach to the inefficiency of controls was never completely successful in eliminating the inefficiencies in controlled markets during $1979 .{ }^{14}$ That these ERA actions may have had some positive effects does not suggest that the inherent inefficiencies in a price and allocation control framework can ever be completely ironed out through ad hoc emergency measures.

Our conclusions regarding the ERA response to the inefficiencies created by their own system of price and allocation controls are thus mixed. Given the control system's existence in 1979, DOE regulators who were faced with managing the inefficiencies created by the controls were able to do some good. However, the existence of control programs which had an impact on the efficiency of products' pricing and allocation caused considerable damage to oil markets and the economy. 


\subsubsection{Decontrolled Products}

Were the distributional problems in decontrolled products which we described in Section 5.2.2 perceived and reacted to correctly by the regulators? Or were these market equity considerations misunderstood by ERA policy-makers as they were by the consumers who were affected by them? Unfortunately, we find that the latter is the case. Let us examine several examples of ERA's reaction to those problems which we documented in Section 5.2.2. In particular, we shall examine ERA's response to the claims of agricultural operators and the trucking industry that diesel "shortages" were ruining their ability to conduct business.

\subsubsection{Department of Energy Response to the Agricultural Industry}

Faced with the prospect of rapidly rising prices for diesel fuel, the agricultural community brought complaints to the Department of Energy beginning in the early spring of 1979. These complaints centered on the inability to secure sufficient diesel from market sources to complete spring planting. As evidence, they produced notices from most major Midwestern diesel suppliers that diesel consumers would be on allocation fractions for an indeterminant period in the future, lasting at minimum through the summer months. Pressure on the Department was exerted through Midwestern states' representatives, such as Representative Tom Harkin (D-Iowa), who testified at the hearings on Special Rule 9 on May 18, 1979. In addition, the major lobbying group for agricultural interests in the Washington policy process, including The American Farm Bureau Federation, the National Council of Farmer Cooperatives, and the Agricultural Energy Users Conference made their views well known. Meetings between these groups and ERA regulators occurred throughout the spring of 1979; and written communications on record highlight the positions taken by these groups in arguing for agricultural relief. Representatives of the farming sector, as 
well as those individual operators who communicated with the Department, termed the developing Midwestern situation a "shortage" of diesel fuel. In their view, this was conclusive evidence that the market was preventing the production of one of America's most important commodities. 15

As our analysis in Section 5.2.2 has demonstrated, problems of absolute product unavailability -- shortage -- in this region during exactly this period of time simply did not exist for consumers of distillate products. Rather, the problem which farmers and other distillate consumers faced was that of coping with the efficient, yet sharply higher prices for the product which were reflected in local spot markets. The allegation by farming interests and others involved in the Special Rule 9 process that an inadequate amount of product was available to them was, in actuality, incorrect. Rather, this allegation stemmed from the distributional concerns of these groups. Their call for "additional supplies" of "fairly priced" product was in fact simply a plea for wealth transfers in the form of additional allotments of the artfficlally cheap distillate product of the major companies. Thus, faced with higher prices on marginal markets, the agricultural community took steps in May of 1979 to secure protection from having to adapt to the changes occurring in the U.S. oil market.

The ERA response to this equity-based demand from the agricultural community was to accept their allegations regarding absolute supply unavailability in the market and to issue regulation as redress. It is obvious that farmers in the Midwest successfully convinced DOE regulators that is was essential to the nation's welfare that their particular industry be kept functioning at traditional levels in traditional ways, and that it be insulated from the new market process by regulatory intervention. The Department responded by issuing an emergency directive, Special Rule 9, on May 16, 1979, ordering that price-lagging majors who were supplying agricultural operators on contract 
furnish their farming customers with 100 percent of current needs in diesel fuel. ${ }^{16}$ This amounted to a giant windfall gain for farmers. With guaranteed access to unlimited, inefficiently cheap oil, farmers were able to continue their production activity through 1979 as if the major supply shocks and price increases in world oil markets had never taken place.

The problems experienced by agriculture constitute a perfect illustration of the confusion between issues of economic efficiency and those of wealth distribution that arise in the oil market adaptation process. The plight of the agricultural community may have merited sertain emergency measures to direct funds to those whose incomes were severely threatened by higher diesel prices. However, there is a clear distinction between providing such temporary relief and forcing distortions in efficient patterns of market interaction. Any measure that insulates an industry from the necessity of confronting higher prices, as Special Rule 9 did, clearly falls into the latter category and causes damage to the economy as a whule.

It is illuminating to note that the diesel-consuming community's response to the regulatory windfall of Special Rule 9 was exactly that which an economic model of rational expectations would predict: there was speculation in diesel fuel by members of the farming industry and by others who sought to take advantage of the weak certification requirements imposed by the ERA. Anticipating still higher prices, fully cognizant of the high spot market price which Special Rule 9 shielded them from, and recognizing the temporary nature of the Rule itself, many agricultural consumers did not stop purchasing diesel under this regulation when they had procured sufficient supplies to guarantee that their springtime operations would function at 100 percent of traditional levels. Moreover, many nonagricultural purchasers suddenly and mysteriously became farmers. These consumers stockpiled in order to cushion themselves from future price increases. 17 
Several suppliers testified at the Special Rule 9 hearings that they had to meet agricultural supply needs of individuals whose agricultural credentials and whose documented "need" were unknown quantities at best. Mr. Charles Head, of Cities Service Company stated:

We do know this, that we have a lot:s of quote "farmers" who are showing up in the middle of Chicago and apparently have no indication that they are in the farming business and we are finding those pretty quickly and we have been swamped since the notice of Special Rule 9 has come out.

Strangely enough, we have had more requests from those type people than we have from historic (agricultural) customers. 18

A large independent diesel operator in the Midwest and West stated:

We have a tremendous amount of farmers coming into our truck stops with their pickup trucks filled with 55 gallon drums telling us that their agricultural cooperative has been cut 100 percent and they just don't have any diesel. And, of course, we have to sell. 19

Further, conversations with DOE regulators who aided in the implementation of this Rule indicate that farm inspections during this period show huge, open tanks in fields, filled to overflowing with diesel fuel. 20

The rule of certain consuming sectors in affecting the market through manipulation of governmental institutions is evident in the regulatory politics that surround Special Rule 9. We suggest that the extent of the price protection that the farming sector secured in diesel bears little relationship to their relative distributional disadvantage. Rather, it appears evident that farmers secured what amounted to favorable price discrimination in diesel fuel due to their possession of some measure of political capital. Agricultural interests have long been extremely well organized in the policy-making process. ${ }^{21}$ Over a span of decades, they appear to have created a symbolic political perception that their industry is endowed with qualities especially valuable to the American way of life, and not'necessarily measurable by the market valuation of their output. It seems evident that the power to secure such regulatory 
protection from market forces as we observe here stems from this symbolic capital.

\subsubsection{Trucking Industry Pressure and DOE Response}

The pressures which are brought to bear in the political marketplace by various actors in the American economy are demonstrated again by the process that led to the rescinding of Special Rule 9 after only half of its intended lifespan had elapsed. 22 Nonagricultural consumers of distillate products suffered losses in economic welfare due to the rule. As greater proportions of laggedprice distillate product were diverted into the agricultural sector, nonagricultural buyers were forced more heavily into the spot market. These groups, most notably the trucking industry, immediately began to bring pressure to bear upon DOE either to rescind Special Rule 9, to grant them equivalent relief from shortages, or both. (Later in the year, trucking industry pressure was augmented and perhaps even eclipsed by pressure from the home heating oil lobby,)

Trucking represents another industry in which the effect of increased oil prices is substantial. A precipitous increase in the price of diesel fuel means large increases in operating expenses for the trucking industry, as fuel represents a major variable input in the production of transportation services. Truckers, like members of the agricultural sector, complained of diesel shortages in hearings before $\mathrm{DOE} .{ }^{23}$ Once again, a close reading of testimony, coupled with a review of the diesel supply situation, indicates that the only shortage which truckers experienced was one of fuel at old, pre-Iranian-crisis prices. It is clear from the transcript that some retailers, whether due to informational imperfections of the sort described earlier or in an effort to maintain customer goodwill, were lagging prices, decreasing supply, and nonprice rationing (by shortening their business hours).. Other retail outlets were going to spot , markets for marginal supply, charging market-clearing prices, and remaining open. 24 
Truckers were eventually successful in securing regulatory intervention on their own behalf, as well as being instrumental in putting an early end to the agricultural community's windfall benefits from Special Rule 9.25 During the summer, DOE, at the trucking industry's behest and inconjunction with the Department of Transportation, set up "safe passage corridors" consisting of major interstate networks along primary trucking routes both east-west and north-south. The Department of Energy and the Department of Transportation took actions to ensure that major suppliers of the retail outlets along these highways would supply sufficient levels of product to enable retallers lo stay open 24 hours a day. ${ }^{26}$ Given that pressure was generally exerted on major suppliers to supply their contract customers, this resulted in the supply of additional price-lagged product to truckstops. This represents the same genre of wealth-transfer regulation as does Special Rule 9. Again, the true nature of this purely distributional aid was masked. Truckers' income problems were, like those of farmers, made to seem problems of market efficiency in allocating goods to those consumers who valued them most.

\subsubsection{Further Perspectives on Governmental Response}

For the purposes of this study, the most important aspect of this examination of the DOE regulatory response is that price-lagging behavior of major oil companies ironically proved the pivotal tool which various aggrieved oil consuming groups utilized as evidence of market breakdown in order to obtain inefficient forms of government relief. Without price-lagging by majors, there would never have been a need for allocation fractions. Without allocation fractions and the majors' lagged prices serving as the prices that DOE regulators and the public perceived as representing the efficient norm, there would have been no illusion of shortage in decontrolled products. Rather, had majors' lagged prices serving as the prices that DOE regulators and the public perceived 
as representing the efficient norm, there would have been no illusion of shortage in decontrolled products. Rather, had majors' prices increased at purely market-determined rates, and had the market been devoid of political pressures, the only perception among policy-makers would have been accurate: that sharply higher prices were creating significant distributional consequences for many sectors of the American economy. Had this perception ruled policymaking in 1979, we might have observed greater attempts to provide direct aid and relief to adversely affected consuming sectors, rather than endless efforts to intervene in the market and obtain "emergency" supplies for sectors experiencing "product shortage" at artificially low prices.

When regulatory actions taken in 1979 in response to price increases in world oil markets are juxtaposed with those from earlier years, there emerges an interesting difference. Before 1979, the trend in regulatory response to price increases had been toward imposition of broad-based, open-ended regulations, such as the price and allocation cuntrols of the Emergency Petroleum Allocation Act. These regulations set overall allocation priorities in oil products, affecting the general petroleum-consuming population as a whole. In 1979 , by contrast, major markets other than gasoline were left decontrolled (although as we have argued, this does not mean unconstrained). Regulatory initiatives in this recent period took the form of the distribution of specific benefits to specific consumers for specific time periods. This shift may well stem from a judgment by regulators that the optimization of the government's political benefit from regulation is closer to its maximum when regulatory bargaining with consumers and producers is not constrained by an infrastructure of long-term regulation. Such long-term regulation clearly confines the bargaining power of both the government and market participants, but particularly that of the government. Hence, we see in petroleum product regulation in 1979 the kind of regulations which appear to grow directly out of competition for 
the short-term maximization of political and monetary capital through the political-regulatory process.

It is interesting to note, as a final perspective on this regulatory process, that there appears to be some set of constraining parameters within which DOE must operate when distributing these benefits through the regulatory system. It seems that it is possible for redistributive "shortage" regulation to be so narrowly focused upon specific beneficiaries that the public and the political community recognize that it in fact achieves wealth transfer rather than market efficiency goals. For example, in 19.79, the Economic Regulatory Administration (ERA) of DOE ordered Mobil Oil to increase supplies of gasoline. and crude oil to three independent refining cooperatives in the Midwest to which Mobil had long-term supply commitments and which Mobil had placed on allocation fraction. The cooperatives had appealed to ERA, claiming, like agriculture and trucking, an inability to obtain adequate supply. However, in this instance, Mobil brought suit against the ERA in federal court, charging that the cooperatives had access to unlimited spot product at a price $8 c$ per gallon higher than that which Mobil was charging, and that all the order amounted to was a windfall transfer away from Mobil's other customers to the cooperatives. 27 The court found for Mobil, indicating that blatantly redistributional regulatory actions may carry negative political implications.

It is an interesting exercise to ponder what reasons lie behind the public's and policy-makers' complete acceptance of large-scale redistributive regulatory intervention, such as the trucking and agricultural cases cited above, as opposed to their obvious opposition to more limited and ultimately less economically damaging redistributional regulations such as this one involving a specific oil company and a few specific beneficlaries. On the surface, it suggests that when an entire sector of the economy is adversely affected by oil price increases, policy-makers are hard-put to believe that serious market 
inefficiency is not involved. By contrast, in smaller cases, the gainersversus-losers nature of the "market problem" is sufficiently obvious that the distributional nature of both the problem and the regulatory cure is plain.

\subsection{Caveats Regarding Consumer, Firm and Governmental Behavior}

Several aspects of transition-period behavior of all actors in the oil market -- firms, consumers, and government -- are subject to certain qualifications. These considerations constitute something of a grab-bag of disparate economic effects; but these behavioral peculiarities are important to note because they cloud the nature of the responses of all actors to both market signals and government policy. In this section, we discuss, first, some consumer expectation problems which appear to exist in the market, and second, various manifestations of wealth distribution issues. We close with a final example of the efficiency/distributional dichotomy.

There appears to exist a perceptual bias in consumer understanding of the operation of the market which is in large part caused by conditions created by government intervention. The primary problem is one of consumer expectations and information in times of sharp oil price increases. It appears that two types of distortions in information and expectations exist among consumers. First, with the advent of a sharp oil price increase, consumers seem to possess an informational gap regarding the technology and economics of oil and substitutes at new, higher prices. Second, and more serious, consumers' understanding of the world adjustment process seems to have been sharply distorted by the inefficiencies caused by government controls on the market which have existed since 1971. With the fall of Iran, discussion among media and consumers reflected expectations of an impending "shortage", product unavailability, and lines. Much of this discussion of mythical "shortfalls" in oil imports, in domestic product supplies, etc. appears to have stemmed from a belief that 
domestic oil markets inherently exhibit nonclearing tendencies during periods of world supply shock. Indeed, it does represent what has happened in gasoline markets twice during the 1970s. But the expectation that actual shortages will occur in American markets, even if they are decontrolled, as an automatic consequence of oil price increases on world markets seriously hampers consumers' ability to prepare for and deal with the real effects of a loss in world oil supply. This loss, of course, reduces purchasing power due to higher prices. This problem of consumer misperceptions will be solved by the government's withdrawal from these markets. Positive governmental initiatives, in the area of information as to the actual causes of shortages, could be of benefit. ${ }^{28}$

Three caveats should be voiced regarding the regulatory distribution of benefits between various groups on the basis of financial hardship suffered because of oil price increases. First, many groups complained of hardship in 1979 due to the distribution pattern of artificially cheap, price-lagged product. In reality, the existence of any price-lagged product in the market constitutes a windfall benefit to consumers. The relative distribution of such product is not really a case of hardship, but of proportionate advantage. Moreover, any attempt to alleviate distributional problems by interfering with the allocation of this artificially low-priced product is an inappropriate form of government intervention. To use the regulatory problem of price-lagging to cure other problems will only serve to institutionalize and worsen this undesirable syndrome -- as the example of Special Rule 9 testifies.

Second, we note that consumer group power does not necessarily conincide with need in times of oil market transition. The business of aiding particular groups distributionally during these periods has the potential to result in little more than pork-barrel politics. Again, this appears to have occurred in 1979; and it is not clear that the trucking and agricultural industries constituted those distillate consumers most in need of relief from higher oil prices. Rather, they may well have been the ones with the loudest voice in 
the political system.

Third, to the extent that consumers of a product expect to be bailed out when faced with a substantial price increase on the product, they will misdirect their investment in that product. ${ }^{29}$ This is only the case is the consumer subsidy is tied to the use of the product in some manner. For example, if a direct dollar subsidy is made available only to consumers with oil furnaces in the face of an oil price increase, and if this is the expected solution to future emergencies, then the decision to heat with oil versus other alternatives is made with this in mind. The tying of the subsidy of heating with oil causes the consumer to make his investment decision based on the reduced uncertainty and reduced cost to the consumer that future oil price increases now pose. This results in an inefficiently large investment in the product tied to the subsidy. Conservation in response to higher prices is thwarted. It should be further noted, as another perspective on the equity/ efficiency confusion in the policy arena, that competition for the wealth transfers inherent in cheap oil in and of itself constitutes much of the basis for the appeals that are made to DOE during these periods. Many groups demand relief from ERA during these periods not because they actually have the greatest income problems and cannot afford oil, but because they see the possibility of realizing a major financial gain from winning access to society's cheap lagpriced oil. In economic terms, the gains that groups realize on these belowmarginal cost products are infra-marginal rents; and much consumer group activity in the policy process may be viewed as competition for these financial rewards.

A final example will make clear the subtleties which are often involved in separating the notions of efficiency and equity in the marketplace. During 1979, there was much discussion among distillate consumers on supply contract to major companies about the allocation of the majors' product. As we have 
seen, this product was priced below market value during this period, and concomitantly, was allocated by nonprice means such as allocation fractions. This constituted an inefficiency in the marketplace. However, complaints began to be brought before DOE in the early summer that these allocation fractions were not being administered fairly -- that the majors were allocating product based upon bribes, the strength of long-term relationships, etc., rather than upon the priorities set in their own allocation fractions.

The allocation by bribes and other financial incentives of this artificially cheap oil may in fact be thought of as a preferable solution to that of simply allocating the underpriced product by simple allocation fraction rule. Those willing to pay companies monetary incentives to increase their allocations were in fact demonstrating a desire to purchase oil at even higher prices; that is, they, were willing to pay for the product at prices which were closer to the efficient, market clearing price. It is probable that many of those who chose not to purchase product at this higher effective price, and who complained of the practice, were those consumers whose valuation of the product was lower -- and who would, therefore, have reduced their consumption had majors priced at more efficient levels. Therefore, with respect to the majors' artifictally cheap distillate, "bribery" to allocate supplies represented a more economically efficient solution than pure allocation by fraction or historical oil consumption patterns. As long as majors' effective prices remain below spot prices, these bribes simply raised the price of the product closer to the spot price (but clearly, not above; had this been the case, these consumers would have turned to the spot market itself for the incremental supplies that they desired). Many actors in the market -- certainly those who brought complaints to the Depratment of Energy -- perceived that this allocation-bybribery constituted yet another market problem in distillate products. However, as should be clear from this discussion, that perception was erroneous. 
Indeed, the market system of allocation-by-price is a system of allocationby-bribery. This issue that marekt "bribery" raises is one of income distribution.

\subsection{Market Problems and Government Response: Conclusions}

We have observed that two major types of problems existed in American oil product markets during 1979 . One was related to the efficient. operation of the market in the economic sense; the other was purely distributional in nature.

Regulatory-based efficiency problems in the market hurt the performance of the U.S. economy to a greater extent than the world market price increases alone would have. This reduced the overall welfare of American consumers. These problems -- the primary efficiency problems that we believe existed or will exist in these markets during past or future periods of disruption -were caused not by the market but by either explicit or implicit government regulation of the market. The government's explicit price and allocation control framework prevented some markets from clearing. These controls and their adverse impact on markets have been the basis for the major problems which the public perceives as arising from world oil crises, including absolute product unavailability and waiting in lines to purchase product.

The government's implicit control over pricing is seen in the price-lagging by major suppliers of both controlled and decontrolled products. We believe that these price lags are caused by the existence of a political-pressure price constraint at work in the market. In decontrolled markets, this tendency probably does not result in inefficiencies that are as serious as those that tend to exist in markets subject to an explicit control framework because the margin of the market continues to operate efficiently.

The second problem that appears to exist in these markets is distributional. 
Oil price increases of a rapid and sudden nature engender precipitous alterations in the way that the nation's wealth is distributed across different members of society. It is this problem of losses in wealth by certain consumers that federal oil regulation has attempted to address over the years. However, in 1979 and in earlier periods, both the nature of this problem and the nature of its available solutions have been misunderstood by policy-makers. Rather than being seen as a problem of consumer income, the distributional issue has been viewed as a market problem, specifically a problem of price level. Consequently, attempts at cures have generally revolved around altering the way in which the market sets price and allocates supplies; either through wholesale interference with the market's price and allocation mechanisms, or, as we have seen in 1979 , through smaller, directed interventions that alter the way the market allocates products among certain specific consumers.

The implications of our conclusions regarding inefficiency in oil markets are simple. Removing all forms of direct government intervention in pricing and distribution of oil products would remove the more serious of the inefficiencies in these markets, such as gasoline lines, which arise in times of upheaval. As with all market inefficiency problems, the cure of that problem would leave the average American better off by promoting an expanded and stronger economy. The inefficiency caused by the price-lagging phenomenon, along with the concomitant allocation-by-fraction, has been caused by government domination of oil markets since the early 1970s. If this is indeed the case, this constraint upon the market's operation will, at best, only disappear with time.

Remedies for the distributional problems that we have focussed upon in this chapter are somewhat more complex. Quite legitimately, the issue of the economic welfare of certain citizens has been DOE's and the Congress' main concern in oil markets over the post-1973 period. Two separate types of distributional problems are evident: (1) when oil prices rise rapidly all consumers 
face net reductions in their real standard of living; and (2) when oil prices rise, certain groups whose livelihoods have been more dependent upon oil products find themselves worse off, in a relative sense, than the rest of society. If political realities dictate the need to provide certain parties with a short-term cushion from the full impact of higher oil prices, the use of tax and transfer mechanisms can be undertaken without destroying the allocative properties of the market. The direct provision of additional income to those targeted in the form of tax breaks or outright federal subsidy constitutes the desirable method of addressing distributional problems. As a general rule, then, we would warn those whose responsibility it is to regulate these markets to keep the problem of efficient resourceallocation separated from that of fairness or equity -- especially in the volatile and confusing times of oil market transition. 30 
NOTES FOR CHAPTER 5

1. We discuss these policies in detail in Section 5.3.1.

2. A further perspective on the effect of tying on consumption may be seen by referring to the discussion in Section 5.4, especially pages 154-155.

3. See Kalt (1981), Harvey and Roush (1980), and Verleger (1979).

4. See Note 16, Chapter 3.

5. Among those Congressional leaders who seem to possess this basic economic misunderstanding are, in the Senate, Edward M. Kennedy (D-Mass.), Henry Jackson (D-Wash.), Howard Metzenbaum (D-Ohio); in the House, Anthony (Toby) Moffett (D-Conn.), Albert Gore (D-Tenn.), Peter Kostmeyer (D-Penn.), among others.

6. Among those Congressional leaders who are on record on this matter are those referred to in Note 5, Bayh (D-Ind.), and Baccus (D-Montana). For examples of distillate consumers on record expressing this view, see Special Rule 9 Hearings Transcript.

7. U.S. DOE/ERA Special Rule 9: Amendment to Provide Middle Distillates for Agricultural Production. 44 FR 28606, May 16, 1979.

8. See Note 10, Chapter 3. 
9. For a perspective on the price and availability of spot market product to these consumers in this period, and a general discussion of the nature of higher prices they faced from all suppliers, see Special Rule 9 Hearings Transcript, especially pages 26, 34, 38, 75, 98, 147, 156, 228, 278, 291, and $318-319$.

10. Ibid.

11. Special Rule 9 Hearings Transcript, pages 143, 144, 147, 156.

12. Several sections of the EPAA allocation regulations specifically empower ERA regulators to make supply adjustments, albeit within fairly rigid constraints, in order to alleviate specific cases of shortage during periods of tight supply. Such reallocations are administered by the Office of Petroleum Operations in ERA. The opccial powere contained in the EPAA, Section 211:14, give DOE authority to redirect limited supplies of refined products. Section 211:107c gives consumers who have been cut to an allocation fraction of less than 75 percent a priority in petitioning the ERA for a new supplier. The Interim Supply Agreement allows a supplier to accept a new or severely supply-aggrieved business without going through the usual time-consuming supply certification petition. Further, ERA and the White House granted state governors temporary authority during 1979 to order intra-state redirection of existing petroleum supplies, and to demand additional interstate products from the major suppliers servicing the state. Finally, the state set-aside in refined products was increased from 3 percent to 5 percent during this year.

13. If new regional shortages are created by reallocation efforts, a comparison 
of the pre- and post-levels of inefficiency involves interpersonal comparisons of the welfare losses which result from the shortages, and is thus inconclusive.

14. That this approach does not result in attainment of efficiency is evidenced by the existence of gasoline lines in 1979.

15. Written communications between the named groups and individuals and ERA are on file in Control Correspondence, Economic Regulatory Administration, Office of Petroleum Operations. See also files of individual groups named for written communications on this subject from their individual constituents, and White House correspondence files for the same period, Office of Stuart Eisenstadt (who managed White House-level development of emergency diesel fuel policy in the spring and summer of 1979). See particularly these files during March-July of that year.

16. See Note 7, above.

17. For specific perspectives on the speculative buying which Special Rule 9 produced, see the Special Rule 9 Hearings Transcripts, especially pages $63,86,157,158$, and $306-308$.

18. Special Rule 9 Hearings Transcript, page 86.

19. Statement of Horace Kimball, Vice President, Telum Corporation, Special Rule 9 Hearings Transcript, page 157. 
20. Conversations with ERA officials detailed to Special Rule 9 implementation process, Washington and Kansas City ERA Offices, Conversations with the authors, July, 1979.

21. See Peltzman (1976) regarding the effects of group pressure on regulators. See Stigler (1971), Baldwin (1975) Chapter 1, Wilson (1980), and Kalt (1981) Chapter 6 for further discussions of capture theories of regulation.

22. The agricultural priorities in Special kule $\dot{y}$ were rescinded on Junt 21 , 1979, after five weeks. Its intended time frame was to have been ten weeks, until July 31, 1979.

23. See the Special Rule 9 Hearings Transcript for examples of trucking industry complaints, especially pages $222-245,296-298$ and 327-343. Trucking interests were ultimately aided by the regulatory process, but, unlike agriculture, hearings were never held to address their complaints in particular.

24. We have discussed this issue regarding diesel retailers' adjustment in Section 4.2.3.1. In addition, we have provided testimony sources in the Special Rule 9 Hearings Transcript regarding the problems in diesel retailers' adjustment process.

25. Trucking industry pressure was applied to the DOE in much the same manner that agricultural pressure was. Many groups representing trucking -including the Independent Truckers Association, the American Trucking Association, and the Independent Truckstop Operators Association -engaged in both verbal and written communication with ERA throughout the spring and summer of 1979, calling for rellef. (Examples of correspondence 
are on file in ERA, Control Correspondence, Office of Petroleum Operations.) An excellent example of trucking industry pressure may be found in the Special Rule 9 Hearings; here, Mike Parkhurst, President of the Independent Truckers Association, inferrentially threatens to call a national strike and blockade of major interstates by his group members if ERA does not grant" his constituency some form of relief (p. 231).

26. The "safe passage corridors" created by DOE/DOT were never officially part of the rulemaking process. Consequently, neither regulation nor hearing can be cited. However, several White House press releases substantiate the existence of these corridors. These first press releases announcing their establishment are dated June 22 and June 28, 1979, (White House Media Liaison offlce). The corridors, and supply jawboning, were undertaken by an interagency task force comprised of members from the Department of Justice, the Interstate Commerce Commission, the DOE, and the DOT, and operated out of the DOT Emergency Transportation Situation Center which existed during this part of 1979 .

27. See Energy Users Report, April 14, 1979. Also see Mobil Oil Corporation vs. the Department of Energy, Case No. 79 CIV 1727.

28. For a full discussion of the role of government advertising and educational campaigns during periods of oil crisis, see Erfle (1980) and Pound (1981).

29. Clear perspective on how directly consumers perceive the effects of government-created incentives or disincentives on their investment decisions may be seen in the testimony of Mike Parkhurst, President of the Independent Truckers Association, in the Special Rule 9 Hearings Transcript, page 229. 
30. Alm and Hogan (1980) present a tax-rebate proposal to reduce the level of consumer-producer wealth transfer during periods of rapid petroleum price increase while preserving efficient pricing in oil product markets. 
Chapter 6

SUMMARY AND CONCLUSIONS

The price changes in the world oil market that occurred during 1979 created major realignments in the domestic economy of the United States. By most measures, certainly by that of absolute price increase alone, this period constituted as grave a crisis in energy markets as did the first period of OPEC price hikes, in 1973-1974.

In this study, we have endeavored to measure the efficiency of U.S. oil markets in adapting to periods of sharp transition such as 1979 . We have been concerned with how quickly these markets adapt to the realities of higher world oil prices, and whether there are significant problems in either the prices charged for oil products or the manner in which the market allocates available oil products across consumers.

An examination of the relationship between United States and world oil product prices during the period of transition has led us to conclude that in most major oil products, there has existed a gap, with world prices consistently above domestic prices. Inefficiency in the worldwide distribution of oil products clearly must result from this price discrepancy. One of the most important conclusions that we have reached regarding American and world pricing structures during periods of transition is that there exists no basis in fact for the oft-heard allegation that American oil prices are artificially high during periods of crisis. Rather, we have found that, if anything, the reverse is true.

Our central conclusion relates to the adaptation process within U.S. markets. Utilizing the U.S. spot price as a base, we have examined the pricing behavior 
of firms within the U.S. economy and have found significant, long-lived price lagging by the major firms in the oil product marketplace. We have seen these firms maintain prices sufficiently below actual marginal prices that they have had to adopt methods of nonprice rationing even in petroleum products which have been formally decontrolled. This price lagging behavior by majors, combined. with the concomitant use of allocation fractions, caused two primary misperceptions among the public during the period of crisis. First, the use of allocation fractions led the public perception of absolute unavailability of some uncontrolled products. Second, the public's perception of price-gouging resulted from a misinformed public and policy-making establishment, who viewed the lagged, artificially low prices of major oil companies as the efficient market prices in these products. We have found that majors lagged prices so severely in 1979 that in gasoline, which remains controlled, the formal ceilings were not the binding constraint on firms' pricing.

Our theory regarding the reasons for price-lagging by the major oil companies rests upon the observed politicization of United States oil markets. Oil consumers, their welfare adversely affected by price increases, have focussed their anger over price increases upon U.S. oil companies through the political process. The resulting political pressure has engendered, in the past seven years, legal and regulatory retribution directed at the oil industry. Consequently, U.S. oil companies with high public visibility have perceived a threat to their well-being arising from price increases. As a result, they have adopted a pricing strategy that results in inefficiently low prices during periods of shock to world oil prices.

Anger is focussed upon the oil companies by three groups whose net societal standing is increased by so doing. These groups -- the political community, regulators, and the media -- constitute the catalysts in the price-lagging process. The policy-making community, in response to this anger restricts 
or at the very least, threatens to restrict various aspects of oil-industry behavior in retribution for higher prices. Regulators abet the policy process to maximize their own capital. The media's treatment of the price-increase phenomenon turns generalized public anger into directed consumer pressure. The political pressure-based constraint only functions when two factors are catalysed to create it: the political visibility of individual firms and the political pressure for lower prices generated by the public. These factors appear to be essentially multiplicative in association. Observation of several other industries' pricing response indicates that without political pressure or without the degree of visibility and vulnerability that we have seen in the oil industry, this pricing constaint does not operate. Thus, our model is not specific to oil-market pricing alone, but rather allows us to make predictions regarding the industries within the U.S. which may become susceptible to a political pressure pricing constraint in the future.

In summary, the political pressure model represents an attempt to formal1ze a relationship between transition-period oil product pricing behavior, which clearly has not followed the textbook marginal rules, and the various constraints which seem to have emerged in unregulated, but nonetheless highly politicized, oil markets. Further research will aim at developing a more formal version of this model and incorporating a quantitative description of the constraints which firms in these markets face.

The nation will continue to see results like those of 1979 when there are sudden alterations in the price and supply equilibrium in world oil markets. The market politicization described here will continue and perhaps intensify. United States' oil companies will thus continue to be forced against their own best interests, and the ultimate best interest of society at large, into inefficient and constrained patterns of adaptation. These patterns clearly have negative Implications for the entire American economy. 
Finally, this study has examined the problems which have existed in domestic oil markets during periods of market transition such as 1979 . These problems can be attributed to various factors in the politico-economic marketplace and have shaped both public perceptions and governmental policy responses. There is evidence of efficiency problems in U.S. markets during the most recent period of transition in 1979. However, the efficiency problems which exist in these markets during periods of transition are not inherent in the market's operation. This study suggests that, in general, market mechanisms, if left on their own, will efficiently allocate oil products across consumers. The efficiency problems which we have found to exist appear to be caused primarily by explicit and implicit government-created constraints on the market. In controlled markets, the direct regulatory constraint has led to the most serious inefficiencies we see in domestic oil markets, with markets at times failing to clear and genuine shortages resulting. In decontrolled markets, the implicit political constraint on major companies results in lagged, art1ficlally low prices and the use of nonprice rationing, in the form of allocation fractions, to allocate available supply. These markets, which clear at the margin, are less inefficient than controlled markets. The major problems in these markets lie in interconsumer misallocation of low-priced product, by the recipients of low prices, underproduction by restrained companies, and wealth transfers between consumers.

Major public misperceptions regarding the efficiency of the market's operation in periods of oil crisis have arisen due to these government-generated inefficiencies. The public's belief that world oil market turbulence leads to genuine product shortages with absolute product unavailability and rationing by such nonprice means as lines apparently derives solely from the distortions which regulation has created. The market chaos which regulation has caused serves to prevent consumers from perceiving and dealing with the real problem 
which the phenomenon of world oil market constriction creates: the problem of reduced consumer welfare steming from higher prices.

Throughout periods of world oil market transition, distributional problems are created for U.S. consumers. These problems are particularly harsh for certain groups of consumers whose livelihood is tied directly to oil products. It is the reality of the income problem that policy-makers have sought to redress over the period since 1973. However, rather than addressing the true problem of adjustment to higher prices, policy-makers have perceived the problem as higher prices themselves. They have sought to soften the transitional blow for consumers by controlling the allocative mechanics of the market. The result has been market intervention to cure distributional problems which should, ideally, have been coped with through policies which do not significantly affect the market's operation. Distributionally-motivated initiatives began in 1973, with the price and allocation controls of the Emergency Petroleum Allocation Act. They may be seen in 1979 in such initiatives as Special Rule 9. These efficiency-distorting responses to distributional problems are the cause of the existing allocative problems which we observe in U.S. oil product markets during periods of transition.

Our conclusions in this study suggest strongly that there exists a need to redefine the U.S. government policy towards domestic oil markets. It is clear that the current framework of policy, which confuses market problems with issues of wealth distribution, has caused considerable damage to the proper functioning of the U.S. economy in times of oil price increase. This basic blas was built Into the varfous phases of domestic refined product price regulation that began with the Nixon Administration Wage and Price Controls in August 1971 and ended only with Reagan Administration decontrol in January 1981. Decontrol has placed the EPAA control framework on stand-by status 
until its formal expiration in October 1981. It is clear that much of the debate in the first session of the Ninety-seventh Congress will concern replacement legislation. This replacement legislation will doubtless shape the way the government plans for and deals with oil market transitions for many years to come.

This study suggests that the termination of EPAA will not terminate less formal methods of price regulation. Nevertheless, it is vital to the proper functioning of the U.S. economy over the next turbulent decade that any formal EPAA replacement which comes out of the new Congress shed the delusions about market functions that were at the core of EPAA. Congress should recognize the economics of oil market crises and, if it sees fit, should make a major effort during 1981 to design programs based upon tax and transfer systems that will directly address the equity issues of rising oil prices. Programs must be designed that are based on the reality of the distributional issues raised by oil crises, not upon the misperceptions of the public, the media and the policy-makers. To do otherwise, to repeat the mistakes of EPAA, will only. serve to create future market difficulties in the U.S. when such difficulties demonstrably need not exist. Such misdirected regulation holds the promise of ultimately harming those whom its past champions have intended to help. 
BIBLIOGRAPHY

Alm, Alvin L., and William W. Hogan, "To Combat Oil Crisis", New York Times, February 2, 1980.

Baldwin, J.R., The Regulatory Agency and the Public Corporation, (Cambridge, Massachusetts:Ballinger Publishing Company, 1975).

Bohi, Douglas R, and Milton Russell, Limiting Oil Imports, (Baltimore, Maryland: Johns Hopkins University Press, 1978).

Bureau of National Affairs, Inc., Energy Users Report, (Washington, D.C.:Bureau of National Affairs, Inc., April 19, 1979).

Commerce Clearing House, Inc., Energy Management, (Chicago, Commerce Clearing House, Inc., Serial).

Duchesneau, Thomas D., Competition in the U.S. Energy Industry, (Cambridge, Massachusetts: Ford Foundation, 1975).

Eppen, Gary, Energy: The Policy Issues, (Chicago, Illinois:University of Chicago Press, 1975).

Erfle, Stephen E., "Demand Reduction Strategies and Consumer Behavior: A Unified Approach", (unpublished manuscript, Harvard University, September, 1980).

Erickson, Edward W., "Changes of Domestic Energy Monopoly: The Dog in the Manager of U.S. Energy Policy" in Traeger, Frank N., editor, Oil Divestiture and National Security, (New York:National Strategy Information Center, 1977), pages 41-65.

and Robert M Spann, "The U.S. Petroleum Industry" in Erickson, Edward $W$, and Leonard Waverman, editors, The Energy Question, An International Failure of Policy, (Toronto, Ontario: University of Toronto Press, 1974), volume 2, pages 5-24.

Harvey, Scott, and Calvin T. Roush, Jr., "Petroleum Product Price Regulations: Output and Efficiency Effects", Prepared for the Carnegie Rochester Public Policy Conference, April, 1980.

Hirshleifer, Jack, Price Theory and Applications, (Englewood Cliffs, New Jersey: Prentice Hall, Inc., 1976).

Jacobs, Allen E., "Wage and Price Guidelines and the Petroleum Industry: Preliminary Notes",." (unpublished manuscript, MIT, May 1980).

Johnson, William A., Richard Messick, Samuel V. Victor, and Frank Wyant, Competition in the Oil Industry, (Washington, D.C., George Washington University Energy Policy Research Project, 1976). 
Kalt, Joseph P., The Economics and Politics of Oil Price Regulations, (Cambridge, Massachusetts:MIT Press, 1981).

Landsberg, Hans H., et al., Energy: The Next Twenty Years, (Cambridge, Massachusetts:Ballinger Publishing Company, 1979).

MacAvoy, Paul W., editor, Federal Energy Administration Regulation: Report to the Presidential Task Force, (Washington, D.C.:American Enterprise Institute, 1977).

McGraw-Hill, Inc., Platt's Oilgram Price Report, (New York:McGraw-Hill, Inc., Daily).

The Oil Daily, Inc., The Oil Daily, (New York, The Oil Daily, Inc., Weekly).

Owen, B.M. and Braeutigam, R., The Regulation Game, (Cambridge, Massachusetts: Ballinger Publishing Company, 1978).

Peltzman, Sam, "Toward a More General Theory of Regulation", Journal of Law and Economics, August 1976, pages 211-248.

Petroleum Intelligence Weekly, Inc., Petroleum Intelligence Weekly, (New York: Petroleum and Energy Intelligence Weekly, Inc., Weekly).

Petroleum Publications Co.,", Oil Buyers Guide, (Lakewood, New Jersey:Perroleum Publications, Co., Weekly).

Petroleum Publishing Co., Oil and Gas Journal, (Tulsa, Oklahoma:'l'he Petroleum Publishing Co., Weekly).

Pound, John, "Demand Reduction Strategies: An Analysis of Equity and Efficiency of Various Regulatory Strategies", Kennedy School of Government, Harvard University, contract for DOE \#DE-AM01-79PE70106-Task Order \#2.

Sampson, Anthony, The Seven Sisters, the Great Oil Companies and the World They Shaped, (New York, Viking Press, 1975).

Schelling, Thomas C., The Strategy of Conflict, (Cambridge, Massachusetts: Harvard University Press, 1980).

Scherer, F.M., Industrial Market Structure and Economic Performance, (Chicago, Illinois:Rand McNally College Publishing Company, 1980).

Stigler, George J., "The Economic Theory of Regulation", The Bell Journal of Economics, Spring, 1971, pages 3-21.

Teece, David J., "Vertical Integration and Vertical Divestiture in the U.S. Petroleum Industry", Graduate School of Business, Stanford University, Research Paper Number 300, March 1976.

U.S. Department of Commerce, "Part 377, Short Supply Controls", Export Administration Regulations, (Washington, D.C., Department of Commerce, June 1, 1978). 
U.S. Department of Energy, Monthly Energy Review, (Washington, D.C.:Government Printing Office, Monthly), formerly, U.S. Federal Energy Administration. , Monthly Petroleum Product Price Report, (Washington, D.C.:Government Printing Office, Monthly).

, Economic Regulatory Administration, Hearings on Amendment to Establish Mandatory Production Levels for Middle Distillates, (Washington, D.C., U.S. DOEl:ERA, Docket number ERAR-79-37, August 1979).

, Hearings on

Mandatory Petroleum Allocation Regulations; Emergency Adoption of Final Rule Providing Entitlement Benefit for Importation of Middle Distillates, (Washington, D.C.:U.S. DOE/ERA, Docket number ERA-R-79-27, May 1979).

, Hearings on

Special Rule 9: Amendment to Provide Middle Distillates for Agricultural Production, (Washington, D.C.:U.S. DOE/ERA, Docket number ERA-R-79-25, May 1979).

, Mandatory

Petroleum Allocation Regulations; Emergency Adoption of Final Rule Providing Entitlement Benefit for Importation of Middle Distillates, (Washington, D.C.:U.S. DOE/ERA, 44 FR 31162, 1979).

- Proposed Rule

to Establish Mandatory Production Levels for Middle Distillates, (Washington, D.C.:U.S. DOE/ERA, 44 FR 46244, 1979).

Special Rule 9:

Amendment to Provide Middle Distillates for Agricultural Production, (Washington, D.C.:U.S. DOE/ERA, 44 FR 28606, 1979).

U.S. Federal Trade Commission, Preliminary FTC Staff Report on Its Investigation of the Petroleum Industry, (Washington, D.C.:U.S. Senate Committee of Interior and Insular Affairs, 1973).

U.S. Treasury Department, Staff Analysis of the Preliminary FTC Staff Report on Its Investigation of the Petroleum Industry, (Washington, D.C.: Government Printing Office, 1975).

Verleger, Philip K., Jr., "A Review of the U.S. Petroleum Crisis of 1979", (unpublished, delivered at the Brookings Panel Meeting, Brookings. Institution, Washington, D.C., October 4-5, 1979).

Wilson, James Q., "The Politics of Regulation", in Wilson, James Q., editor, The Politics of Regulation, (New York:Basic Books, 1980).

Wright, Lindsay with Loren C. Cox, "The Impacts of Energy Price Increases on Low Income Groups", MIT Energy Laboratory Working Paper, \#MIT-EL-80 025WP, July, 1980. 